\title{
Comparison of Aerosol Properties Within and Above the ABL at the ARM Program's SGP Site
}

Luca Delle Monache M.S. Thesis

May 1, 2002 


\section{DISCLAIMER}

This document was prepared as an account of work sponsored by an agency of the United States Government. Neither the United States Government nor the University of California nor any of their employees, makes any warranty, express or implied, or assumes any legal liability or responsibility for the accuracy, completeness, or usefulness of any information, apparatus, product, or process disclosed, or represents that its use would not infringe privately owned rights. Reference herein to any specific commercial product, process, or service by trade name, trademark, manufacturer, or otherwise, does not necessarily constitute or imply its endorsement, recommendation, or favoring by the United States Government or the University of California. The views and opinions of authors expressed herein do not necessarily state or reflect those of the United States Government or the University of California, and shall not be used for advertising or product endorsement purposes.

This work was performed under the auspices of the U. S. Department of Energy by the University of California, Lawrence Livermore National Laboratory under Contract No. W-7405-Eng-48.

This report has been reproduced directly from the best available copy.

Available electronically at http://www.doe.gov/bridge

Available for a processing fee to U.S. Department of Energy

and its contractors in paper from

U.S. Department of Energy

Office of Scientific and Technical Information

P.O. Box 62

Oak Ridge, TN 37831-0062

Telephone: (865) 576-8401

Facsimile: (865) 576-5728

E-mail: reports@adonis.osti.gov

Available for the sale to the public from

U.S. Department of Commerce

National Technical Information Service

5285 Port Royal Road

Springfield, VA 22161

Telephone: (800) 553-6847

Facsimile: (703) 605-6900

E-mail: orders@ntis.fedworld.gov

Online ordering: http://www.ntis.gov/ordering.htm

\section{OR}

Lawrence Livermore National Laboratory

Technical Information Department's Digital Library

http:/ / www.llnl.gov/tid/Library.html 
Comparison of Aerosol Properties Within and Above the ABL at the ARM Program's SGP Site

\author{
A Thesis Presented to \\ The faculty of the Department of Meteorology \\ San Jose State University
}

In Partial Fulfillment

Of the Requirements for the Degree

Master of Science

by

Luca Delle Monache

May 2002 

APPROVED FOR THE DEPARTMENT OF METEOROLOGY

Prof. Kevin Perry

Prof. Robert Bornstein

Dr. Richard Cederwall

APPROVED FOR THE UNIVERSITY 


\section{ABSTRACT \\ Comparison of Aerosol Properties Within and Above the ABL at the ARM Program's SGP Site by Luca Delle Monache}

The goal of this thesis is to determine under what conditions, if any, measurements of aerosol properties made at the Earth's surface are representative of aerosol properties within the column of air above the surface. This thesis will use data from the Atmospheric Radiation Measurement (ARM) site at the Southern Great Plains (SGP) which is the only location in the world where ground-based and in situ airborne measurements are made on a routine basis. All flight legs in the oneyear period from March 2000 - March 2001 were categorized as either within or above the atmospheric boundary layer using an objective mixing height determination technique. The correlations between the aerosol properties measured at the surface and the measured within and above the ABL were then computed. The conclusion of this comparison is that the aerosol extensive and intensive properties measured at the surface are representative of values within the $\mathrm{ABL}$, but not within the free atmosphere. 


\section{Acknowledgments}

I would like be gratefully thank to Dr. Richard Cederwall and Prof. Kevin Perry for their precious guidance in all stages of this work and its publication.

I'm also deeply thank to Prof. Bob Bornstein, who gave me the possibility to come to the San Jose State University to work on this research project. This project was part of a collaboration between this university and the Lawrence Livermore National Laboratory, which I want to thank for having given me the possibility to work with the unique data set at the Atmospheric Radiation Measurement Southern Great Plains site, in Oklahoma.

John Ogren has given me precious suggestions in the discussion of my results regarding the aerosol properties measurements, and I want to thank him for this. I would like to thank also John Nasstrom for giving me part of the IDL code I used for the MH determination, and Daniel Rodriguez and John Yio for the their precious help in using IDL.

On a personal level, deepest gratitude is expressed to the faculty, staff, and students of the San Jose State University Meteorology Department for the friendly environment I experienced during this thesis 
work. In particular, I would like be thank to Giovanni, who shared with me almost every moment of my stay in San Jose.

TABLE OF CONTENTS

$\underline{\text { Page }}$

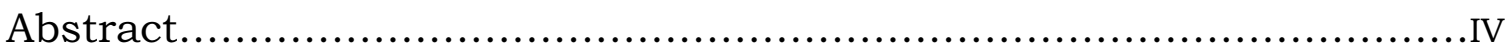

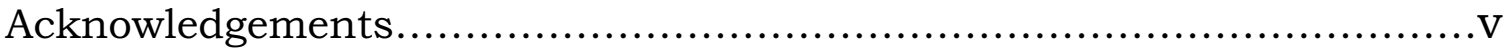

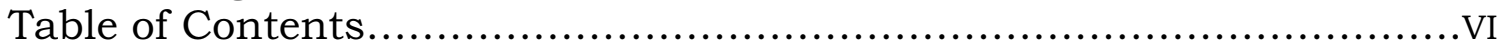

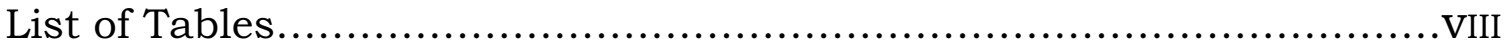

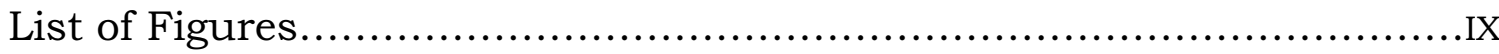

1. BACKGROUND 1

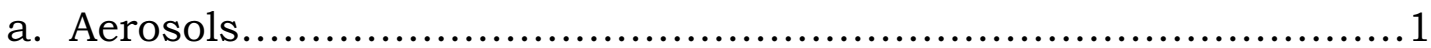

1) Definition..........................................................

2) Aerosol Extensive and Intensive Properties .......................5

3) Aerosol Measurement Platforms..................................6

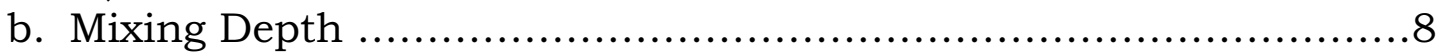

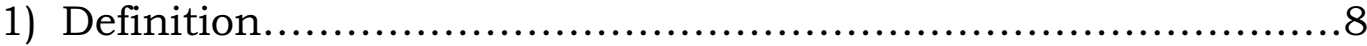

2) Temporal Evolution of the Mixing Layer............................12

3) Meteorology (Mixing Depth) Effects on Vertical Profiles of Aerosol Extensive Properties.........................................15

c. Atmospheric Radiation Measurement (ARM) Program................20

1) Goals and objectives............................................22

2) Overview of the Research Plan and Methodology..................23

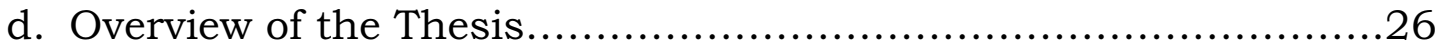

2. INSTRUMENTATION AND DATA DESCRIPTION 27

a. Ground-based, In Situ Instrumentation.............................30

1) The Aerosol Observing System......................................30

2) Eddy Correlation Flux Measurement System......................32

3) Energy Balance Bowen Ratio System..............................37

4) Balloon Borne Soundings System...............................38

b. Remote sensing instrumentation................................. 38 
1) $915 \mathrm{Mhz}$ Radar Wind Profiler Radio Acoustic Sounding System........................................................... 38

2) Atmospheric Emitted Radiance Interferometer...................42

3) CART Raman Lidar...............................................44

c. Aircraft Instrumentation and Flight Tracks .......................47

1) Aircraft and Flight Description....................................47

2) Relevant Airborne Instrumentation..............................48

3. MIXING HEIGHT DETERMINATION METHODOLOGY 50

a. MH-Determination Techniques using Surface Data...................51

1) Blackdar and Tennekes Formula................................56

2) Zilitinkevich Formula............................................58

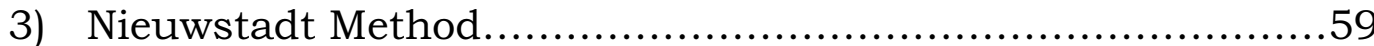

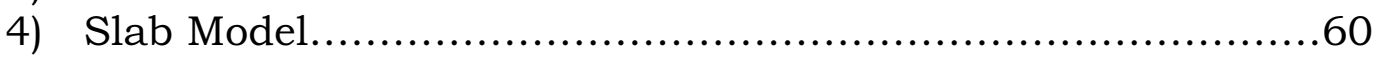

b. MH-Determination Techniques using Vertical Profiles...............61

1) Parcel Method......................................................61

2) Surface-Based Temperature Inversion Technique...............62

3) Height of Low-level Relative Wind Maximum Technique........63

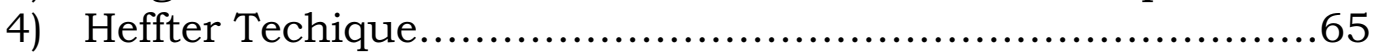

4. RESULTS 66

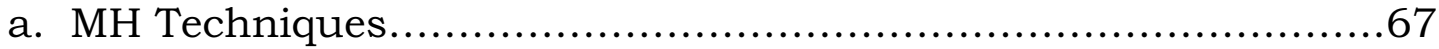

1) Methodology .......................................................67

2) Comparison of $\mathrm{MH}$-Determination Techniques....................69

3) Selection of the "Best" Technique.....................................73

b. Vertical Variation of Extensive and Intensive Aerosol

Properties...................................................... 75

1) Initial Hypothesis................................................ 75

2) Revised Hypothesis..............................................76

3) Vertical variation of Aerosol Properties Within the ABL...........80

5. CONCLUSION 82

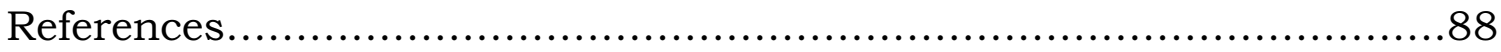

Appendix A: List of Acronyms........................................... 98

Appendix B: List of Symbols............................................. 100 


\section{LIST OF TABLES}

Table 1. Types of Particulate Suspensions.

Table 2. Long-term, Ground-based Aerosol Measurement Platforms.

Table 3. Airborne Aerosol Measurement Campaigns.

Table 4. Remote Sensing Aerosol Measurement Platforms.

Table 5. Derived quantities from AOS system, where all symbols are defined in Appendix B.

Table 6. MH-Determination Techniques Based on Surface Data Only.

Table 7. MH-Determination Techniques Based on Methods Requiring Vertical Profiles.

Table 8. Least-squares linear regression statistics of surface and column integrated aerosol extensive and intensive properties.

Table 9. Least-squares linear regression statistics of surface and integrated aerosol intensive properties within and above the ABL.

Table 10. Altitude ranges and flight days within and above the ABL. 


\section{LIST OF FIGURES}

Fig. 1. The ABL consists of three major parts: turbulent Mixing Layer; less turbulent Mixed Layer with patches of TKE? 0, and Nocturnal Stable Boundary layer of sporadic turbulence that is generally less thick than the Nocturnal Radiative Inversion.

Fig. 2. ABL aerosol concentration distribution. Aerosols are well mixed in the Mixing Layer (sparsely dotted) with low concentrations, and is limited to a thin layer close to the surface in the night, resulting in higher concentration (densely dotted).

Fig. 3. Southern Great Plains (SGP) ARM site map.

Fig. 4. Flow schematic for AOS.

Fig. 5. Number of flights as function of day time.

Fig. 6. CBL scaling regimes, where all symbols are defined in Appendix B.

Fig. 7. SBL scaling regimes, where all symbols are defined in Appendix B.

Fig. 8. MH-determination comparison on 7-11 July.

Fig. 9. MH-determination techniques comparison on 7 July.

Fig. 10. Temperature and dew point temperature, potential temperature, wind speed vertical profiles at 0228 GMT of 8 July. "True", with computed MHs.

Fig. 11. Same as in Fig. 10, but at 0827 GMT on 8 July. 
Fig. 12. Same as in Fig. 10, but for the morning case.

Fig. 13. Same as in Fig. 10, but for the afternoon case.

Fig. 14. Same as in Fig. 10, but at 0825 GMT on 11 July.

Fig. 15. Heffter Techinque $\mathrm{MH}$ values with a critical lapse rate of 0.001 and $0.005 \mathrm{~K} \mathrm{~m}^{-1}$.

Fig. 16. Absorption coefficient (green) measured at the surface (AOS) versus same quantity measured within (x) and above ( ) ABL (IAP), for all 59 days. Also included: regression line and statistics for values within $\mathrm{ABL}$ (bold line), and above the ABL (solid thin line), 1:1 line (dashed).

Fig. 17. Same as in Fig. 16, but for scattering coefficient (blue).

Fig. 18. Same as in Fig. 16, but for scattering coefficient (green).

Fig. 19. Same as in Fig. 16, but for scattering coefficient (red).

Fig. 20. Same as in Fig. 16, but for backscatter ratio (blue).

Fig. 21. Same as in Fig. 16, but for backscatter ratio (green).

Fig. 22. Same as in Fig. 16, but for backscatter ratio (red).

Fig. 23. Same as in Fig. 16, but for single scattering albedo (green).

Fig. 24. Same as in Fig. 16, but for Angstrom exponent.

Fig. 25. Same as in Fig. 16, but for backscatter ratio (blue), and for the 10 well-mixed days.

Fig. 26. Same as in Fig. 16, but for backscatter ratio (green), and for the 10 well-mixed days.

Fig. 27. Same as in Fig. 16, but for Angstrom exponent, and for the 10 well-mixed days.

Fig. 28. Same as in Fig. 16, but for single scatter albedo (green) 
Fig. 29. Plot of IAP/AOS of scattering coefficient (blue) values. The Averaged ratios ( ) and standard deviations (horizontal bar) shown within ABL (bold line), and above the ABL (solid thin line), and the ratio $=1$ line (dashed) also given .

Fig. 30. Same as Fig. 29, but for scattering coefficient (green) ratio values.

Fig. 31. Same as Fig. 29, but for scattering coefficient (red) ratio values.

Fig. 32. Same as Fig. 29, but for absorption coefficient (green) ratio values.

Fig. 33. Same as Fig. 29, but for single scatter albedo (green) ratio values.

Fig. 34. Same as Fig. 29, but for backscatter ratio (blue) ratio values.

Fig. 35. Same as Fig. 29, but for backscatter ratio (green) ratio values.

Fig. 36. Same as Fig. 29, but for backscatter ratio (red) ratio values.

Fig. 37. Same as Fig. 29, but for Angstrom exponent ratio values. 



\section{BACKGROUND}

\section{a. Aerosol}

\section{1) Definition}

Many different types of microscopic particles exist in the atmosphere at any given time. Common types of particulate matter include: mineral dust, black carbon (i.e., soot), sulfates, nitrates, organics, sea salt, plant debris, and atmospheric clouds of water droplets and/or ice crystals. Mineral dust, black carbon, sea-salt, and plant debris are primary pollutants because they are emitted directly into the atmosphere. Sulfates, nitrates, and organics are secondary pollutants because their precursor species are emitted as gases and are converted to the particulate form through a series of photochemical and aqueous-phase chemical reactions. Atmospheric clouds of water droplets and/or ice crystals are generated by a secondary process (i.e., condensation and/or deposition) that does not require any type of chemical reaction.

These primary and secondary airborne particles are all examples of aerosol. An aerosol is defined, in its simplest form, as a collection of solid and/or liquid particles suspended in a gas. By definition, aerosol is a two phase system consisting of both the particles and the gas in which they are suspended. To be classified as an aerosol, the solid and/or liquid particles must be stably suspended in the atmosphere for at least a 
few seconds. Most aerosol that meet this criterion have geometric diameters between $20 \mathrm{~nm}$ and $100 \mu \mathrm{m}$.

The word aerosol was coined about 1920 (Hinds 1999) as an analog to the term hydrosol, which refers to a stable liquid suspension of solid particles. Aerosol is also referred to as suspended particulate matter, aerocolloidal systems, and disperse systems. Although the word aerosol is popularly used to refer to pressurized spray-can products, it is the universally accepted scientific term referring to particulate matter suspended in a gaseous medium.

Atmospheric aerosol are important for a variety of reasons. They play a key role in the formation of clouds by acting as cloud condensation nuclei $(\mathrm{CCN})$. They serve as sites for heterogeneous chemical reactions in the atmosphere. They scatter and absorb light which reduces atmospheric visibility. They adversely affect human health. They have even been identified as having both direct and indirect effects on climate.

Aerosol affect regional climate directly by scattering a portion of the incoming solar radiation back to space (e.g., Hansen and Lacis 1990; Charlson et al. 1992; Kiehl and Briegleb 1993; Taylor and Penner 1994; Russell et al. 1997; Haywood et al. 1999). This process leads to cooling at the surface because it reduces the amount of solar radiation received at the surface. The addition of aerosol to a cloudy area may also indirectly affect climate by altering the reflective properties (i.e., albedo) of clouds. 
It has been shown that increasing aerosol concentrations reduces the effective radius of cloud droplets which results in brighter clouds with longer lifetimes. These modified clouds tend to last longer because the smaller cloud droplets are less likely to precipitate (e.g., Twomey 1974, 1991; Coakley et al. 1987; Albrecht 1989; Radke et al. 1989; King et al. 1993; Jones et al. 1994; Kogan et al. 1997; Rotstayn 1999).

The magnitude of the direct effect of aerosol on the radiative balance of the troposphere depends on the size and composition of the aerosol and on the reflective properties of the underlying surface (i.e., surface albedo). Recent research has shown that the presence of aerosol in polluted regions of the world might be sufficient to offset the expected warming due to increases in the amount of carbon dioxide (NRC 1996; Sokolik and Toon 1996; Boucher et al. 1997; Pan et al. 1997; Barnett et al. 1998). The magnitude of the indirect effect of aerosol on climate, which is also highly dependent on aerosol composition, is highly uncertain (NCR 1996; Pan et al. 1998) and is a topic of vigorous research at this time.

The significance of atmospheric aerosol makes it imperative that we understand their sources, transport mechanisms, physical and chemical transformations, and ultimate fate. To accomplish this, however, we must also have a clear understanding of how meteorological 
factors affect aerosol concentrations and properties in both the boundary layer and the free atmosphere.

Aerosol are but one of the several types of particulate suspensions (Table 1). All are two component systems having special properties that depend on size of the particles and their concentration in the suspending medium. All have varying degrees of stability that also depends on particle size and concentration. They vary greatly in their ability to affect not only visibility and climate, but also our health and quality of life.

Aerosol can be subdivided according to the physical form of the particles and their method of generation. Common aerosol subdivisions include: dust, fumes, smoke, bioaerosol, mist and fog, spray, haze, and smog (Hinds 1999). "Dust" refers to a solid-particle aerosol formed by mechanical disintegration (i.e., crushing or grinding of a parent material). The particles are usually irregularly shaped and have diameters ranging from $\sim 0.1 \mu \mathrm{m}$ to $>100 \mu \mathrm{m}$. "Fumes" refer to a solid-particle aerosol produced by the condensation of vapors or gaseous combustion products. These submicrometer particles often consist of clusters or chains of primary particles. The latter are usually $<0.05 \mu$ m diameter. "Smoke" refers to a visible aerosol resulting from incomplete combustion. Particles may be solid and/or liquid and are usually $<1 \mu \mathrm{m}$ in diameter. Smoke is often agglomerated like fume particles. "Bioaerosol" refers to an aerosol of biological origin. Bioaerosol includes viruses, viable organisms (i.e., 
bacteria and fungi), and products of organisms (i.e., fungal spores, pollen, and plant detritus). "Mist and fog" refers to a liquid-particle aerosol formed by condensation or atomization. Particles are spherical with diameters ranging from $<1 \mu \mathrm{m}$ to $\sim 200 \mu \mathrm{m}$. "Spray" refers to a droplet aerosol formed by the mechanical breakup of a liquid. Particle diameters are generally $>1 \mu \mathrm{m}$. "Haze" refers to an atmospheric aerosol that reduces visibility. Particles that effectively scatter visible radiation have diameters ranging from $\sim 0.1 \mu \mathrm{m}$ to $10 \mu \mathrm{m}$. "Smog" refers to visible atmospheric pollution in certain urban areas. The term was originally derived from the words "smoke" and "fog". "Photochemical smog" is the more precise term referring to an aerosol formed in the atmosphere by chemical reactions involving sunlight, hydrocarbons, and oxides of nitrogen. These secondary smog particles typically have diameters $<2.5 \mu \mathrm{m}$.

2) Aerosol Extensive and Intensive Properties

When studying the vertical distribution of aerosol it is often useful to differentiate between intensive and extensive properties. Extensive properties are those that depend upon the amount of aerosol that is present in the atmosphere (i.e., either the number or mass concentrations). Extensive properties include the number, surface area, and volume (mass) aerosol distributions, the total scattering and absorption coefficients, and the mass of coarse and submicron aerosol. The extensive 
properties of the aerosol will usually change with altitude even if the geometric mean diameter, geometric standard deviation, and chemical composition remain fixed. This change results from vertical variations in pressure and volume that affect the number, surface area, and volume (mass) distributions.

By contrast, intensive properties are those that do not depend upon the amount of aerosol present. Examples of intensive properties include the single scatter albedo $(\omega)$, angstrom exponent $(\AA)$, the backscatter fraction (b), lidar backscatter ratio, geometric mean diameter, and the geometric standard deviation. The intensive properties of the aerosol will not vary with height in the atmosphere if the chemical composition and the shape of the particle size distribution are independent of altitude.

\section{3) Aerosol Measurement Platforms}

A wide variety of techniques exist for measuring the extensive and intensive properties of aerosol. Broadly speaking, however, they can all be classified as either ground based, airborne, or remotely sensed techniques.

Ground-based instruments usually provide detailed in situ measurements at a fixed location or locations (Table 2). These ground-based platforms are designed to run continuously and provide long-term meas- 
urements of both the spatial and temporal variability of aerosol. These data can also be used to diagnose long-term trends and seasonal cycles in aerosol surface properties. They cannot, however, provide information about the vertical variability of aerosol properties. Detailed information about aerosol properties above the surface can only be obtained by in situ, airborne measurements (Table 3) or by remote sensing techniques (Table 4).

Although airborne aerosol instrumentation is similar to what is used at the surface, the high airspeeds create additional problems during the aerosol collection phase. These problems prevent the sampling of most coarse-mode aerosol (i.e., diameters $>1 \mu \mathrm{m}$ ) and lead to somewhat lower measurement accuracies for aerosol extensive and intensive properties. Although airborne measurements can be made at any altitude below the ceiling of the aircraft, the vertical resolution is typically quite low $(\sim 500 \mathrm{~m})$ compared to the vertical resolution of a radiosonde balloon ( $20 \mathrm{~m})$. In addition, the high operational cost of flight time limits the frequency and duration of flights. As a result, aircraft measurements cannot provide a continuous time series of the aerosol extensive or intensive properties.

By definition, remote-sensing platforms provide information about aerosol from a distance. These platforms can be mounted at a fixed ground site, onboard an aircraft, or on an orbiting satellite. The scale of 
the observations will obviously be affected by the location of the remotesensing equipment. Although ground-based and satellite remote sensing instruments provide more frequent observations than aircraft measurements, the accuracy of the measurements with remote sensing instruments is somewhat lower than those provided by in situ aircraft instrumentation.

It must be kept in mind, however, that no single instrument platform can provide a comprehensive suite of aerosol measurements at all altitudes. Thus, all three types of measurement platforms must be used simultaneously at one site to fully characterize the tropospheric aerosol. These types of experiments are somewhat rare (Table 3) and are typically of short duration. The only sites to attempt these kinds of measurements for long periods of time are the Department of Energy (DOE) Atmospheric Radiation Measurement (ARM) Program sites, where all the acronyms are listed in appendix A. A detailed description of the instruments from the DOE ARM site at the Southern Great Plains (SGP) site that are used in this thesis is contained in Chapter 2.

\section{b. Mixing Depth}

\section{1) Definition}

Substances emitted into the atmospheric boundary layer (ABL) are gradually dispersed horizontally and vertically through the action of tur- 
bulence. If there are no significant sinks, the emitted substances will gradually become completely mixed over this layer. As a result, it has become customary in air pollution meteorology to use the term "mixed layer" or "mixing layer" (ML). Since complete mixing is often not achieved under stable atmospheric conditions, the term "mixing layer" is preferable because it emphasizes the process more than the result. Obviously, the mixing layer coincides with the ABL if the latter is defined as the turbulent domain of the atmosphere adjacent the ground. The direct correspondence between the ML and the ABL, however, does not hold true if alternative definitions of the ABL are used (e.g., the domain influenced by the nocturnal radiative exchange processes).

The mixing height $(\mathrm{MH})$, which is defined as the depth of the ML, is a key parameter for most air pollution models because it determines the volume available for the dispersion of pollutants and for other relevant atmospheric processes. Estimates of the $\mathrm{MH}$ are required for many predictive and diagnostic methods and/or models that assess pollutant concentrations. The $\mathrm{MH}$ is also an important parameter in atmospheric flow models. Although the MH is a very important quantity, it is not measured by standard meteorological practices. Moreover, it is often a rather unspecific parameter whose definition and estimation are not straightforward. 
The practical and theoretical problems associated with the determination of the $\mathrm{MH}$ are reflected in the numerous definitions found in the literature (e.g., Stull 1988; Garrat 1992; Seibert et al. 1998). A cursory examination of the many different definitions of $\mathrm{MH}$ reveals that they are primarily driven by the availability of different types of data and not differences in the physical meaning of the MH. For example, some methods are based upon profile measurements of meteorological parameters, while others are based upon parameterizations and simple models that only require operationally available input data from measurements or from numerical weather prediction (NWP) models. A detailed discussion of the different approaches used to compute the $\mathrm{MH}$ in this thesis will be presented in Chapter 3.

Although these methods differ in the details, it is possible to define the $\mathrm{MH}$ as the "height of the layer adjacent to the ground over which pollutants or any constituents emitted within this layer or entrained into it, become vertically dispersed by convection or mechanical turbulence within a time scale of about an hour" (Seibert et al. 1998). In order to proceed from this general definition to practical realizations, it is necessary to consider separately the structure of the stable boundary layer (SBL) and of the convective boundary layer (CBL). This distinction is necessary because most of the methods used to compute the MH work only in a specific stability regime (see Chapter 3). 
An important feature of the $\mathrm{CBL}$ is the entrainment layer (Gryning and Batchvarova 1994). The entrainment layer is a zone between the $\mathrm{ABL}$ and the free atmosphere that is not well-mixed and where the turbulent intensity declines toward its top (Fig. 1). The above definition delineates the top of the entrainment layer. The most widespread definition of the entrainment layer, however, is the height, $z i$, where the heat flux gradient reverses its sign. The parameter $z_{i}$ is usually applied for scaling purposes and it is the definition closest to the thermodynamical CBL height definition in a zero-order jump model (i.e., where the entrainment layer thickness is neglected). One should be aware, however, that turbulence extends beyond $z_{i}$. Thus, care must be taken when specifying the turbulence parameterization for dispersion models.

The SBL can be divided into two layers: a layer of continuous turbulence and an outer layer of sporadic or intermittent turbulence (Fig. 1). Under very stable conditions, the layer of sporadic turbulence may extend to the ground. Since it is extremely difficult to measure sporadic turbulence, and even more difficult to develop a related scaling theory, the scaling height, $h$, typically used for the SBL is the depth of the layer of continuous turbulence. As in the convective case, however, this does not mean that turbulence is strictly confined to the region below $h$.

The asymptotic case with the heat flux approaching zero from either stable or unstable stratification is often termed the neutral bound- 
ary layer. It must be kept in mind, however, that even in this case, stable stratification will prevail above the ABL. This stable stratification above the ABL limits the validity of idealized concepts based on an infinitely deep neutral boundary layer. In this situation, like in the SBL, wind shear is the main source of turbulence. As a result, the neutral boundary layer can be subsumed under the SBL (Fig. 1). It should also be noted that there are many meteorological situations where these definitions have to be carefully discussed and possibly modified. Specific examples include:

- patches of sporadic turbulence caused by the breaking of gravity waves - regions of turbulence generated by the wind shear due to low-level jets - situations with strong non-stationarity (e.g., the evening period)

- presence of clouds (e.g., cloud venting of the CBL, or in frontal zones)

- situations with significant horizontal advection

- regions with complex terrain.

2) Temporal Evolution of the Mixing Layer

The temporal evolution of the ML can be divided in four typical phases (Stull 1988):

- formation of a shallow ML, which slowly deepens

- rapid ML growth

- deep ML of nearly constant thickness 
- shrinking ML with decaying turbulence.

During the early morning, the mixed layer is shallow. The depth of the early morning ML ranges from the order of tens of meters for calm situations to depths of a couple hundreds meters for situations with stronger wind shear (Fig. 1). Its depth increases slowly at first because a strong nocturnal stable layer often caps the young ML. This first phase is sometimes referred to as the burning off of the nocturnal inversion.

By late morning, the cool nocturnal air has been warmed to a temperature near that of the residual layer, and the top of the ML has moved up to the residual layer base. Since there is virtually no stable layer capping the ML at this point, the thermals penetrate rapidly upward during the second phase. This penetration by thermals allows the top of the mixed layer to rise at rates of up to $1 \mathrm{~km}$ per $15 \mathrm{~min}$.

During free-convection, buoyant thermals from the surface layer gain momentum as they rise through the ML. Upon reaching the warmer free atmosphere (FA) they find themselves negatively buoyant, but overshoot a short distance because of their upward momentum. This overshoot is called penetrative convection (Deardoff et al. 1969). The tops of the overshooting thermals form dome or hummock-like structures. There is little turbulence in the FA, and hence no way to disperse air from the overshooting thermals into the rest of the FA. The negatively 
buoyant thermals, therefore, sink back down into the ML mostly intact. Any pollutants from the ML return to, and are trapped within the ML.

During the overshoot into the inversion, wisps or sheets of warm FA air are pushed into the ML. The curtains of FA air rapidly mix down into the ML because of the strong turbulence there, and do not return up to the capping stable layer in spite of their positive buoyancy. The net result is entrainment of FA air into the ML. Thus, the ML grows in thickness due to a one-way entrainment process in which less turbulent air is entrained into more turbulent air. In this manner, the ML erodes into the FA. The ML can never become shallower by entrainment.

When the thermals reach the capping inversion at the top of the residual layer they meet resistance to vertical motion and the ML growth rate rapidly decreases. During this third phase, which encompasses most of the afternoon, the ML depth is relatively constant. Slow depth changes are related to the balance between entrainment and subsidence. These final depths vary widely from place to place, depending on synoptic and mesoscale conditions and the nature of the underlying surface. Final depths of $400 \mathrm{~m}$ have been observed over some tropical ocean regions, while depths in some desert areas reach $5 \mathrm{~km}$. The depth of the ML over land in mid-latitudes is typically 1 to $2 \mathrm{~km}$.

As the sun sets, the generation rate of convective turbulence decreases to the point where turbulence cannot be maintained against dis- 
sipation (Nieuwstadt and Brost 1986). In the absence of mechanical forcing, turbulence in the ML decays completely, causing the reclassification of that layer as a residual layer. Temperature fluctuations decay the fastest, while turbulent kinetic energy (TKE) decays more slowly. During this decay process, the last few weak thermals may still be rising in the upper part of the ML. These-weakly rising thermals can still entrain FA air even though the surface layer has already become stably stratified (Stull and Driedonks, 1987). Thermals and other eddies, formed as the surface heating approaches zero, appear to scale to the time scale that existed at the time of the thermal creation. This fact results in a possible decoupling of large and small scales (e.g., old thermals vs. new shear eddies) and a failure of similarity theory.

3) Meteorology (Mixing Depth) Effects on Vertical Profiles of Aerosol Extensive Properties Prior work regarding the possible effects of the $\mathrm{MH}$ on the vertical profiles of aerosol properties can be divided into two categories: those that use in situ (airborne) measurements and those that use groundbased (lidar) techniques. This section will provide a brief description of some of the more interesting research results. The results from these studies will then be synthesized into a conceptual model of MH effects on aerosol extensive properties. 
Fitch and Cress (1981) utilized an aircraft to study the number and mass concentration of particles at three sites in Germany, during 1979. This study identified a well-defined haze layer in the ABL with a distinct submicron aerosol (i.e., accumulation mode) peak. By contrast, the FA above the haze layer had a distinct coarse-mode peak with a much lower concentration of accumulation-mode particles. The total concentration of particles in each of the two modes were highly correlated when coarse-mode concentrations were high.

Tanaka et al. (1990) observed a similar pattern with enhanced submicron aerosol within the ABL haze layer and enhanced coarse-mode aerosol in the FA during a three day study in urban Japan. This study, however, showed considerable day-to-day variability.

A two day aerosol case study off the eastern coast of the United States during the summer of 1982 was carried out by Sebacher et al. (1985). They made simultaneous measurements of the aerosol size distribution and chemical composition within the lower troposphere. The measurements demonstrated that the structure and stability of the $\mathrm{ABL}$ had a significant influence on the aerosol vertical properties. On the first day, a distinct aerosol layer was observed at altitudes between 700 and $1400 \mathrm{~m}$. On the second day a more well-mixed aerosol concentration was observed in the ABL with a lower overall concentration. The difference was attributed to the presence of a warm frontal system that in- 
cluded precipitation and substantial vertical dispersion of pollutant aerosol from the lower troposphere into the upper troposphere.

Kilsby (1990) made airborne measurements of aerosol extensive properties during a heavy straw-burning pollution episode adjacent to the North Sea. This two-day experiment, which took place during the summer of 1985, observed very high concentrations of smoke in the lowest layer of the atmosphere due to a shallow marine inversion that formed at night. By contrast, aerosol concentrations over land and nearer the coast were much lower because the aerosol was mixed throughout a much deeper ABL. This effect was also observed by Jarzembski et al. (1999) who used aerosol backscatter measurements collected over North America and the Pacific Ocean during September 1995.

A similar study was conducted by Raga and Jonas (1995) who measured the vertical profiles of aerosol and CCN near the British Isles. This experiment collected data on four days that represented different synoptic situations and different seasons. They observed significant changes in the aerosol profiles that were related to distinct thermodynamic features such as temperature inversions and dry layers.

One of the most extensive airborne studies of aerosol vertical profiles was conducted by Kim et al. (1993). This study combined data from four field projects to obtain data from a total of 31 flights. These flights 
were held over central New Mexico during the summer and winter of 1989 and 1990. Kim et al. (1993) reported that the vertical distribution of aerosol number concentration showed seasonal differences between winter and summer. On average, $\mathrm{CN}$ concentrations were higher when the ML was shallow (i.e., winter) and lower when the ML was deep (i.e., summer). This study also found that the aerosol number concentration stayed relatively constant within the surface mixed layer and decreased rapidly to lower values above the mixed layer.

Gunter et al. (1993) used the same data set as Kim et al. (1993) to examine the contributions of aerosol optical scattering and absorption to short-wave extinction. Although the average $\mathrm{CN}$ concentrations differed (Kim et al. 1993), the average aerosol extinction was quite similar in summer and winter even though the ABL depth was quite different during the two seasons. This result was not altogether unexpected given that the optical properties of aerosol depend on much more than just the $\mathrm{CN}$ concentration (i.e., particle number, size, shape, chemical composition, and hygroscopicity).

Wendisch et al. (1996) studied the influence of a strong temperature inversion in cloudless conditions on aerosol extensive and intensive properties during a three-day experiment that took place in Germany during the fall 1993. This study used vertical profile measurements of the aerosol size distributions (extensive properties) to calculate different 
intensive properties. These calculations demonstrated that the aerosol stratification strongly influenced both the extensive (volume scattering coefficient) and intensive (asymmetry factor and hemispheric backscattering ratio) aerosol properties considered. This study concluded that simple aerosol concentration measurements were an insufficient substitute for in situ aerosol size distribution measurements when it comes to deriving a realistic picture of the optical conditions of the atmosphere. The results of this study are consistent with Gunter et al. (1993).

Zelenka (1997) completed an interesting study that related the vertical variability of aerosol, meteorological parameters, and aerosol acidity. Based on a database for the Uniontown-Pittsburgh area, this study used 17 meteorological parameters and aerosol acidity $\left(\mathrm{H}^{+}\right)$data collected near Pittsburg, PA, during the summer of 1990. Clear evidence of the mixing depth effect on aerosol acidity was observed. Aerosol acidity was found to be inversely related to the estimated $\mathrm{MH}$.

Ahonen et al. (1997) utilized data collected in Finland from 1992 to 1995 to determine the diurnal and annual characteristics and correlations of aerosol properties. Like many of the previous studies, this study determined that the $\mathrm{MH}$ is a basic parameter affecting the concentrations of the particulate matter suspended in the lower troposphere. Sequeira and Lai (1998) utilized data collected in Hong Kong from 1990 to 1992 to 
conclude that the mixing height is the most important meteorological variable affecting the visibility.

In summary, the literature shows that the vertical profile of aerosol extensive properties is significantly affected by the depth of the ML. These studies have shown that a low MH leads to high particle concentrations near the surface, while a larger $\mathrm{MH}$ results in lower concentrations near the surface. This difference is caused by dilution of the aerosol in the ABL, when the $\mathrm{MH}$ is high. It is also clear that the top of the boundary layer acts as a lid for most aerosol particles, with relatively high and constant number and mass concentrations within the ABL, and lower concentrations above it in the FA. This conceptual model of MH effects on aerosol extensive properties is shown graphically in Fig. 2.

Although the studies cited in this literature review provide a detailed description of the vertical variation of aerosol extensive properties, the Wendisch et al. (1996) study was the only one that discussed what is known about the vertical variation of aerosol intensive properties and how these properties change throughout the day as the ABL evolves. It is for this reason, that this thesis will focus on characterizing the vertical variability of intensive aerosol properties.

c. Atmospheric Radiation Measurement (ARM) Program 
As noted previously, very few locations around the globe have simultaneous ground-based, airborne, and remote sensing aerosol measurements, in conjunction with measurements of the meteorological parameters necessary to estimate the MH. One of these sites is the ARM SGP site located in Oklahoma.

The ARM Program is a major atmospheric measurement and modeling initiative intended to improve our understanding of the processes and properties that affect atmospheric radiation. ARM's particular focus is on the influence of clouds on radiative transfer and identifying the role of clouds on radiative feedback mechanisms. The United States Global Change Research Program (USGCRP) identified the scientific issues surrounding climate and hydrological systems as its highest priority concern (Stokes and Schwartz 1994). Among climate issues, the USGCRP identified the role of clouds as the top priority research area. ARM, a major activity within the USGCRP, is designed to meet these research needs and is an outgrowth and direct continuation of the decade-long Department of Energy (DOE) effort to improve global climate models (GCMs). The goal of these GCMs is to provide reliable simulations of regional and long-term climate changes in response to increasing greenhouse gas concentrations.

The ARM Program, initiated in 1989, operates field research sites, called Cloud and Radiation Testbeds (CARTs), to study the effects of 
clouds on the tropospheric radiative balance. The three primary sites are located in the:

- Southern Great Plains ( $\left.36^{\circ} 37^{\prime} \mathrm{N}, 97^{\circ} 30^{\prime} \mathrm{W}\right)$

- Tropical Western Pacific $\left(10^{\circ} \mathrm{N}\right.$ to $10^{\circ} \mathrm{S}$, from $120^{\circ} \mathrm{E}$ to $\left.150^{\circ} \mathrm{W}\right)$

- North Slope of Alaska ( $\left.71^{\circ} 19^{\prime} \mathrm{N}, 156^{\circ} 36^{\prime} \mathrm{W}\right)$.

These locations were chosen because they represent the entire range of climate conditions that must be studied. Each CART site has been heavily instrumented to gather massive amounts of data in support of climate research.

\section{1) Goals and Objectives}

The overall goal of the ARM Program is to develop and test parameterizations of important atmospheric processes, particularly cloud and radiative processes, for use in atmospheric models (i.e., GCMs). A central feature of ARM is an experimental testbed for the measurement of atmospheric radiation and the cloud properties controlling this radiation. A principal objective of this testbed is to develop a quantitative description of the spectral radiative energy balance profile under a wide range of meteorological conditions. The intent is to develop a sufficiently comprehensive database to allow testing of parameterizations through the direct comparison of field observations with calculations of the radiation field and associated cloud and aerosol interactions. 
The two primary ARM objectives are provided below:

- To relate observed radiative fluxes in the atmosphere, spectrallyresolved and as a function of position and time, to the atmospheric temperature, composition (specifically including water vapor and clouds), and surface radiative properties.

- To develop and test parameterizations that describe atmospheric water vapor, clouds, and the surface properties governing atmospheric radiation in terms of relevant prognostic variables, with the objective of incorporating these parameterizations into GCMs and related models.

The achievement of these objectives should lead to the improvement of the treatment of atmospheric radiation in climate models, explicit recognition of the crucial role of clouds in influencing this radiation, and the consequent need for an accurate description of the presence and properties of clouds in GCMs.

\section{2) Overview of the ARM Research Plan and Methodology}

The number of processes pertinent to the transfer of radiation in the atmosphere that must be represented in climate models is large, and any given process can, in principle, be represented in a variety of possible ways. The requirement for a program such as ARM is to test many candidate parameterizations of important atmospheric processes and identify those that are most suitable for use in GCMs. ARM will attempt 
to achieve this objective by using data to test models and parameterizations operated in a predictive mode, rather than simply relying exclusively on phenomenological and for empirical parameterizations.

Acquisition of data necessary for the model development and testing was accomplished by establishing and maintaining several sites, whose spatial resolution extent is comparable to the size of a typical GCM grid cell (i.e., approximately $300 \mathrm{~km}$ on a side). Each of these ARM sites makes continuous measurements of atmospheric radiation and of atmospheric and surface properties that influence the transfer of radiation in the atmosphere. These measurements, which will be made for a period of 7-10 years, will be used to develop and test the model parameterizations.

The research component of ARM, which focuses on the actual development and testing of specific models and parameterizations, is the province of the ARM Science Team. The science team consists of more than 50 research groups whose efforts fall into three broad categories: - developing and testing parameterizations - developing and testing instruments - participating as site scientists.

The first group is focused on the actual development and testing of parameterizations. These investigators are involved in the full cycle of parameterization development, ranging from the basic delineation of 
phenomena to be parameterized, to the development of detailed theoretical models to serve as the basis for parameterizations, to the actual testing of the parameterizations themselves. Within this group, each investigator defines one or more experiments to be conducted at the ARM site. An experiment consists of the comparison of measurements with model output. The model may be initialized with input variables specified by observations at the ARM sites and/or by data obtained from other sources such as the National Weather Service or operational satellites.

The second major activity within the science team is the Instrument Development Program (IDP). Investigators within the IDP focus on the development and testing of instruments that may be suitable for future deployment to meet measurement requirements at ARM sites. The final component of the science team consists of the site scientists (one for each ARM site).

While the objectives of ARM are distinctly focused on modeling results, the path to these results has a strong coupling to experiment. The next major element of ARM, after the science team, is the CART, which consists of the measurement facilities and the process of assembling the data to meet the experimental requirements of the members of the science team. CART has been designed so that the observations will support the measurement requirements of multiple research groups with the same data streams. CART may thus be viewed as a facility for the pro- 
spective testing of models in a shared data environment. CART consists of several observing facility sites. The need of several sites is dictated by the wide range of geographical and meteorological situations that must be accurately represented by climate models. The sites have been selected to allow the observation of a sufficiently wide range of meteorological situations, permitting models to be tested under virtually all climatically relevant conditions.

\section{d. Overview of the Thesis}

This thesis will use the unique data set available at the ARM SGP site to determine under what conditions, if any, ground-based measurements of aerosol intensive properties are representative of the atmosphere above the site.

Attempting to answer this important scientific question will provide a deeper understanding of the vertical variation of aerosol properties and how they are related to meteorological processes and parameters. From the practical point of view, answering this question should allow ARM scientists to minimize the number of required aircraft measurements and to optimize the flight schedule over the ARM SGP site.

This thesis will study the vertical variation of aerosol intensive properties by correlating surface measurements with similar measurements made onboard a research aircraft. Since previous work has es- 
tablished that the aerosol extensive (and possibly intensive) properties are sensitive to the $\mathrm{MH}$, the aircraft measurements from the ARM SGP site will be divided into two groupings: those within the ABL and those within the FA. To accomplish this, however, it is necessary to determine which of the many techniques available provides the most reliable method for computing the MH. It will also correlate the surface measurements with measurements within the ABL to assess the degree of mixing and to gain a deeper understanding of the vertical variation of aerosol intensive properties in the lower layer of the troposphere.

The following chapters will include a detailed description of the instrument and data sets used (Chapter 2), a description of the methodology used to compute the $\mathrm{MH}$ (Chapter 3), a discussion on the results (Chapter 4), and finally the conclusions (Chapter 5).

\section{INSTRUMENTATION AND DATA DESCRIPTION}

The results of this thesis are based entirely upon data collected at the ARM SGP site. Thus, this chapter will discuss why this location was chosen and provide a thorough description of all instrumentation used to generate this data set. The instrumentation descriptions will be subdi- 
vided into three categories: ground-based instrumentation, remote sensing instrumentation, and airborne instrumentation.

The SGP CART site is the largest of the ARM fixed locations for climate research and is one of only a few sites in the world that makes routine measurements of the aerosol properties at both the surface and aloft. Deployment of the first instrumentation at the SGP site occurred in the spring of 1992, just 24 months after the program was approved by the DOE. The site was dedicated in November 1992. Additional instrumentation and data processing capabilities have been incrementally added in succeeding years.

Atmospheric data of unprecedented quality, consistency, and completeness are being collected from this real "laboratory without walls". The data are made freely available for worldwide distribution and can be specially packaged for scientists upon request. The Great Plains of Kansas and Oklahoma was chosen as the location of the CART site for several reasons:

- relatively homogeneous geography - widely variable cloud types and surface flux properties - large seasonal variations in temperature and specific humidity - large existing network of weather and climate research instrumentation - opportunity for mutually beneficial activity with investigators in many other federal and state climate research programs. 
On the CART site, about three dozen clusters of in situ and remotesensing instruments are arrayed across approximately $141000 \mathrm{~km}^{2}$ of north-central Oklahoma and south-central Kansas (Fig. 3). This CART site was designed to cover an area roughly $375 \mathrm{~km}$ (225 miles) on a side, about the size of a single grid cell of a GCM.

The heart of the CART site is the heavily instrumented central facility which is located on 160 acres of cattle pasture and wheat fields southeast of Lamont, Oklahoma. Here, technicians implement experiments, monitor data from instruments throughout the site, and provide routine maintenance for the instruments.

More than 30 instrument clusters have been placed around the CART site. These instrument clusters are located at the central facility and at boundary, extended, and intermediate facilities. The instrument locations were chosen so that the measurements would reflect conditions over the typical distribution of land uses within the site.

The continuous observations at the CART site are supplemented by intensive operational periods (IOPs), when the frequency of measurements is increased and special measurements are added to address specific research questions. During such periods, nearly a gigabyte of data (one billion bytes) is generated daily. Both during IOPs and at other times, scientists bring their own specialized instruments to the CART site, typically for several weeks at a time. 
a. Ground-based, In Situ Instrumentation

1) The Aerosol Observing System

The Aerosol Observing System (AOS) is the primary ARM platform for in situ aerosol measurements at the surface level (10 m AGL). The system is located at the SGP site in Oklahoma and was constructed at the DOE Environmental Monitoring Laboratory (EML) in New York. It has been operational since April 1996 and is currently producing continuous aerosol data. The aerosol data are stored in a file format that meets ARM data processing and archival requirements. The Aerosol Group at NOAA/Climate Monitoring and Diagnostics Laboratory (CMDL) took over the quality control and quality assurance of the AOS in early 1997 (Wiley 1995).

The primary quantities measured with the AOS system are:

- total scattering and hemispheric backscattering coefficients in $\mathrm{m}^{-1}$ for three wavelengths

- absorption coefficient in $\mathrm{m}^{-1}$ for one wavelength

- total condensation nuclei $(\mathrm{CN})$ concentration in $\# \mathrm{~cm}^{-3}$

- number distribution in $\# \mathrm{~cm}^{-3}$ for particles with sizes ranging from 0.1 to $10 \mu \mathrm{m}$. 
- ozone concentration in ppbv.

The sampling interval for all aerosol measurements is $1 \mathrm{mi}$. Thus, a total of 1440 data points are generated each day if the system operates correctly.

Many quantities of interest to aerosol and radiative transfer modeling research can be derived from these basic aerosol measurements (Table 5). These quantities include:

- extinction coefficient, $\beta_{\text {ext }, \lambda}$, computed as the sum of the total light scattering $\left(\beta_{s p, \lambda}\right)$ and absorption coefficients $\left(\beta_{a p, \lambda}\right)$

- single scatter albedo, $\omega$, calculated as the ratio of the total scattering coefficient $\left(\beta_{s p, \lambda}\right)$ to the extinction coefficient $\left(\beta_{\text {ext }, \lambda}\right)$

- co-albedo, 1- $\omega$

- hemispheric backscatter fraction, $b$, computed as the ratio of the hemispheric backscattering coefficient $\left(\beta_{b s p, \lambda}\right)$ to the total scattering coefficient $\left(\beta_{s p, \lambda}\right)$.

- Angstrom exponent, Å, computed as

$$
\AA=-\ln \left(\beta_{s p, \lambda_{1}} / \beta_{s p, \lambda_{2}}\right) / \ln \left(\lambda_{1} / \lambda_{2}\right)
$$

where all the symbols are defined in Appendix B and $\lambda_{1}=450 \mu \mathrm{m}$ (blue), and $\lambda_{2}=550 \mu \mathrm{m}$ (green) 
The AOS samples air at a volumetric flow rate of $1,000 \mathrm{~m}^{3} \mathrm{~min}^{-1}$ (Fig. 4). The main flow into the sampling stack is split into five lines, four of which are isokinetic to prevent particle losses within the sampling lines. The flow rate in each instrument line is $30 \mathrm{~m}^{3} \mathrm{~min}^{-1}$. Ozone is sampled from a separate line coated with Teflon and the sampling line is mounted on the main aerosol sampling stack. The stack can be tilted down for regular maintenance. Particles with aerodynamic diameters > $10 \mu \mathrm{m}$ are removed from the air stream by an impactor before they reach all of the instruments with the exception of the optical particle counter $(\mathrm{OPC})$ and the condensation nuclei counter $(\mathrm{CNC})$.

The aerosol sample stream is conditioned to be less than $40 \%$ relative humidity $(\mathrm{RH})$ and lower than $40^{\circ} \mathrm{C}$ before it enters the five sampling lines. This sample conditioning provides a reference point where the properties of ambient aerosols are measured. However, it is wellknown that aerosol chemical and physical properties are functions of relative humidity. Thus, the measured quantities taken under such a condition may not reflect the true ambient conditions at the time of the measurements.

2) Eddy Correlation Flux Measurement System

The Eddy Correlation Flux Measurement System (ECOR) provides in situ, 30-minute averages of the surface vertical fluxes of momentum, 
sensible heat, and latent heat representative of an area of crops several hundred meters upwind of the station. The fluxes are obtained by the eddy-correlation technique which correlates the vertical wind component with the horizontal wind component, the sonic temperature (which is approximately equal to the virtual temperature), and the water vapor density. The fluxes are computed from the following directly measured quantities:

- orthogonal components of the wind velocity: $\mathrm{u}, \mathrm{v}$, and $\mathrm{w}$ (measured in $\mathrm{m} \mathrm{s}^{-1}$ by a sonic anemometer)

- sonic temperature (determined in $\mathrm{K}$ by the sonic anemometer from the speed of sound)

- water vapor density (measured in $\mathrm{g} \mathrm{m}^{-3}$ by an infrared hygrometer)

- air temperature, in $\mathrm{K}$, and barometric pressure, in $\mathrm{hPa}$ (both measured by solid-state devices).

The 3-D sonic anemometer uses three pairs of orthogonally oriented, ultrasonic transmitter/receiver transducers to measure the transit time of sound signals traveling between the transducer pairs. The wind speed along each transducer axis is determined from the difference in transit times. The sonic temperature is computed from the speed of sound which is determined from the average transit time along the vertical axis. A pair of measurements are made along each axis a hundred times per second (i.e., $100 \mathrm{~Hz}$ ). Ten measurements are averaged to pro- 
duce ten wind measurements along each axis and ten temperatures each second (i.e., $10 \mathrm{~Hz}$ ).

The infrared hygrometer measures the water vapor density by detecting the absorption of infrared radiation by water vapor in the light path. Two infrared wavelength bands are used, one centered on a band strongly absorbed by water vapor and one centered on a band (the reference band) which is not absorbed. By normalizing the absorption band by the reference band, instrument drift caused by light source and photodetector changes are eliminated. Measurements are made forty times per second (i.e., $40 \mathrm{~Hz}$ ). Four measurements are averaged to produce ten water vapor density measurements each second (i.e., $10 \mathrm{~Hz}$ ).

The ambient air temperature and barometric pressure are determined by using an analog to digital converter to measure the output of the solid state sensors at a rate of $10 \mathrm{~Hz}$. Both of these sensors have a response time of about one second. They are sampled more frequently for the sole purpose of being reported along with the humidity data.

Data processing and control is accomplished by the use of a PCbased computer. The PC uses a nonstandard, multitasking operating system developed specifically for this system. One task acquires and stores the data in files of 30-min duration. A second task processes the data and computes the fluxes. Another task computes power spectra 
and cospectra. The system software is stored in EPROM and all resultant data are stored on removable disks.

Vertical momentum fluxes are computed taking into account the following considerations about turbulent mixing:

- Horizontal momentum of the air is transferred toward the ground where it is dissipated in frictional drag. Energy is transferred from larger eddies aloft downward to smaller eddies by turbulent mixing.

- The rate of change in momentum due to downward transfer can be determined directly from the correlation between the horizontal and vertical eddy velocities.

- The eddy velocities are departures from a characteristic mean. The period for this mean is a function of height.

- The vertical fluxes of sensible and latent heat can be determined directly from the correlation between departures of the vertical velocity, and of temperature, and water vapor density from a characteristic mean.

A 200-second mean is the appropriate characteristic mean for the $3 \mathrm{~m}$ ECORs. On these systems, a 200-second running mean of the turbulent parameters (the three orthogonal components of the wind, the computed horizontal wind speed, the sonic temperature, and the water vapor density) are computed recursively and continuously updated by the task which collects and stores the data. Data analysis, which starts 
precisely on the hour and half-hour, includes computation of the means and of the variances and covariances of departures of the input data from their running means and for the means of the entire analysis period. Three dimensional coordinate rotations are applied to the variances and covariances of departures from the means. The rotations result in zero mean vertical and transverse wind speeds.

The appropriate characteristic mean time constant is very large for the 20 and $60 \mathrm{~m}$ ECORs. Therefore, instead of using departures from a running mean, the coefficients of linear trends in the data are computed and used to remove the effects of these linear trends on the variances and covariances. Three dimensional coordinate rotations are applied to the detrended variances and covariances. The coordinate rotations result in zero mean vertical and transverse wind speeds.

The mixing ratio, air density, specific heat of dry air at constant pressure, and the heat of vaporization of water are computed from the average values of water vapor density, air temperature, and barometric pressure. These coefficients are used with the coordinate-rotated covariances from the running means or the coordinate-rotated, detrended covariances to compute the friction velocity, sensible heat flux, and latent heat flux.

Power spectra and cospectra are obtained using an in-place, direct, Fast Fourier Transform (FFT). A two-butterfly, Cooley-Tukey, radix-2 
FFT and a lookup table for the sine - cosine transfer functions are used. Since it is preferable for the number of input data values to an FFT to be a power of two, and since it is desirable to have the fluxes computed from the same data as the spectra, statistical and spectral analysis are performed on the first 27 minutes and 18 seconds of data in each 30-min period.

\section{3) Energy Balance Bowen Ratio System}

The Energy Balance Bowen Ratio (EBBR) system is a ground-based system that uses in situ sensors to estimate the vertical fluxes of sensible and latent heat at the local surface. Flux estimates are made from observations of net radiation, soil heat flow, and the vertical gradients of temperature and relative humidity. These data are then used in the Bowen ratio energy balance technique (Lewis 1995).

The primary quantities measured are 30-minute averages of the energy flux densities $\left(\mathrm{W} \mathrm{m}^{-2}\right)$ of sensible and latent heat representative of the grassy area within about $50 \mathrm{~m}$ of the EBBR station. Secondary quantities include air temperature, reference temperature, relative humidity, net radiation, near-surface soil moisture, near-surface soil heat flux, near-surface soil temperature, atmospheric barometric pressure, wind direction, wind speed, and battery voltage. Units and heights (or depths) of secondary quantities vary (units vary depending on averaging 
time). The EBBR stations use a standard approach to compute the average values that has been described by textbooks and articles. A general description can be found in Field et al. (1992).

4) Balloon-Borne Sounding System

The Balloon-Borne Sounding System (BBSS) provides in situ measurements (i.e., vertical profiles) of both the thermodynamic state of the atmosphere and the wind speed and direction (Lesht 1995). The following quantities are measured as functions of time during a free-balloon ascent:

- pressure $(\mathrm{hPa})$, temperature $\left({ }^{\circ} \mathrm{C}\right)$, relative humidity $(\% \mathrm{RH})$, wind speed $\left(\mathrm{m} \mathrm{s}^{-1}\right)$, and wind direction (deg).

Secondary (derived) quantities include: in the data stream, also measured as functions of time, include: altitude (geopotential meters), dew point temperature $\left({ }^{\circ} \mathrm{C}\right)$, ascent rate $\left(\mathrm{m} \mathrm{s}^{-1}\right)$, latitude of sonde $\left({ }^{\circ} \mathrm{N}\right)$, longitude of sonde $\left({ }^{\circ} \mathrm{W}\right)$, East/West component of wind velocity $\left(\mathrm{m} \mathrm{s}^{-1}\right)$, and North/South component of wind velocity $\left(\mathrm{m} \mathrm{s}^{-1}\right)$.

b. Remote-Sensing Instrumentation

1) $915-\mathrm{MHz}$ Radar Wind Profiler and Radio Acoustic Sounding System 
The 915 MHz Radar Wind Profiler (RWP) Radio Acoustic Sounding System (RASS) measures wind profiles from (nominally) 0.1 to $5 \mathrm{~km}$ and virtual temperature profiles from 0.1 to $1.5 \mathrm{~km}$. It operates by transmitting electromagnetic energy into the atmosphere and measuring the strength and frequency of backscattered energy. Virtual temperatures are recovered by transmitting an acoustic signal vertically and measuring the electromagnetic energy scattered from the acoustic wavefront. The propagation speed of the acoustic wave is proportional to the square root of the virtual temperature.

The primary quantities measured with the RWP are the intensity and Doppler frequency of backscattered radiation. The wind speed is determined from the Doppler frequency of energy scattered from refractive index fluctuations (caused primarily by moisture fluctuations but also by temperature fluctuations) embedded within the atmosphere. The virtual temperature is determined from the Doppler frequency of microwave energy scattered from acoustic energy propagating through the atmosphere.

The RWP operates by transmitting in two different vertical planes and receiving backscattered energy from refractive index fluctuations that are moving with the mean wind. By sampling in the vertical direction and in two tilted planes, the three components of motion can be determined. The system consists of a single phased array antenna that 
transmits alternately along five pointing directions: one vertical, two in the North-South vertical plane (one South of vertical, one North of vertical), and two in the East-West vertical plane (one East of vertical, one West of vertical). The non-vertical beams are tilted at about $14^{\circ}$ from vertical.

Radial components of motion along each pointing direction are determined sequentially. It takes, nominally, 30 - $45 \mathrm{~s}$ (dwell time) to determine the radial components from a single pointing direction. Thus, at the SGP CART site the system cycles through five beams (South, North, East, West, and vertical) at low power, and then cycles the five beams again at a high power (longer pulse length) setting. Then the whole process is repeated.

About five minutes elapse before the system returns to the beginning of its sequence. Within an averaging interval, the estimates from each beam-power combination are saved (11-12 in a 1-hr period) and these values are examined and compared at the end of the period to determine the consensus-averaged radial components of motion.

Briefly, consensus averaging consists of determining if a certain percentage (e.g., 50\%) of the values fall within a certain range of each other (e.g., $2 \mathrm{~m} \mathrm{~s}^{-1}$ ). If they do, those values are averaged to produce the radial wind estimate. The radial values at each altitude are then combined to produce the wind profile. 
The RWP system transmits pulses at about $1-10 \mathrm{kHz}$ into the atmosphere. The backscatter from each transmitted pulse is sampled at 1 MHz. The resulting vertical resolution is $\sim 150 \mathrm{~m}$. The samples at each range gate are averaged together (time domain integration) over some number (e.g., 100) of pulses to produce a phase value for input into a FFT. After (e.g., 64) values are produced, the FFT is performed (one for each range gate). This process takes on the order of $1 \mathrm{~s}$. A number (about 30) of these spectra are then averaged together during the dwell time. At the end of the dwell time, a single averaged spectrum is produced from each range gate along the designated pointing direction.

The spectra are analyzed by the system before moving to the next pointing direction. This analysis produces estimates of the signal to noise ratio, the noise, the mean velocity (proportional to frequency), and the first moment (spectral width) at each range gate.

RASS operation is essentially the same as the RWP, except that the averaging time is about $10 \mathrm{~min}$, and only a single pointing direction (vertical) is used. Also, the atmosphere is "seeded" with a sound wave. The index of refraction changes created by the sound wave are the signal source. In order to sample both the sound wave (speed about $340 \mathrm{~m} \mathrm{~s}^{-1}$ ) and the atmosphere (to remove air velocity from temperature estimates) a larger FFT is required. This requires a smaller number of points for each time domain integration and increases the processor time required to 
calculate the FFT. In normal operation, temperature profiles are determined during the first ten minutes of every hour and the wind profile is averaged over the remaining fifty minutes.

\section{2) Atmospheric Emitted Radiance Interferometer}

The Atmospheric Emitted Radiance Interferometer (AERI) measures the absolute infrared spectral radiance $\left(\mathrm{W} \mathrm{m}^{-2} \mathrm{Sr}^{-1}\right.$ wavenumber $\left.{ }^{-1}\right)$ of the sky directly above the instrument. The spectral measurement range of the instrument is 500 to 3300 wavenumbers $\left(\mathrm{cm}^{-1}\right)$ or 20 to $3 \mu \mathrm{m}$. The spectral resolution is $1.0 \mathrm{~cm}^{-1}$ while the instrument field-of-view is 1.3 degrees. A calibrated sky radiance spectrum is produced every ten minutes.

The AERI data can be used for the evaluation of line-by-line radiative transport codes, for the detection/quantification of cloud effects on ground-based measurements of infrared spectral radiance, and for the calculation of vertical atmospheric profiles of temperature and water vapor. The primary quantities measured are:

- absolute infrared spectral radiance of the sky ( $\mathrm{W} \mathrm{m}^{-2} \mathrm{Sr}^{-1}$ wavenumber-1) - sky brightness temperature as a function of wavenumber (K).

The following are quantities derived from the AERI data:

- variance of sky infrared spectral radiance as a function of wavenumber 
- vertical atmospheric profiles of temperature, potential temperature, mixing ratio, and relative humidity.

To determine the temperature profile of the atmosphere, the radiative transfer equations are inverted and then an iterative scheme is used to compute the best estimate of the atmospheric temperature profile (Smith 1970). The AERI instrument gathers information about the infrared spectra with a Fourier transform infrared (FTIR) spectrometer. The FTIR spectrometer measures the light absorbed or emitted from an air sample as a function of wavelength. It consists of an optical system for collecting and concentrating light, an interferometer for algebraically combining the light from the two light paths, a detector to change the light intensity into an electrical signal, signal conditioning electronics, and a computer for extracting spectral data from the signal using FTIR methods.

In general, interferometers combine light from two light paths algebraically resulting in variations in light intensity across the aperture of the interferometer. These light intensity variations are called interference fringes (for non-coincident or non-identical wavefronts). One light path is scanned to vary the optical path length. The other path is a reference path. If light entering the interferometer is an unknown combination of wavelengths, like light from a source having a broadband spectrum, the result will be a complex combination of intensities due to the multiple 
wavelengths. As the optical path length of one path is slowly, but uniformly changed, the difference in path length for each wavelength will change.

Since the wavelengths are different, the path difference expressed as a factor of the wavelength will be different for each wavelength, and will change at a different rate. Path differences, resulting in a variation in output intensity, will change more quickly for short wavelengths than for long wavelengths. If a detector converts the intensity variations into electrical variations, the temporal signal will be a superposition of cosines with periods representing the time variations in intensity. Deconvolution of this series into its component frequencies (with coefficients characteristic of the relative intensities of the individual wavelength components present in the incident light) is accomplished using a FFT algorithm. The algorithm is ideally suited for deconvoluting signals comprising a series of sines or cosines, resulting in the electromagnetic spectrum of the incident light.

\section{3) CART Raman Lidar}

The CART Raman Lidar (RL) is an active, ground-based laser remote sensing instrument that measures vertical profiles of water-vapor mixing ratio and several cloud- and aerosol-related quantities (Goldsmith et al. 1998). Lidar (light detection and ranging), which is the optical 
analog of radar, uses pulses of laser radiation to probe the atmosphere. This system is fully computer automated and will run unattended for many days following a brief ( 5-min. ) startup period.

The CART Raman Lidar has independent measurement channels that record range-resolved backscatter signals from molecular water vapor, molecular nitrogen, and combined Rayleigh and aerosol contributions (the latter at polarizations parallel and perpendicular to the polarization of the laser beam). Primary quantities obtained from these backscatter signals include range-resolved:

- vertical profiles of water-vapor mixing ratio $\left(\mathrm{g} \mathrm{kg}^{-1}\right)$

- aerosol scattering ratio

- backscatter depolarization ratio (\%).

Additional cloud- and aerosol-related measurements can also be derived from the backscatter signals.

Raman lidar systems detect selected species by monitoring the wavelength-shifted molecular return produced by vibrational Raman scattering from the chosen molecule or molecules. Narrow band, narrow field-of-view operation provides good daytime performance (discrimination of the weak Raman backscatter signal above the background daylight) without sacrificing nighttime performance. The system has been implemented as a dual field-of-view instrument because narrow field-ofview operation provides very weak short-range signals. A set of "wide" 
field-of-view channels provides better results for short-range signals (out to $\sim 500 \mathrm{~m}$ for water vapor).

For each channel, the signal as a function of range, $z$, is inversely proportional to the range squared and proportional to the product of constant k, the overlap function $(O)$, the Raman cross-section $(\sigma)(180$ deg backscatter), number density $(n)$, attenuation of the laser beam traveling to the region of interest $\left(q_{1}\right)$, and the attenuation of the backscattered radiation $\left(q_{b}\right)$. By taking the ratio of the signal at the water-vapor wavelength to the signal at the nitrogen wavelength, most of the rangedependent terms drop out and one is left with a quantity that is almost directly proportional to the water-vapor mixing ratio expressed as grams of water vapor per kilogram of dry air (a small correction for the wavelength dependence of the second attenuation term is easily taken into account). Similarly, by taking the ratio of the signal at the laser wavelength to the signal at the nitrogen wavelength, one is left with the aerosol ratio. This ratio is normalized such that it is unity in "clean air" (laser-wavelength scattering is caused only by Rayleigh scattering) and is in excess of unity for scattering by parcels of air that contain aerosol (including cloud droplets and/or ice crystals).

Finally, analysis of the polarization dependence of the backscatter signal at the laser wavelength provides information on particle shape (phase). Spherical particles (cloud droplets) do not depolarize the laser 
backscatter, whereas nonspherical particles (such as ice crystals in cirrus clouds) can significantly depolarize the laser backscatter.

\section{c. Aircraft Instrumentation and Flight Tracks}

\section{1) Aircraft and Flight Description}

The combined suite of measurements available at the ARM SGP site is nearly sufficient to allow calculation of radiative flux perturbations due to aerosol. However, several limiting assumptions about the aerosol are required. Primary among these assumptions is the column-averaged single-scattering albedo and hemispheric backscatter fraction, which cannot currently be determined reliably from around-based or satellite sensors. The aircraft program at the site is designed to make long-term in situ measurements of these key aerosol climate forcing properties.

Members of the CMDL Aerosols and Radiation Group have recently outfitted a Cessna C-172N single-engine, light aircraft with aerosol instrumentation similar to the AOS. The goal of the aircraft flights is to provide long-term measurements of the vertical variation of aerosol optical properties over the SGP Central Facility. Fig. 5 shows a histogram of the number of flights that occurred during each part of the day. This figure shows a bimodal distribution with peaks between 0800 - 0900 and $1600-1700$ LT. 
The aerosol inlet was built into the leading edge of the wing and passes particles through large-diameter conductive tubing to the instrument rack. The instruments rack which replaced the front passenger seat, has a laptop computer for instrument control and data logging. A portable Global Positioning System (GPS) provides latitude, longitude, and altitude information while an externally-mounted Vaisala probe monitors ambient temperature and relative humidity.

The research flights began in March 2000 and have been conducted several times per week (weather permitting) for a project duration of two years. The aircraft flight track, which covers the SGP site area, consists of an upward spiral interrupted by periods of level flight. Flightlevel altitudes are normally 500, 660, 990, 1350, 1650, 2000, 2600, 3300 , and $3900 \mathrm{~m}$ above MSL. The surface elevation at the site is $~ 330$ $\mathrm{m}$ MSL, so the lowest passes over the facility are $\sim 170 \mathrm{~m}$ above ground. Clouds generally are not sampled. However, clear air above and below clouds in the aircraft altitude-range are sampled when present. Instrument calibrations are performed in flight before and after the vertical profiles. The total duration of each flight is $\sim 90$ minutes.

2) Relevant Airborne Instrumentation Airborne instrumentation used in this study include: 
- Nephelometer (TSI Model\#3563). Measures forward and backward scattering by aerosol particles at three wavelengths: blue $(450 \mathrm{~nm})$, green $(550 \mathrm{~nm})$, and red $(700 \mathrm{~nm})$.

- Particle Soot/Absorption Photometer (PSAP). Measures light absorption by particles at a single wavelength: green $(565 \mathrm{~nm})$.

- Size and Relative Humidity Control. A $1 \mu \mathrm{m}$ impactor is located upstream of the nephelometer and PSAP. The impactor ensures that only submicron particles, which are the dominant contributors to light scattering and absorption, are measured. It also avoids the difficult of accurately sampling larger particles (i.e., diameter $>1 \mu \mathrm{m}$ ) at typical aircraft velocities (i.e., $\sim 50 \mathrm{~m} \mathrm{~s}^{-1}$ ). The aerosol samples are heated, if necessary, to maintain the $\mathrm{RH}$ at less than $40 \%$.

- Temperature/Humidity (T/RH) sensor Vaisala "Humicap". Measures atmospheric temperature and relative humidity. The sensor is mounted inside a counterflow inlet on the bottom of the aircraft wing.

- DRUM Sampler. The Detection and Evaluation of the Long-range Transport of Aerosol (DELTA) research group at the University of California Davis has a drum sampler on board to make size-segregated aerosol chemical composition measurements. The DRUM sampler physically separates aerosol into three size ranges (i.e., 1.0-0.56, 0.56-0.34, and 0.34-0.07 $\mu \mathrm{m}$ ) based upon their aerodynamic diameter. The impaction substrates are taken to the Advance Light Source at Lawrence Berkeley 
National Laboratory where they are analyzed by synchroton-X-ray fluo-

rescence (S-XRF). S-XRF analysis provides elemental concentration data for almost all elements from sodium $(z=11)$ through uranium $(z=92)$.

\section{MIXING HEIGHT DETERMINATION METHODOLOGY}

The literature reviewed in Chapter 1 clearly demonstrated that the vertical profile of aerosol extensive properties is very sensitive to the $\mathrm{MH}$. Thus, it is possible that the vertical profile of aerosol intensive properties will also be affected by the MH. Since the goal of this thesis is to use aircraft measurements from the ARM SGP site to determine if the aerosol intensive properties are affected by the $\mathrm{MH}$, an objective method for determining the MH must be used. Toward this end, this chapter will review four ground-based and four in situ/remote-sensing techniques for the determination of the MH. The techniques described in this chapter will then be tested with data available from the ARM SGP site. Once the "best" technique has been identified, it will then be used to classify each aircraft flight leg as either within or above the ABL.

This section will begin by describing the MH-determination techniques that require surface data only. This discussion will be followed by a description of the MH-determination techniques that rely upon vertical 
profile measurements. Each technique description will consists of a discussion of the physical idea upon which it is based, as well as its strengths and weaknesses.

Techniques include (Table 6) surface data only techniques and (vertical profile techniques (Table 7), which include the formula or principles upon which each approach is based, the stability regime in which it is valid, and measurements necessary to apply it. The last column describes which of the ARM site instruments fulfills the needs of the technique.

\section{a. MH-Determination Techniques using Surface Data}

The classical way to describe the structure of the ABL is through similarity theories (e.g., Kazanskii and Monin 1960; Zilitinkevich and Deardoff 1974) where the only influencing agents are rotation of the Earth and buoyancy. It is generally assumed that the ABL structure depends on external parameters such as the Coriolis parameter $(f)$, the surface roughness length $\left(z_{0}\right)$, and on internal turbulent parameters such as the surface momentum flux and the surface heat flux.

The surface momentum flux is proportional to the friction velocity $\left(u_{*}\right.$, defined as $\sqrt{\tau / \rho}$, where the surface heat flux $\left[\overline{\left(w^{\prime} \theta^{\prime}\right)_{0}}\right]$ is expressed as the Reynolds average of the product of the turbulent components of the 
vertical velocity $\left(w^{\prime}\right)$ and of the potential temperature $\left(\theta^{\prime}\right)$ at the surface. Classically, the ABL height is assumed to be a function of the Ekman length $\left(L_{E}\right)$ and Monin-Obukhov length $\left(L_{*}\right) . \quad L_{E}$ is defined as $u_{*} / f$, and $L_{*}$ is defined as $u_{*}^{3} / \beta \overline{\left(w^{\prime} \theta^{\prime}\right)_{0}}$, where $\beta=g / T$ is the buoyancy parameter. Zilitinkevich and Deardoff (1974) introduced the intrinsic ABL height, $h$, as a relevant scale since it embodies the effects of non-stationarity, especially under strong unstable conditions when the ABL grows quickly through powerful convective thermals. According to this general similarity theory, the statistical properties of the ABL depend on $h / L_{*}$ and $h / L_{E}$ when non-dimensionalized with the proper scales.

It should be noted, however, that some length scales can become irrelevant for certain stability and height combinations within the ABL. Thus, the ABL can be subdivided into three different domains each characterized by its own set of scaling parameters (Holtslag and Nieuwstadt 1986). These domains include the unstable, stable, and neutral boundary layers.

- The unstable ABL domain is divided into five separate regions (Fig. 6): the surface layer, the free convection layer, the near-neutral upper layer, the mixed layer, and the entrainment layer. The basic scaling parameters are $z, h$, the surface momentum flux $\left(\tau_{0}=-\rho \overline{w^{\prime} u^{\prime}}=\rho u_{*}^{2}\right)$, and the surface heat flux $\left(H_{0}=\rho c_{p} \overline{\left(w^{\prime} \boldsymbol{\theta}^{\prime}\right)_{0}}=\rho c_{p} \boldsymbol{\theta}_{*} u_{*}\right)$. 
- The stable ABL domain (Fig. 7) differs from the unstable ABL domain because local scales are expressed in terms of local fluxes prevailing in specific regions.

- The neutral boundary layer is an asymptotic limit of the stable and the unstable regime.

The different scaling regions are presented in Figs. 6 and 7 for unstable and stable conditions respectively. In these plots the horizontal axes is given by the stability parameter $h / L_{*}$, while the vertical axes is given by the scaling height $z / h$.

For the unstable ABL (Fig. 6) the turbulence and mean profiles of meteorological parameters are closely related to $z / L_{*}$, within the surface layer. In the ML, however, $z / z_{i}$, where $z_{i}$ is the height of the inversion, is more appropriate than $z / L_{*}$ for scaling purposes. The free convection layer that forms in strongly convective situations near the ground can be thought of as the region between the top of the surface layer and the bottom of the ML.

In the free convection layer, neither $L_{*}$ nor $z_{i}$ length scales are rele-

vant. In this case, the appropriate scaling factors are $\overline{\left(w^{\prime} \theta^{\prime}\right)_{0}}$ and $z$. The near-neutral upper layer is similar to the residual layer except that it is still turbulent and still being affected by the surface. These conditions can occur on a windy day with clear skies over land, when both buoyant 
and mechanical generation of turbulence are present. These conditions might also exist in a stratocumulus-topped mixed layer.

For stable conditions (Fig. 7), the region in the upper right portion of the graph corresponds to strongly stable air that is in the top of the surface boundary layer. Turbulence in this region is likely to be intermittent because strong stability suppresses the turbulence. In the middle of the stable boundary layer is a region that might be continuously turbulent, but which is independent of height above ground and of surface fluxes. In this $z$-less scaling region, only the magnitude of the local fluxes are important. Below this region, local scaling continues to be important for more neutral stability, but now the turbulence senses the bottom boundary and is dependent on $z$. Finally, adjacent to the ground is the usual surface layer where surface fluxes and $z$ are important. Note that the near neutral upper layer defined in this graph is within the surface layer and is therefore not the residual layer that lies above the surface layer.

It is difficult to fully characterize and understand the structure and evolution of the ABL because:

- the ABL it is not always well defined

- turbulent fluxes are not easily observable and are rarely measured above the surface layer 
- turbulent characteristics are strongly inhomogeneous in both time and space.

In addition, turbulent characteristics can be intermittent in certain domains and regimes. To complicate matters further, the stable ABL evolution is highly nonstationary especially during the first hours after sunset and later during the night. Under these conditions, time scales of most of the relevant processes are much longer than in the convective $\mathrm{ABL}$. In theory, a quasi-stationary regime is approached as the night progresses, but in reality this progression occurs very slowly, if at all.

Under stable ABL conditions with no buoyant turbulence production, wind shear is the only mechanism that creates turbulence. As a result, stable background stratification associated with negative buoyancy will act as a sink for TKE. Therefore, in the SBL, a sensitive equilibrium exists between production and destruction of turbulence. Consequently, turbulence does not necessarily occur continuously, but may have an intermittent or patchy character.

Since the general level of turbulence is weak, other effects such as radiative cooling, gravity waves, advection or subsidence may also influence the structure of the SBL. Thus, a great variety of SBL structure types can be observed, and this is the main reason why the stable case is the most difficult type of domain in which to determine the $\mathrm{MH}$. 


\section{1) Blackdar and Tennekes Formula}

The Blackdar and Tennekes (1968) formula for estimating MH is given as:

$$
M H=\frac{0.2 u_{*}}{|f|} .
$$

This equation is one of the most popular diagnostic equations used to determine the $\mathrm{MH}$. It is obtained following asymptotic similarity theory and is applicable to the near-neutral ABL, when $u_{*} /\left|f L_{*}\right|<4$.

In this formula, the $\mathrm{MH}$ is given by the ratio of $u_{*}$ multiplied by the constant 0.2 , over the absolute value of the Coriolis parameter $(f=2 \Omega \sin \phi)$. This formula is simple to implement and gives reasonable results in cases when the predominant mechanism in the $\mathrm{MH}$ formation is mechanical in nature (e.g., wind shear production, surface roughness production, etc.).

The Blackdar and Tennekes formula is derived from the equation for the Ekman layer depth by applying appropriate scaling arguments for a near-neutral ABL. The Ekman layer is the layer of the ABL between the top of the surface layer and the base of the FA (i.e., the top of the $\mathrm{ABL})$. Thus, the Ekman layer represent a transition zone between the surface boundary layer, where the shearing stress is constant, and the FA where the atmosphere is treated as an ideal fluid in approximate geostrophic equilibrium. If the flux-gradient approximation is used to 
represent momentum flux divergence terms in the ABL momentum equations, and the value of the diffusivity $\left(K_{m}\right)$ is taken to be constant, the equations of the classical Ekman layer are:

$$
\begin{aligned}
& K_{m} \frac{f^{2} u}{f z^{2}}+f\left(v-v_{g}\right)=0 \\
& K_{m} \frac{f^{2} v}{f z^{2}}+f\left(u-u_{g}\right)=0
\end{aligned}
$$

These equations can be solved to determine the height dependence of the geostrophic wind (i.e., the departure of the wind field in the ABL from geostrophic balance) (Holton 1992).

The theoretical weakness of this approach is the fact that the Ekman layer concept was originally derived for a stationary, neutral ABL. It is also physically questionable to consider $1 / f$ as the only relevant time scale and as one of the most relevant parameters when it is clear that the ABL depth also depends on other parameters such as the buoyant period $\left(1 / N_{b v}\right)$, where $N_{b v}$ is the Brunt-Vaisala frequency), the eddy period $\left(1 / f_{\max }\right)$, where $f_{\max }$ is the frequency at the peak in the turbulent spectrum), the convective ML time scale $\left(t_{*}^{M L}\right)$, the surface layer time scale $\left(t_{*}^{S L}\right)$, and the time required for wind to move distance $x(x / \bar{u}$, where $\bar{u}$ is the mean wind).

The Blackdar and Tennekes formula predicts that the $\mathrm{MH}$ varies only with wind speed under neutral conditions. In practice, however, 
elevated inversion layers often exist even when a major portion of the $\mathrm{ABL}$ is neutral. In this case, the ABL depth is limited by the height of the elevated inversion and the Blackdar and Tennekes formula will not work well.

Another shortcoming of the Blackdar and Tennekes formula (Eq. 1) is that it yields unrealistic $\mathrm{MH}$ values in the tropics where the $f$ approaches zero. To address this limitation, it has become standard practice to put a lower limit on the latitude when calculating $f$. Although many authors use 0.2 as a multiplier in the Blackdar and Tennekes formula (Eq. 3-1) several studies have chosen to alter this constant. This change, of course, leads to different MH estimates.

\section{2) Zilitinkevich Formula}

The Zilitinkevich (1972) formula is given by:

$$
M H=0.4 \overline{\frac{a_{*} L_{*}}{|f|}} y^{1 / 2} .
$$

It is obtained following similarity theory and is only applicable to the case of stable conditions when (i.e., $u_{*} /\left|f L_{*}\right|>4$ ). In the same manner as Blackdar and Tennekes formula, the Zilitinkevich formula is derived from the equation of the Ekman layer depth. Because it was derived in much the same way, the Zilitinkevich formula has the same strengths and weaknesses as the Blackdar and Tennekes Formula. 
The performance of the Zilitinkevich Formula formula also suffers under low surface heat flux conditions. Under these conditions, $L_{*}$ may become quite large which leads to an overestimate of the MH. Thus, it is advisable in practice to use the Blackdar and Tennekes formula (near neutral $\mathrm{ABL}$ ) as an upper limit for $\mathrm{MH}$ determinations in cases for which the Zilitinkevich formula gives higher values. This corresponds with the requirement that the neutral estimate should be taken when $u_{*} /\left|f L_{*}\right|<4$.

\section{3) Nieuwstadt Method}

The method of Nieuwstadt (1981) is a combination of the Zilitinkevich and Blackdar and Tennekes formulae, and is given by:

$$
M H=\frac{0.3 u_{*}}{|f| \overline{1}+1.9 \frac{M H}{L_{*}} \sqrt{ }} .
$$

This formula reduces to the neutral and stable forms as $L_{*} \times$ (negligible surface heat flux) and $L_{*} \bullet 0$ (negligible friction velocity), respectively. Although the same general form of the expression has been used by many different authors, the constants used in Equation (5) are sometimes modified. For example, Van Ulden and Holtslag (1985) used in Eq. 50.2 instead of 0.3 and 1.25 instead of 1.9 . 
The main strength of the Nieuwstadt method (as compared to the Blackdar and Tennekes and Zilitinkevich formulae) is that it is well behaved as conditions transition from the neutral to stable regimes or vice versa. Because the Nieuwstadt method is also based on the Ekman layer model, it has the same theoretical limitations as Blackdar and Tennekes Formula and the Zilitinkevich Formula.

\section{4) Slab Model}

The slab model (Tennekes 1973; Carson 1973) was developed to describe the rate of growth of the daytime unstable boundary layer. This model assumes that mean values of variables such as the potential temperature are constant with height within the unstable ABL and that the entrainment layer can be represented as an infinitesimally thin layer across which there is a discontinuous jump in the value of a variable. The effect of latent heating, horizontal advection, divergence of the radiation heat flux, and large-scale vertical velocities are neglected.

The slab model uses the following two equations:

$$
\begin{aligned}
& \frac{d(M H)}{d t}=1.4 \frac{\overline{w^{\prime} \theta_{0}^{\prime}}}{\gamma M H} \\
& \frac{d(M H)}{d t}=5 \frac{\theta}{g} \frac{u_{*}{ }^{3}}{\gamma M H^{2}}
\end{aligned}
$$


Equation 6 is used when buoyancy-generated turbulence dominates (i.e. when $\overline{w^{\prime} \theta_{0}^{\prime}}>0$ ), while Eq. 7 is used when mechanically generated shear turbulence dominates. The latter condition is most likely to occur when the surface heat flux is zero (i.e., $\overline{w^{\prime} \theta^{\prime}}=0$ ). In both cases, it is assumed that the heat flux varies linearly with height.

The slab model approach has been used extensively in air pollution and dispersion modeling due to its simplicity and efficiency. The weakness of the approach is the singular behavior of the formula as the atmospheric lapse rate $(\gamma)$ approaches zero. This singular behavior causes an over-prediction of the $\mathrm{MH}$ for small lapse rates and prevents this method from being used to treat the neutral ABL.

b. MH-Determination Techniques using Vertical Profiles

1) Parcel Method Technique

The parcel method (Holzworth 1964, 1967, 1972) estimates the MH as the altitude where the dry adiabat starting at surface temperature intersect the observed temperature profile. This theoretical air parcel is lifted dry adiabatically until it reaches its equilibrium level (i.e., the height where the temperature of the air parcel equals that of the environment). Then, the $\mathrm{MH}$ is assumed to be the same as the height of the 
equilibrium level. This method is obviously most representative of a situation in which air parcels rise from the surface.

The parcel method gives satisfactory results where near ground maximum temperature contains an excess temperature respect to the surface temperature and when the atmosphere is absolutely unstable or near-neutral in cases when shear-produced turbulence is negligible. It should be noted, however, that predictions of $\mathrm{MH}$ using this method depend strongly on the estimated maximum surface temperature and that a high degree of uncertainty in the estimated $\mathrm{MH}$ value may result in situations without a pronounced inversion at the top of the ABL. Some authors have noticed that the MH determined with this method is not strongly correlated with observed trace gas concentrations (Aron 1983; Jones 1985).

2) Surface-Based Temperature Inversion Technique

The temperature profile in the SBL is strongly governed by longwave radiative cooling that begins at the surface and progresses upward (Anfossi et al 1976; Stull 1983b). Usually, this process results in the formation of a near-surface temperature inversion.

The surface-based temperature inversion method (Seibert et al. 2000) simply assumes that the MH is equivalent to the height of the surface inversion. This method works best when there is a well-defined 
nocturnal stable ABL. In this case, the inversion acts as a lid for the air mass between the surface and the inversion height limiting the mixing processes to that specific region.

This method works well when the surface inversion is evident. However, for different reasons (synoptic conditions, overcast conditions, etc.), the inversion can be weak, and in those cases the MH estimated by the surface-based temperature inversion method can be very different from the real depth of the ABL. In addition, this method, needs a fairly high vertical resolution (e.g. 10-20 m) of the temperature profile, in order to work properly.

\section{3) Height of Low-level Relative Wind Maximum Technique}

A common phenomenon connected to the SBL is the nocturnal low-level jet (LLJ). The LLJ is generated by an inertial oscillation of the ageostrophic wind vector in those layers that are decoupled from the influence of surface friction following the rapid decay of turbulence during the evening transition period (Blackadar 1957). The characteristic features of the LLJ are the appearance of a supergeostrophic wind speed maximum 4-7 $\mathrm{h}$ after sunset and a steady clockwise turning (in the Northern hemisphere) of the wind vector with height. The LLJ is typically located between 100-300 m AGL and can cause wind shear below the LLJ axis to be as strong as $\sim 0.1 \mathrm{~s}^{-1}$. The strength of the LLJ and the 
timing of its maximum intensity depend on the magnitude and phase of the ageostrophic wind component during the evening stabilization period. Due to small values of the ageostrophic wind component in the upper part of the daytime ABL, and to the larger ageostrophic deviations near the ground, the LLJ occurs first at higher altitudes and subsequently descends with time, thereby increasing in strength. The height of low-level relative wind maximum technique (Angevine et al. 1994) simply chooses the height of the LLJ as the MH.

It is important to note that no significant relationship exists between the height scales based on the temperature profile and the height of the low-level wind maximum. This independence results from the different time evolution of the temperature and wind profiles during the night. Normally, a temperature derived ABL height scale in stable conditions is smaller than the height of the wind maximum at the beginning of the night, whereas towards morning the opposite often holds true. Thus, the structure and the evolution of the ABL should be considered when deriving the stable $\mathrm{MH}$ from temperature or wind profiles or when comparing $\mathrm{MH}$ values derived from different observing systems under stable conditions.

The height of low-level relative wind maximum technique works properly if the LLJ is well defined. Unfortunately, with adverse synoptic conditions, the LLJ can be extremely weak, and the method will fail. In 
addition, this method needs a high vertical resolution (e.g. $\sim 10 \mathrm{~m}$ ) of the wind in order to work properly.

4) Heffter Techique

In this method (Heffter 1980), potential temperature profiles are computed from the vertical profile of temperature and pressure. The profiles are analyzed for the existence of a "critical inversion", which is assumed to mark the top of the mixed layer. In this scheme, a critical inversion is defined as the lowest inversion that meets the following two criteria:

$$
\begin{gathered}
\Delta \theta / \Delta z>0.005 \mathrm{~K} \mathrm{~m}^{-1} \\
\theta_{t}-\theta_{b}>2 \mathrm{~K},
\end{gathered}
$$

where $\Delta \theta / \Delta z$ is the potential temperature lapse rate in the inversion layer and $\theta_{\mathrm{t}}$ and $\theta_{\mathrm{b}}$ refer to the potential temperatures at the top and bottom of the critical inversion layer, respectively. The $\mathrm{MH}$ is that point in the inversion at which the temperature is $2 \mathrm{~K}$ greater than the temperature at the inversion base. The strength of this method is the property to recognize the likelihood of mixing (caused by buoyant thermals) to overshoot the base of the critical inversion. This physical process is overlooked in many similar schemes (Marsik et al. 1995). 
One possible error source of this technique is that it does not directly address the possible vertical extension of the mixed layer caused by wind shear effects within the critical inversion. Another possible source of error is the overestimation of the depth of mixing within a surface-based nocturnal inversion. Under such conditions, the only source of TKE available to cause mixing near the surface is from mechanical effects such as surface wind shear. The degree of mixing under such conditions is likely to be quite shallow (less than $100 \mathrm{~m}$ ). Since the Heffter technique chooses the critical inversion to be at a level corresponding to $2 \mathrm{~K}$ greater than the inversion base (in this case the surface), the estimated depth of mixing may be somewhat overestimated.

\section{RESULTS}

The results of this thesis can be divided into two parts. The first will describe how the various $\mathrm{MH}$-determination techniques are tested and evaluated. Specific questions to be addressed in this part include:

- What are the desirable performance characteristics?

- How can the "true" MH be estimated?

- How do the various techniques perform under different stability conditions? 
- Which technique performs the best under the conditions encountered at the ARM SGP site?

The second section of this chapter will characterize the vertical profiles of both extensive and intensive aerosol properties at the ARM SGP site. The results of this analysis will be used to determine under what conditions, if any, the surface values of aerosol properties are representative of the same quantities measured in the column of air above the site.

\section{a. MH Techniques}

\section{1) Methodology}

The various $\mathrm{MH}$-determination techniques were tested using data from one of the ARM IOPs, which are scheduled, intermittent periods of time when the observation frequencies are increased. The IOP datasets augment routine observations and are designed to meet either scientific or technical objectives within the scope of ARM.

The IOP selected to test the various $\mathrm{MH}$-determination techniques took place from 18 June through 18 July 1997. This period was characterized by three distinct weather segments. The first segment was dominated by local convection and frequent, heavy precipitation. The second segment was generally clear and hot. The last segment was affected by a large convective complex with sustained precipitation. 
The first step in evaluating the various techniques is to define the desirable characteristics. In order to be operationally useful, the chosen MH-determination technique should work in every kind of stability regime and rely upon data frequently available at the ARM SGP site. Although high vertical resolution is often desirable, it is not crucial for this study. The reason for this is that the MH values will be used to determine which flight legs are within and above the $\mathrm{ABL}$, and the legs are at altitude intervals of roughly $500 \mathrm{~m}$. Moreover, a method that generally overestimates the $\mathrm{MH}$ is preferred because it will result in a more conservative correlation of the aerosol properties measured at the surface and within the ABL.

The second step in evaluating the various techniques is to determine the "true" value of MH against which the performance of the techniques will be judged. The "true" value was selected by manually evaluating the temperature, potential temperature, and moisture vertical profile measurements from each radiosonde launch. In the well-mixed cases, the potential temperature is nearly constant throughout the ABL. In this situation, the "true" $\mathrm{MH}$ is estimated by identifying the level where the potential temperature begins to increase. Another relatively simple case in which the "true" MH can be determined is when there is a pronounced surface or elevated temperature inversion. In this case, the "true" MH can be estimated close to the height of the inversion. The final 
value is chosen slightly above or slightly below that height, depending upon whether or not the moisture profile indicates the presence of a cloud base at that altitude.

As usual, the transition periods (i.e., early morning and late afternoon) are the most difficult cases because the vertical profiles do not clearly indicate the depth of the ABL. Here, the "true" MH is estimated based on the aforementioned manual techniques and on the trend of the ABL growth that is inferred from the earlier and later profiles. Once the "true" MH value has been established, a comparison of all the methods with meaningful values (i.e., the methods that were able to give a $\mathrm{MH}$ values for the specific regime analyzed) can then be performed.

\section{2) Comparison of MH-Determination Techniques}

Since the various $\mathrm{MH}$ techniques are based on data with different temporal and vertical resolutions, it is very difficult to make direct comparisons between them. The method that was chosen to overcome this problem was to plot a time series of each $\mathrm{MH}$-determination technique on a single chart. An example of this type of plot is shown in Fig. 8. This figure, which shows data from 8-11 July, permits visual comparison of the techniques throughout the day and during different stability regimes. Due to theoretical limitations, the Heffter technique is the only one of the MH techniques that works for all stability conditions (see Table 6 and 7 
for details). As a result, this figure only plots the $\mathrm{MH}$ estimates for those techniques applicable in that specific case. It is possible, however from an operational standpoint to make composite techniques that work for all stability conditions. Examples of composite techniques that utilize the same input data include:

- combination of the Blackdar and Tennekes (stable) and Zilitinkevich (near neutral) formulas

- combination of surface temperature inversion formula (stable) and parcel method (neutral, unstable).

The first composite technique utilized the ECOR while the other composite technique can use either radiosonde data or the AERI. To facilitate a detailed comparison of the techniques, the first 24-hour period from Fig. 8 has been expanded and enlarged in Fig. 9.

This figure can be subdivided into four 6-h segments representing the - development of a nocturnal stable layer (0000 - 0006 GMT) - fully developed nocturnal stable layer (0006 -0012 GMT) - rapid entrainment and subsequent growth of the $\mathrm{ABL}$ during the morning (0012 - 0018 GMT) - afternoon convective ABL (0018 - 0024 GMT).

In the evening (i.e., $0000-0006$ GMT), during the formation of a stable nocturnal $\mathrm{ABL}$, the $\mathrm{MH}$ gradually drops from a value slightly below 
$1000 \mathrm{~m}$ to a depth of only $100-200 \mathrm{~m}$ (Fig. 9). The Heffter technique is the only one able to capture the timing of this feature, even if is still underestimates the "true" MH. For example, at 0228 GMT 8 July the Heffter technique reported a $\mathrm{MH}$ value of $324 \mathrm{~m}$ while the true value was 1100 (Fig. 10). In this case, the other techniques produced results that were even lower than the Heffter technique. The surface temperature inversion technique produced very noisy values using the AERI data and $\mathrm{MH}$ values that were too low when the radiosonde data was used. The wind maximum technique failed to provide a $\mathrm{MH}$ value in the first half of this time period. The slab model is incapable of providing an estimate of the MH under this stable condition.

In the nighttime (i.e., 0006-0012 GMT), a stable nocturnal layer forms with a very low MH (Fig. 9). Most of the MH methods produce MH estimates ranging from $100 \mathrm{~m}$ to $300 \mathrm{~m}$ during this time period. The two exceptions include the wind maximum method and the surface temperature inversion (with AERI data). Both of these techniques produce results close to $600 \mathrm{~m}$. During this stable case, the Nieuwstadt method, the Heffter technique, and the Blackdar and Tennekes and the Zilitinkevich formulas (with radiosonde) are well behaved and produce results similar to the "true" value. The wind maximum technique provides only sporadic results that are often too high compared to the "true" $\mathrm{MH}$ values. Fig. 11 shows a detailed plot for the Heffter technique, wind 
maximum technique, and the "true" value at 0827 GMT on 8 July. At this time, neither the surface temperature inversion technique nor the slab model approach provide valid $\mathrm{MH}$ values.

In the morning (i.e., 0012-0018 GMT), the rapid growth of the $\mathrm{ABL}$ is captured quite well by the slab model (MH 1900 m) (Fig. 9), the Heffter technique $(\mathrm{MH}=2894 \mathrm{~m})$, and the parcel method $(\mathrm{MH}=2552 \mathrm{~m})($ Fig. 12). The latter two of these techniques, however, overestimate the "true" MH (i.e., 2000 $\mathrm{m}$ ) during this time period. The Blackdar and Tennekes and the Zilitinkevich formulas clearly underestimate the $\mathrm{MH}$ in this stability condition. At this time, neither the wind maximum technique nor the Nieuwstadt method provide valid $\mathrm{MH}$ values.

In the afternoon (i.e., $0018-0024$ GMT), the Heffter technique, the parcel method (both with radiosonde), and the slab model all capture the depth of the well-mixed afternoon ABL (Fig. 9). The Heffter technique, however, overestimates the "true" MH again (Fig. 13). The Blackdar and Tennekes and the Zilitinkevich formulas significantly underestimates the depth of the ABL again, and the wind maximum and the Nieuwstadt methods do not provide valid $\mathrm{MH}$ values at this time.

The previous examples demonstrate the basic performance characteristics of each $\mathrm{MH}$-determination technique under a variety of stability conditions. Although these examples were all from one day these general patterns of behavior were observed in many other cases. One 
needs to look no further than the four-day time series of $\mathrm{MH}$ values shown in Fig. 8 for corroboration of this fact. This plot shows three consecutive nights of similar behavior.

During the last night (i.e., 11 July) the stability situation is not as well defined as in the previous cases and the Nieuwstadt technique and the Blackdar and Tennekes and the Zilitinkevich formulas, which had performed well on previous nights, produced only intermittent and noisy values. The Heffter technique clearly performs better than the other technique on this day. For example, at 0825 UTC on 11 July, the Heffter technique predicted a $\mathrm{MH}$ value of $45 \mathrm{~m}$ while the "true" value at this time was $\sim 55 \mathrm{~m}$ (Fig. 14). By contrast, the surface inversion technique and the low-level relative wind maximum technique gave estimates of 122 and 294 m, respectively (Fig. 14). In this case, the Nieuwstadt method significantly underestimated the MH value because $L_{*} \bullet 0$.

3) Selection of the "Best" Technique

Based on all the above considerations, the method that performs best under the widest possible conditions is the Heffter Technique. This technique works in every kind of stability regime, and almost in every case gives estimates of the ABL depth that are at or above the "true" $\mathrm{MH}$. The next question to answer is which data should be used as input for the Heffter technique: AERI or radiosonde. 
The four-day time series shown in Fig. 8 points out a severe weakness of the AERI data, namely the very low vertical resolution. On the other hand, the AERI data have a good temporal resolution. However, the poor vertical resolution results in more scattered $\mathrm{MH}$ values. In many cases, the uncertainty associated with this noisy data is so large that it would be impossible to determine if a given flight leg was within or above the ABL. In addition, use of the AERI data generally gives lower $\mathrm{MH}$ values. Underestimating the $\mathrm{MH}$ is undesirable because it could artificially enhance correlations between ABL values and the surface. The only advantage of the AERI data is that it has a much higher time resolution compared to the radiosonde data. In any case, the radiosonde data has a sufficient time resolution (eight per day during the $\mathrm{IOP}_{\mathrm{s}}$ and four per day during normal operation) to completely cover the different stability regimes each day. Thus, this thesis will use the radiosonde data as input for the Heffter technique.

The most important limitation of the Heffter technique is its extreme sensitivity to the choice of the critical lapse rate. A value of 0.005 (Table 7) is often used (Heffter 1980). In this work, however, agreement with the "true" $\mathrm{MH}$ values was achieved using a value of $0.001 \mathrm{~K} \mathrm{~m}^{-1}$ and this is the value that has been used throughout the previous discussion. This modification to the Heffeter techniques was necessary because the 
original value led top unrealistically high estimates of the MH. An example of this problem is shown in Fig. 15.

b. Vertical Variation of Extensive and Intensive Aerosol Properties The aerosol extensive properties considered in this study are the absorption coefficient for green light $\left(\beta_{a p, g}\right)$ and the total scattering coefficients for blue $\left(\beta_{s p, b}\right)$, green $\left(\beta_{s p, g}\right)$ and red light $\left(\beta_{s p, r}\right)$. Moreover the aerosol intensive properties considered here are the hemispheric backscatter ratios for blue $\left(b_{b}\right)$, green $\left(b_{g}\right)$ and red channel $\left(b_{r}\right)$, the single scattering albedo $(\omega)$, and the Angstrom exponent $(\AA)$.

\section{1) Initial Hypothesis}

The goal of this thesis is to determine under what conditions, if any, the surface values of aerosol properties are representative of the same quantities measured in the column of air above the surface. The initial hypothesis to be tested is that the surface aerosol intensive properties measured at the surface are representative of the air above the site. This hypothesis begins with the assumption that the vertical profile of aerosol intensive properties does not behave in the same manner as the extensive properties. Recall that the aerosol extensive properties are those properties that depend upon the amount of aerosol present (i.e., either the number or mass concentrations). 
The literature review contained in Chapter 1 demonstrated that extensive aerosol properties within the ABL are typically highly correlated with the values measured at the surface. By contrast, the values measured above the top of the ABL typically have a much lower correlation with the surface values.

To test the aforementioned hypothesis, the surface (AOS) aerosol intensive properties were compared to the column-averaged values for all of the 59 days in which flight data were available. This comparison includes data collected in the one-year period between March 2000 and March 2001. The resulting correlation values are quite low (Table 8). Correlation values for the aerosol extensive properties, which are known to vary across the $\mathrm{ABL}$, have been included for comparison purposes. This poor correlation indicates that the original hypothesis is not valid (i.e., the surface values are not representative of the column-averaged aerosol intensive properties). Thus, the original hypothesis must be reformulated and retested.

\section{2) Revised Hypothesis}

The revised hypothesis is that the aerosol intensive properties measured at the surface are representative of the air within the wellmixed ABL but not within the FA (i.e., the intensive properties behave in the same manner as the extensive properties). To test this hypothesis, 
the MH must be identified using an objective criteria and the aerosol properties within and above the ABL must be averaged. Based upon the results shown in the first part of this chapter, the $\mathrm{MH}$ will be estimated by using the radiosonde data as input for the Heffter technique.

Figs. 16 - 19 show how the aerosol extensive properties measured above the ARM SGP site compare with the surface values. In each case, the data is consistent with the previous research. Aerosol extensive properties measured at the surface are representative of values within, but not above the ABL. The results of this analysis are summarized in the top half of Table 9. In each case, the Pearson correlation coefficient $(R)$ is greater than 0.85 and the slope is $\sim 1.0$. The only exception is $\beta_{a p, g}$ which had a slope of 0.77 (Fig. 16). This figure shows the same general pattern as the scattering values but is offset somewhat. This offset could be a systematic difference between the surface AOS and IAP measurements, or possibly a result of the fact that most of the absorption coefficients are less than twice the instrument noise for one-minute-averaged data (i.e., $0.9 \mathrm{Mm}^{-1}$ ).

There are two techniques that could be used to compute the average values of aerosol intensive properties. The first computes the average values of the intensive properties for each flight leg and then averages the data from each flight leg. The second technique computes the average values of the extensive properties for each flight leg and then av- 
erages the data from each flight leg. The averaged intensive properties are then calculated from these values. In this thesis, the second of the two techniques has been used to compute the average intensive properties. In general, this procedure results in less noisy data.

An average for all of the intensive aerosol quantities within the ABL and above the ABL was computed for each of the 59 flight days. The results of this comparison are shown in Figs. $20-24$ and in the lower half of Table 9. From these figures and the data in Tables 8 and 9, it is apparent that the intensive aerosol properties within the ABL are more similar to the surface values than those above the ABL. In fact, there is almost no correlation at all between the surface and those above the ABL. Thus, it appears that the revised hypothesis (i.e., that the aerosol intensive properties are affected by the $\mathrm{MH}$ in much the same way as the extensive aerosol properties) is correct. Although the correlations, slopes and intercepts of the aerosol intensive properties were improved by removing the above ABL data, the regression statistics for the intensive properties are still not as good as those for the extensive properties within the ABL (Table 9). The best results thus far were obtained for $b_{g}$ (Fig. 21) while the worst results were obtained for $b_{r}$ (Fig. 22).

One possible explanation is that measurements for $b_{r}$ are near the minimum detectable limit, which might lead to noise in the computed results. It is also possible that the red phototube in the nephelometer ex- 
perienced problems during the IAP (J. A. Ogren 2001, personal communication).

All these plots indicate that the $\mathrm{MH}$ has a significant effect on the aerosol intensive properties and that the refined hypothesis is correct. If this hypothesis is correct then the correlation between the IAP values within the ABL and the AOS values at the surface should be higher under well-mixed conditions.

This refined hypothesis will now be tested. "Well mixed" days were identified as soundings with a layer of constant potential temperature with a capping inversion. The quantities considered to test the refined hypothesis are those quantities that satisfied the revised hypothesis (i.e., $\left.b_{b}, b_{g}, \AA, \omega\right)$. The results of this comparison are shown in Figs. 25 - 28. All the variables with the exception of $\omega$ had significantly improved correlations between the $\mathrm{ABL}$ and the surface. In fact, the slope of the regression lines for $b_{b}$ and $b_{g}$ are extremely close to 1.0. The slope for the $\AA$ increased from 0.62 to 0.81 for the well-mixed case as well. It is unclear what is happening with $\omega$ (Fig. 28), since the results for the well-mixed cases are slightly worse than the ones for all the 59 days (i.e., Fig 23). The reduced correlation for the $\omega$ with the 10 wellmixed days can be explained by looking at the plot for 10 days versus the $\omega$ plot for 51 days within the PBL. There is a greater range of values 
with the 51 days (especially for smaller $\omega$ values), which tends to better constrain the least-squares regression.

3) Vertical Variation of Aerosol Properties Within the ABL

In an effort to further understand the behavior of the vertical variation of aerosol extensive and intensive properties, another approach has been exploited. In this test, the flight legs were categorized as either within or above the ABL using the Heffter Technique. The respective categories were then divided into different altitude ranges (Table 10).

The results of this two-tiered screening process are shown in Figs. 29 - 37. Each of these plots show the average values of the ratio of the IAP aerosol data over the AOS values. This procedure normalizes all of the data to make it obvious if the surface and IAP data agree or not. The standard deviation of these normalized data are included on each plot as well.

The previous discussion on the vertical variability of the extensive properties can be repeated here with even more strength. Looking at the plots for $\beta_{s p, b}$ (Fig. 29), $\beta_{s p, g}$ (Fig. 30) and $\beta_{s p, r}$ (Fig. 31), it is clear that the ratio IAP/AOS is very close to one in the $\mathrm{ABL}$ and less than 0.5 above the ABL. Although the standard deviations are smaller within the ABL than they are above it, they gradually increase with height in both the ABL and the FA. The only exception to this pattern occurs at the highest two 
altitude intervals (i.e., $2900-3100$ and $3400-3800 \mathrm{~m}$ ). This analysis confirms once again that the aerosol extensive properties measured at the surface are representative of the air within the ABL, but not in the FA. It should be noted that $\beta_{a p, g}$ (Fig. 32) shows a similar general pattern as the scattering values but is offset by approximately $30-40 \%$. Moreover, for this variable there is a much larger standard deviation within the ABL than there is in the FA. This offset appears to be real and might possibly be caused by a systematic difference between the IAP and the surface measurements. In this case IAP $>$ AOS.

A similar comparison of the aerosol intensive properties is made in Figs. $33-37$. Although there is still a significant difference in the IAP/AOS ratio computed for the flight legs below the $\mathrm{MH}$ and the flight legs above the $\mathrm{MH}$, the differences are less pronounced. For $\omega, b_{b}, b_{g}$, and $b_{r}$ the AOS values are quite close to the IAP values measured below the $\mathrm{MH}$, and significantly different from the IAP values measured above the $\mathrm{MH}$. Also, the standard deviation values are significantly smaller for the legs within the ABL compared with the legs above it. Here, a much better result for $b_{r}$ was obtained, compared with the discussion concerning Fig. 22. The argument that $b_{r}$ measurements are often near the minimum detectable limit, and this leads to noise in the computed results, however, is still valid, but the different calculation approach used 
here (i.e., the average across altitude intervals) acts to smooth out much of the noise in the data.

In the plot referring to $\AA$ (Fig. 37), it is not clear what is happening. The most unexpected result is the fact that in the ABL, the lowest leg is the one that has IAP average values that deviate most from the AOS surface values. Also, in this case, the averages of IAP values computed for the legs above the $\mathrm{MH}$ are generally closer to the AOS surface values than the averages computed for the legs within the ABL. It should be noted, however, that the standard deviations of the $\AA$ are much larger then for the other variables at all levels.

\section{CONCLUSION}

The goal of this thesis was to determine under what conditions, if any, ground-based measurements of aerosol intensive properties are representative of the atmosphere above the site. The results of this thesis are based entirely upon data collected at the ARM SGP site. The SGP CART site is the largest of the ARM fixed locations for climate research and is one of only a few sites in the world that makes routine measurements of the aerosol properties at both the surface and aloft. Thus, it 
provided a unique opportunity to study the vertical variation of aerosol properties.

The initial hypothesis tested was that the aerosol intensive properties measured at the surface are representative of the air above the site. This hypothesis was tested by comparing the surface (AOS) aerosol intensive properties to the column-averaged values for all of the 59 days in which flight data were available. This comparison included data collected in the one-year period between March 2000 and March 2001. The results of this comparison clearly demonstrated that the surface values are not representative of the column-averaged aerosol intensive properties. In fact, the aerosol extensive properties which are known to vary across the ABL were more highly correlated with the surface values than the aerosol intensive properties.

Due to the poor performance of the original hypothesis, a revised hypothesis was created by assuming that the aerosol intensive properties measured at the surface are representative of the air within the wellmixed $\mathrm{ABL}$ but not within the FA. In order to test this hypothesis, however, it was necessary to identify an objective criteria for determining the MH.

A total of eight $\mathrm{MH}$-determination techniques were evaluated. Half of these techniques used ground-based measurements while the other half relied upon in situ/remote-sensing data. These techniques were 
tested with data from one of the IOPs at the ARM SGP site. The MHdetermination method that performed best under the widest possible conditions was the Heffter Technique. This technique works in every kind of stability regime, and in almost every case provides estimates of the $\mathrm{ABL}$ depth that are at or above the "true" $\mathrm{MH}$.

Using the Heffter technique to determine the $\mathrm{MH}$, averages for all of the intensive aerosol quantities within and above the ABL were computed for each of the 59 flight days. The results of this comparison demonstrated that the intensive aerosol properties within the ABL were much more similar to the surface values than those above the ABL. In fact, there was almost no correlation at all between the surface values and those above the ABL. Thus, this analysis indicates that the revised hypothesis (i.e., that the aerosol intensive properties are affected by the $\mathrm{MH}$ in much the same way as the extensive aerosol properties) is correct.

Much of the evidence to support this conclusion is contained in Table 9. Although the correlations, slopes and intercepts of the aerosol intensive properties were all improved by grouping the ABL and above ABL values together (Table 9), they were still not as good as those for the extensive properties. The best results obtained were for $b_{g}$ while the worst results were obtained for $b_{r}$. One possible explanation is that many of the $b_{r}$ measurements are near the minimum detectable limit, which might lead to noise in the computed results. It is also possible 
that the red phototube experienced problems during the IOP (John Ogren personal communication).

Although $\beta_{a p, g}$ exhibited the same general pattern as the other extensive properties, it appeared to be offset somewhat relative to the other extensive properties. This offset could be a systematic difference between the surface AOS and IAP measurements or possibly just a reflection of the fact that most of the absorption coefficients are less than twice the instrument noise for $1 \mathrm{~min}$-averaged data (i.e., $0.9 \mathrm{Mm}^{-1}$ ). Further work will be needed to clarify this issue.

The best agreement between the surface AOS and IAP measurements of aerosol intensive properties was observed on the days with a well-mixed ABL. On these days, significantly improved correlations between the $\mathrm{ABL}$ and the surface were observed for all the variables with the exception of $\omega$. In fact, the slope of the regression lines for $b_{b}$ and $b_{g}$ are extremely close to 1.0 . The slope for the $\AA$ increased from 0.62 to 0.81 for the well-mixed case as well.

In an effort to further understand the behavior of the vertical variation of aerosol intensive properties in the ABL, another approach was exploited. The flight legs were categorized as either within or above the ABL using the Heffter Technique. The respective categories were then divided into different altitude ranges. The average values of the ratio of the IAP aerosol data over the AOS values were then computed for 
each altitude range. This procedure normalized all of the data to make it obvious when the surface and IAP data disagreed.

The ratio IAP/AOS was very close to one in the ABL and less than 0.5 above the ABL for all of the aerosol extensive properties excluding $\beta_{a p, g}$. The standard deviations of the normalized IAP/AOS values were also smaller within the ABL than they were above it. The standard deviations gradually increased with height in both the $\mathrm{ABL}$ and the FA, with few exceptions. This analysis confirmed, once again, that the aerosol extensive properties measured $\left(\beta_{a p, g}, \beta_{s p, b}, \beta_{s p, g}\right.$, and $\left.\beta_{s p, r}\right)$ at the surface are representative of the air within the BL, but not in the FA.

The lone exception again was $\beta_{a p, g}$, which showed a similar general pattern as the scattering values but was offset by approximately 30-40 $\%$. Moreover, for this variable there was a much larger standard deviation within the ABL than there was in the FA. This offset appears to be real and might possibly be caused by a systematic difference between the IAP and the surface measurements. In this case IAP $>$ AOS.

A similar analysis was performed for the aerosol intensive properties as well. In this case the IAP/AOS ratio was very close to one in the ABL and 1.2 above the ABL for $b_{b}, b_{g}$, and $b_{r}$. Thus, these values are actually higher in the FA then they are in the ABL.

Here, a much better result for $b_{r}$ was obtained, compared with the previous discussion. The argument that $b_{r}$ measurements are often near 
the minimum detectable limit, and this leads to noise in the computed results, however, is still valid, but the different calculation approach used here (i.e., the average across altitude intervals) acts to smooth out much of the noise in the data.

For $\AA$ it is not clear what was happening. The most unexpected result was the fact that in the ABL, the lowest leg is the one that had IAP average values more different than the AOS surface values. Also, in this case, the average IAP values computed for the legs above the MH are generally closer to the AOS surface values than the averages computed for the legs within the ABL. It should be noted, however, that the standard deviations of the $\AA$ are much larger then for the other variables at all levels.

From all the above, it is clear that assuming that the aerosol intensive properties are constant with the height or decrease with height (similar to aerosol extensive properties) will lend to wrong estimates of the aerosol radiative forcing in the troposphere. Thus, this work shows that vertical profile measurements of aerosol properties must continue to be made in both the ABL and in the FA.

In this thesis, the MH was considered as the main meteorological parameter that affected the vertical profiles of aerosol extensive and intensive properties. Future work should try to identify other meteorological parameters that might affect aerosol vertical profiles. Other parame- 
ters that could be investigated include: the effects of wind shear (which is closely related to diverging backward air mass trajectory), potential seasonal differences, and the relationship between aerosol vertical properties and synoptic-scale events such as frontal passages and stagnation events. Other important questions to be addressed include whether the aerosol intensive properties are affected by RH variations and how the inclusion of coarse aerosols would affect the results of this thesis. However, neither of the last two issues can be addressed using the IAP data because of the size-selective and humidity controlled inlet system.

\section{REFERENCES}

Ahonen, T., P. Aalto, U. Rannik, M. Kulmala, E. D. Nilsson, S. Palmroth, H. Ylitalo, and P. Hari, 1997: Variations and vertical profiles of trace gas and aerosol concentrations and $\mathrm{CO}_{2}$ exchange in eastern Lapland. Atmos. Environ., 31, 3351-3362.

Albrecht, B. A., 1989: Aerosol, cloud microphysics, and fractional cloudiness. Science, 245, 1227-1230.

Anfossi, D., P. Bacci, A. Longetto, 1976: Forecasting of vertical temperature profiles in the atmosphere during nocturnal radiation inver- 
sions from air temperature trend at screen height. Quart. J. Roy. Meteor. Soc., 102, 173-180.

Angevine, W. M., M. Trainer, D. D. Parrish, M. P. Buhr, F. C. Fehsenfeld, and G. L. Kok, 1994: Wind profiler mixing depth and entrainment measurements with chemical applications. Proceedings of the Eighth AMS Conference on Air Pollution Meteorology and AWMA, Nashville, 32-34.

Aron, R, 1983: Mixing Height - an Inconsistent indicator of potential air pollution concentrations. J. Atmos. Sci., 17, 2193-2197.

Barnett, T. P., G. C. Hegerl, B. Santer, and K. Taylor, 1998: The potential effect of GCM uncertainties and internal atmospheric variability on anthropogenic signal detection. J. Geophys. Res., 88, 1075310768.

Blackadar, A. K., 1957: Boundary-layer wind maxima and their 'significance for the growth of nocturnal inversions. Bull. Amer. Meteor. Soc., 38, 283-290. , and H. Tennekes, 1968: Asymptotic similarity in neutral barotropic planetary boundary layers. J. Atmos. Sci., 25, 10151020.

Boucher, O., S. E. Schwartz, T. P. Ackerman and T. L. Anderson, 1997: Intercomparison of models representing direct shortwave radiative forcing by sulfate aerosols. J. Geophys. Res., 103, 16979-16998. 
Carson, D. J., 1973: The Development of a dry inversion-capped convectively unstable boundary layer. Quart. J. Roy. Meteor. Soc., 99, $450-467$.

Charlson, R. J., S. E. Schwartz, J. M. Hales, R. D. Cess, J. A. Coakley Jr., J. E. Hansen, and D. J. Hofmann, 1992: Climate forcing by anthropogenic aerosols. Science, 255, 423-430.

Coakley Jr., J. A., R. L. Bernstein, and P. A. Durkee 1987: Effect of ship effluents on cloud reflectivity. Science, 237, 1020-1022.

Deardoff, J. W., G. E. Willis, and D. K. Lilly, 1969: Laboratory studies of the entrainment zone of a convective mixed layer. J. Fluid Mech., 100, Part 1, 41-64.

Field, R., T. L. Fritschen, E. T. Kanemasu, E. A. Smith, J. Stewart, S. Verma, and W. Kustas, 1992: Calibration, comparison, and correction of net radiation instruments used during FIRE. J. Geophys. Res., 97, 18343-19110.

Fitch, B. W., and T. D. Cress, 1981: Measurement of aerosol size distributions in the lower troposphere over northern Europe. J. Appl. Meteor., 20, 1119-1128.

Garrat, J. R., 1992: The Atmospheric Boundary Layer. University Press, Cambridge, 316 pp. 
Goldsmith, J. E. M., F. H. Blair, S. E. Bisson, and D. Turner, 1998:

Turn-key Raman lidar for profiling atmospheric water vapor, clouds, and aerosols. Appl. Opt., 37, 4979-4990.

Gryning, S.-E., and E. Batchvarova, 1994: Parametrization of the depth of the entrainment zone above the daytime mixed layer. Quart. J. Roy. Meteor. Soc., 120, 47-58.

Gunter, R. L., A. D. A. Hansen, J. F. Boatman, B. A. Bodhaine, R. C. Schnell, and D. M. Garvey, 1993: Airborne measurements of aerosol optical properties over south-central New Mexico. Atmos. Environ., 27A, 1363-1368.

Hansen, J. E., and A. A. Lacis, 1990: Sun and dust versus greenhouse gases: an assessment of their relative roles in global climate change. Nature, 346, 713-719.

Haywood, J. M., V. Ramaswamy, and B. J. Soden, 1999: Tropospheric aerosol climate forcing in clear sky satellite observations over the ocenans. Science, 283, 1299-1303.

Heffter, J. L., 1980: Transport layer depth calculations. Second Joint Conference on Applications of Air Pollution Meteorology, New Orleans, LA (1980).

Hinds, W. C., 1999: Aerosol Technology: Properties, Behavior, and Measurement of Airborne Particles. John Wiley \& Sons Inc, New York, $483 \mathrm{pp}$. 
Holton, J. R., 1992: An Introduction to Dynamic Meteorology. Academic Press, San Diego, CA, 511 pp.

Holtslag, A. A. M., and F. T. M. Nieuwstadt, 1986: Scaling the atmospheric boundary layer. Bound.-Layer Meteor., 36, 201-209.

Holzworth, C. G., 1964: Estimates of mean maximum mixing depths in the contiguous United States. Mon. Wea. Rev., 92, 235-242.

— 1967: Mixing depths, wind speeds and air pollution potential for selected locations in the United States. J. Appl. Meteor., 6, 1039-1044.

, 1972: Mixing depths, wind speeds and potential for urban pollution throughout the contiguous United States. EPA, Office of Air Programs Publ. AP-101, 118 pp. (Can be obtained from EPA, Research Triangle Park NC 277711, USA).

Jarzembrski, M. A., V. Srivastava, and J. Rothermel, 1999: Vertical variability of aerosol backscatter from an airborne-focused continuouswave $\mathrm{CO}_{2}$ lidar at 9.2- $\mu m$ wavelength. Appl. Opt., 38, 908-915.

Jones, D. E., 1985: Mixing Depth in La Trobe Valley. Clean Air in Australia, 19, 49-51.

— D. L. Roberts, and A. Slingo, 1994: A climate model study of indirect radiative forcing by anthropogenic sulfate aerosols. Nature, 370, 450-453. 
Kazanskii, A. B., and A. S. Monin, 1960: The turbulent regime above the surface atmospheric layer. Izv. Acad. Sci. Sr. Geof., 1, 165-168.

Kiehl, J. T., and B. P. Briegleb, 1993: The relative roles of sulfate aerosols and greenhouse gases in climate forcing. Nature, 260, 311-314.

Kilsby, C. G., 1990: A study of aerosol properties and solar radiation during a straw-burning episode using aircraft and satellite measurements. Quart. J. Roy. Meteor. Soc., 116, 1173-1192.

Kim, Y. J., J. F. Boatman, R. L. Gunter, D. L. Wellman, and S. W. Wilkinson, 1993: Vertical distribution of atmospheric aerosol size distribution over south-central New Mexico. Atmos. Environ., 27A, 1351-1362.

King, M. D., L. F. Radke, and P. V. Hobbs, 1993: Optical properties of marine stratocumulus clouds modified by ships. J. Geophys. Res., 98, 2729-2739.

Kogan, Z. N., Y. L. Kogan, and D. K. Lilly, 1997: Cloud factor and seasonality of the indirect effect of anthropogenic sulfate aerosols. $J$. Geophys. Res., 102, 25927-25939.

Lesht, B.M., 1995: An Evaluation of ARM Radiosonde Operational Performance. Ninth Symposium on Meteorological Observations and Instrumentation, American Meteorological Society, Boston, MA, 6-10. 
Marsik, F.J., K.W. Fischer, T.D. McDonald, P.J. Samson, 1995: Comparison of methods for estimating mixing height used during the 1992 Atlanta field intensive. J. Appl. Meteor., 34, 1802-1814.

National Research Council, 1996: Aerosol Radiative Forcing and Climate Change. National Academic Press, Washington D. C., 161 pp. Nieuwstadt, F. T. M., 1981: The steady-state height and resistance laws of the nocturnal boundary layer: theory compared with Cabauw observation. Bound.-Layer Meteor., 20, 3-17.

, and R. A. Brost, 1986: The decay of convective turbulence. J. Atmos. Sci., 43, 532-546.

Pan, W., M. A. Tatang, G. J. McRae, and R. G. Prinn, 1997: Uncertainty analysis of direct radiative forcing by anthropogenic sulfate aerosols. J. Geophys. Res., 102, 30023-30030.

$\_,-, \ldots$, and $\_, 1998$ : Uncertainty analysis of indirect radiative forcing by anthropogenic sulfate aerosols. J. Geophys. Res., 103, 3815-3823.

Radke, L. F., J. A. Coakley, Jr., and M. D. King, 1989: Direct and remote sensing observations of the effects on ships on clouds. Science, 246, 1146-1149.

Raga, G. B., and P. R. Jonas, 1995: Vertical distribution of aerosol particles and $\mathrm{CCN}$ in clear air around the British Isles. . Atmos. Environ., 29, 673-684. 
Rotstayn, L. D., 1999: Indirect forcing by anthropogenic aerosols: A global climate model circulation of the effective-radius and cloudlifetime effects. J. Geophys. Res., 104, 9369-9380.

Russell, P. B., S. A. Kinne, and R. W. Bergstrom, 1997: Aerosol climate effects: local radiative forcing and column closure experiments. $J$. Geophys. Res., 102, 9397-9407.

Sebacher, D. I., R. C. Harriss, W. R. Cofer III, and E. V. Browell, 1985: Influence of meteorological conditions on aerosol vertical distribution and composition off the northeast American coastline. Atmos. Environ., 19, 423-428.

Seibert, P., F. Beyrich, S. E. Gryning, S. Joffre, A. Rasmussen, and P. Tercier, 1998: Mixing layer depth determination for dispersion model inf. European Commission. COST Action 710 - Final Report, [Available from European Commission, L-2985 Luxembourg, EUR 18195 EN (ISBN 92-828-3302-X).]

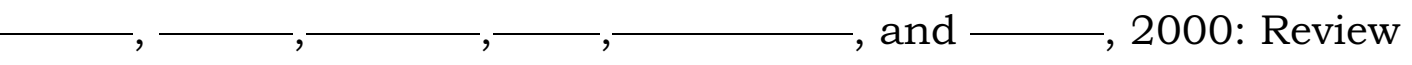

and intercomparison of operational methods for the determination of the mixing height. Atmos. Environ., 34, 1001-1027.

Sequeira, R, and K-H Lai, 1998: The effect of meteorological parameters and aerosol constituents on visibility in urban Hong Kong. Atmos. Environ., 32, 3865-2871. 
Smith, W. L., 1970: Iterative solution of the radiative transfer equation for the temperature and absorbing gas profile of an atmosphere. Appl. Opt., 9, 1993-1999.

Sokolik, I. N., and O. B. Toon, 1996. Direct radiative forcing by anthropogenic airborne mineral aerosols. Nature, 381, 681-683.

Stokes, M., G., and S. E. Schwartz, 1994: The Atmospheric Radiation Measurement (ARM) Program: programmatic background and design of the cloud and radiation test bed. Bull. Amer. Meteor. Soc., 75, 1201-1221.

Stull, R. B., 1983: Integral scales for the nocturnal boundary layer. Part I: empirical depth relationship. J. Clim. Appl. Meteor., 22, 673-686.

—, 1988: An Introduction to Boundary Layer Meteorology. Kluwer Academic Publisher, Dordrecht, 670 pp.

— , and A. G. M. Driedonks, 1987: Application of the transilient turbulence parameterization to atmospheric boundary layer simulations. Bound.-Layer Meteor., 40, 209-239.

Tanaka, M., T. Hayasaka, and T. Nakajima, 1990: Airborne measurement of optical properties of tropospheric aerosols over an urban area. $J$. Meteor. Soc. Japan, 68, 335-345.

Taylor, K. E., and J. E. Penner, 1994: Response of the climate system to atmospheric aerosols and greenhouse gases, 369, 734-737. 
Tennekes, H., 1973: A model for the dynamics of the inversion above a convective boundary layer. J. Atmos. Sci., 30, 558-567.

Twomey, S., 1974: Pollution and the planetary albedo. Atmos. Environ., 8, $1251-1256$.

- 1991: Aerosols, clouds and radiation. Atmos. Environ., 25A, 2435-2442.

Van Ulden, A. P., and A. A. M. Holtslag, 1985: Estimates of atmospheric boundary layer parameters for diffusion applications. J. Clim. Appl. Meteor., 24, 1196-1207.

Wendish, M., S. Mertes, M. W., A. Ruggaber, and T. Nakajima, 1996: Vertical profiles and radiation and the influence of a temperature inversion: Measurements and radiative transfer calculations. $J$. Appl. Meteor., 35, 1703-1715.

Wiley, J., 1995: In Situ Observations of Aerosol Properties in Aerosol Forcing of Climate. R.J. Charlson, and J. Heintzenberg, New York, $704 \mathrm{pp}$.

Zelenka, M. P., 1997: An analysis of the meteorological parameters affecting ambient concentrations of acid aerosols in Unintown, Pennsylvania. Atmos. Environ., 31, 869-878.

Zilitinkevich, S. S., 1972: On the determination of the height of the Ekman boundary layer. Bound.-Layer Meteor., 3, 141-145. 
and J. W. Deardoff (1974): Similarity theory of the planetary boundary layer of time-dependent height. J. Atmos. Sci., 31, 1449-1452..

\section{APPENDIX A: LIST OF ACRONYMS}

ABL Atmospheric Boundary Layer

AERI Atmospheric Emitted Radiance Interferometer

AGL Above Ground Level

AOS Aerosol Observing System

ARM Atmospheric Radiation Measurement

BBSS Balloon-Borne Sounding System

BL Boundary Layer

CART Cloud and Radiation Testbed

CBL Convective Boundary Layer

CMDL Climate Monitoring and Diagnostics Laboratory

CCN Cloud Condensation Nuclei

CN Condensation Nuclei

CNC Condensation Nuclei Counter

DELTA Detection and Evaluation of the Long-range Transport of Aerosol 


$\begin{array}{ll}\text { DOE } & \text { Department of Energy } \\ \text { EBBR } & \text { Energy Balance Bowen Ratio } \\ \text { ECOR } & \text { Eddy Correlation Flux Measurement System Eddy Correla- } \\ & \text { tion } \\ \text { EML } & \text { Environmental Monitoring Laboratory } \\ \text { FA } & \text { Free Atmosphere } \\ \text { FFT } & \text { Fast Fourier Transform } \\ \text { FMT } & \text { Flux Measurement System } \\ \text { FTIR } & \text { Fourier Transform Infrared Spectrometer } \\ \text { GCM } & \text { General Circulation Model } \\ \text { GPS } & \text { Global Positioning System } \\ \text { IAP } & \text { In situ Aerosol Profile } \\ \text { IOPs } & \text { Intensive Operational Periods } \\ \text { IDP } & \text { Instrument Development Program } \\ \text { LLJ } & \text { Low-Level Jet } \\ \text { MH } & \text { Mixing Height } \\ \text { ML } & \text { Mixing Layer } \\ \text { MSL } & \text { Mean Sea Level } \\ \text { NRC } & \text { National Research Council } \\ \text { NOAA } & \text { National Oceanic and Atmospheric Administration } \\ \text { NWP } & \text { Numerical Weather Prediction } \\ \text { Optical Particle Counter }\end{array}$




\title{
APPENDIX A (continued)
}

\author{
PBL Planetary Boundary Layer \\ PSAP Particle Soot/Absorption Photometer \\ RASS Radio Acoustic Sounding System \\ RL Raman Lidar \\ RWP Radar Wind Profiler \\ SBL Stable Boundary Layer \\ SGP Souther Great Plains \\ S-XRF Synchroton-X-Ray Fluorescence \\ TKE Turbulent Kinetic Energy \\ USGCRP United States Global Change Research Program
}

\section{APPENDIX B: LIST OF SYMBOLS}

Roman
$\AA$
Angstrom exponent
$b$
hemispheric backscatter fraction
$c_{p}$
specific heat of dry air at constant pressure
f
Coroilis parameter
$f_{\max }$
frequency at the peak in the turbulent spectrum 


\begin{tabular}{|c|c|}
\hline$g$ & gravitational acceleration \\
\hline$h$ & scaling height \\
\hline$H^{+}$ & aerosol acidity \\
\hline$k$ & constant \\
\hline$K_{m}$ & momentum eddy diffusivity \\
\hline$L_{E}$ & Ekman length \\
\hline$L_{*}$ & Monin-Obukhov length \\
\hline$n$ & number density \\
\hline$N_{b v}$ & Brunt-Vaisala frequency \\
\hline$O$ & overlap function \\
\hline$q_{b}, q_{l}$ & $\begin{array}{l}\text { attenuation of the backscattered radiation and laser beam, } \\
\text { respectively }\end{array}$ \\
\hline$R$ & Pearson correlation coefficient \\
\hline RH & relative humidity \\
\hline$T$ & temperature \\
\hline$t_{*}^{M L}$ & convective ML time scale \\
\hline$t_{*}^{S L}$ & surface layer time scale \\
\hline$u, v$ & zonal and meridional velocity components, respectively \\
\hline $\bar{u}$ & horizontal mean wind \\
\hline$u_{g}, v_{g}$ & $\begin{array}{l}\text { zonal and meridional geostrophic velocity components, re- } \\
\text { spectively }\end{array}$ \\
\hline
\end{tabular}




\title{
APPENDIX B (continued)
}

\author{
$u_{*} \quad$ friction velocity \\ $w$ \\ vertical wind component \\ $w^{\prime}$ \\ turbulent component of the vertical velocity \\ Z \\ vertical coordinate \\ $Z_{i}$ \\ inversion height \\ $Z_{o}$ \\ surface roughness
}

Greek

$\beta \quad$ buoyancy

$\beta_{a p, \lambda} \quad$ absorption coefficient for wavelength $\lambda$

$\beta_{b s p, \lambda} \quad$ hemispheric backscattering coefficient for wavelength $\lambda$

$\beta_{\text {ext }, \lambda} \quad$ extinction coefficient for wavelength $\lambda$

$\beta_{s p, \lambda} \quad$ total scattering coefficient for wavelength $\lambda$

$\gamma \quad$ temperature lapse rate

$\kappa \quad$ von-Karman constant

$\theta \quad$ potential temperature

$\theta^{\prime} \quad$ turbulent component of potential temperature 


\section{APPENDIX B (continued)}

$\begin{array}{ll}\theta_{\mathrm{t}}, \theta_{\mathrm{b}} & \begin{array}{l}\text { potential temperatures at the top and bottom of the critical } \\ \text { inversion layer, respectively }\end{array} \\ \theta_{*} & \text { potential temperature scale } \\ \lambda & \text { wavelength } \\ \lambda_{1} & \text { blue wavelength } \\ \lambda_{2} & \text { green wavelength } \\ \rho & \text { air density } \\ \sigma & \text { Raman cross-section } \\ \phi & \text { latitude } \\ \omega & \text { single scattering albedo } \\ \Omega & \text { angular rotation rate of the Earth } \\ \tau & \text { Reynold stress }\end{array}$


Table 1. Types of Particulate Suspensions.

\begin{tabular}{|c|c|c|c|}
\hline \multicolumn{4}{|c|}{ Suspended Particles } \\
\hline $\begin{array}{c}\text { Suspending } \\
\text { Medium }\end{array}$ & Gas & Fog, Mist, Spray & Fume, Dust \\
\hline \multirow{3}{*}{ Gas } & Foam & Emulsion & $\begin{array}{c}\text { Colloid, } \\
\text { Suspension, } \\
\text { Slurry }\end{array}$ \\
\cline { 2 - 4 } Liquid & Sponge & Gel & Alloy \\
\cline { 2 - 4 } Solid & Solid & \\
\hline
\end{tabular}

[Source: Hinds 1999] 
Table 2. Long-term, Ground-based Aerosol Measurement Platforms.

\begin{tabular}{|c|c|c|c|c|}
\hline Name & Description/Parameters & Location & Time Period & Web Address \\
\hline AEROCE & $\begin{array}{l}\text { In situ physical and } \\
\text { chemical characterization of } \\
\text { aerosol: nss-SO } \mathrm{SO}_{4}=\mathrm{NO}_{3}^{-} \\
\mathrm{NH}_{4}^{+} \text {, sea-salt }\end{array}$ & $\begin{array}{l}\text { Global/ } \\
\text { oceanic }\end{array}$ & 1987 to present & $\begin{array}{l}\frac{\text { http: } / / \text { www.msc- }}{\text { smc.ec.gc.ca/ }} \\
\text { natchem/particles_ } \\
\text { aeroce_e.html }\end{array}$ \\
\hline NOAA CMDL & $\begin{array}{l}\text { In situ characterization of } \\
\text { averages, variability, and trends of } \\
\text { climate-forcing by aerosol: } \AA, \beta \text {, } \\
\omega, \mathrm{g}, \mathrm{b}, \text { meteorological } \\
\text { parameters, mass }\end{array}$ & $\begin{array}{l}\text { Global/ } \\
\text { USA }\end{array}$ & 1975 to present & $\begin{array}{l}\text { http://www.cmdl. } \\
\text { noaa.gov/ } \\
\text { index.html }\end{array}$ \\
\hline USP/Artaxo & $\begin{array}{l}\text { In situ physical and } \\
\text { chemical characterization of } \\
\text { aerosol: chemical } \\
\text { compounds, mass }\end{array}$ & Brazil & 1988 to present & $\begin{array}{l}\text { http://aeronet.gsfc. } \\
\text { nasa.gov:8080/ } \\
\text { Operationalcontact_ } \\
\text { list.html }\end{array}$ \\
\hline NOAA PMEL & $\begin{array}{l}\text { Research vessels with } \\
\text { complete instrumentation for } \\
\text { physical, chemical and } \\
\text { optical aerosol properties }\end{array}$ & $\begin{array}{c}\text { Global } \\
\text { oceanic }\end{array}$ & 1991 to present & $\frac{\text { http://saga.pmel. }}{\text { noaa.gov }}$ \\
\hline IMPROVE & $\begin{array}{l}\text { PM10, and PM } 2.5 \text { mass, } \\
\text { chemical composition }\end{array}$ & USA & 1987 to present & $\begin{array}{l}\text { http://vista.cira. } \\
\text { colostate.edu/ } \\
\text { improve }\end{array}$ \\
\hline ANSTO & $\begin{array}{l}\text { In situ trace gas (radon) and } \\
\text { fine particles concentrations }\end{array}$ & $\begin{array}{l}\text { Australia/ } \\
\text { Tasmania }\end{array}$ & 1981 to present & $\begin{array}{l}\text { http://www.ansto. } \\
\text { gov.au/ansto/ } \\
\text { environment1/ } \\
\text { index.html }\end{array}$ \\
\hline
\end{tabular}

Key:

AEROCE - AtmosphERe/Ocean Chemistry Experiment

NOAA CMDL - National Oceanic and Atmospheric Administration Climate Monitoring and Diagnostics Laboratory

USP/Artaxo - Universidade de São Paulo/Artaxo (First Investigator)

NOAA PMEL - National Oceanic and Atmospheric Administration Pacific Marine Environmental Laboratory

IMPROVE - Interagency Monitoring of PROtected Visual Environments

ANSTO - Australian Nuclear Science and Technology Organization 
Table 3. Airborne Aerosol Measurement Campaigns.

\begin{tabular}{|c|c|c|c|c|}
\hline Name & Description/Parameters & Location & Time Period & Web Address \\
\hline ACE $1 / 2 / 3$ & $\begin{array}{l}\text { Chemical, physical, and } \\
\text { radiative characterization of } \\
\text { aerosol properties, deter- } \\
\text { mination of controlling } \\
\text { processes of the aerosol in } \\
\text { remote marine atmosphere, } \\
\text { in coastal areas, in desert }\end{array}$ & $\begin{array}{l}\text { Hawaii, New } \\
\text { Zealand, } \\
\text { Australia, } \\
\text { North } \\
\text { Atlantic, } \\
\text { China, } \\
\text { Japan, Korea }\end{array}$ & $\begin{array}{l}1995,1997 \\
2001\end{array}$ & $\begin{array}{l}\text { http://saga.pmel. } \\
\text { noaa.gov/ace1.html }\end{array}$ \\
\hline SCAR A/B/C & $\begin{array}{l}\text { Biomass burning, smoke, } \\
\text { cloud, radiation mea- } \\
\text { surements }\end{array}$ & $\begin{array}{l}\text { USA, } \\
\text { Atlantic, } \\
\text { Brazil }\end{array}$ & $\begin{array}{l}1993 \text { to } \\
1995\end{array}$ & $\begin{array}{l}\text { http://asd- } \\
\text { www.larc.nasa.gov/ } \\
\text { scar/ }\end{array}$ \\
\hline SUCCESS & $\begin{array}{l}\text { Radiative effects of con- } \\
\text { trails, direct/indirect } \\
\text { radiative effects of aircraft } \\
\text { exhaust, cirrus, ozone }\end{array}$ & Kansas & 1996 & $\begin{array}{l}\frac{\text { http://asd- }}{\text { www.larc.nasa.gov/ }} \\
\frac{\text { fire/FIRE_III/ }}{\text { success.html }}\end{array}$ \\
\hline TARFOX & $\begin{array}{l}\text { Chemical, physical, and } \\
\text { optical properties of } \\
\text { anthropogenic aerosol in } \\
\text { the troposphere }\end{array}$ & $\begin{array}{l}\text { US Atlantic } \\
\text { Coast }\end{array}$ & 1996 & $\begin{array}{l}\text { http://geo.arc. } \\
\text { nasa.gov/ } \\
\text { sgg/tarfox/ }\end{array}$ \\
\hline SAFARI & $\begin{array}{l}\text { Characterization and quant- } \\
\text { ification of processes driving } \\
\text { biogenic, pyrogenic and } \\
\text { anthropogenic emissions }\end{array}$ & $\begin{array}{l}\text { Southern } \\
\text { Africa }\end{array}$ & 2000 & $\begin{array}{l}\text { http://safari.gecp. } \\
\text { virginia.edu/ }\end{array}$ \\
\hline FIRE I/II/III & $\begin{array}{l}\text { Characterization of radiative } \\
\text { and physical processes for } \\
\text { cirrus and marine boundary } \\
\text { layer cloud systems, } \\
\text { subtropical and tropical } \\
\text { cirrus clouds, tropical } \\
\text { cirrus, arctic clouds }\end{array}$ & $\begin{array}{l}\text { Northeastern } \\
\text { Pacific, } \\
\text { Northeastern } \\
\text { Atlantic, } \\
\text { Arctic }\end{array}$ & $\begin{array}{l}1984 \text { to } \\
2000\end{array}$ & $\begin{array}{l}\text { http://asd- } \\
\text { www.larc.nasa.gov/ } \\
\text { fire/ }\end{array}$ \\
\hline ABLE 1/2/3 & $\begin{array}{l}\text { Saharan dust transport, } \\
\text { aerosol chemistry }\end{array}$ & $\begin{array}{l}\text { Tropical } \\
\text { Atlantic } \\
\text { Ocean, } \\
\text { Brazil, } \\
\text { Northern } \\
\text { Wetlands } \\
\end{array}$ & $\begin{array}{l}1984 \text { to } \\
1990\end{array}$ & $\begin{array}{l}\text { http://www- } \\
\text { gte.larc.nasa.gov/ } \\
\text { able/able_hmpg. } \\
\text { htm }\end{array}$ \\
\hline INDOEX & $\begin{array}{l}\text { Characterization of radiative } \\
\text { and physical processes } \\
\text { marine aerosol, aerosol } \\
\text { chemistry }\end{array}$ & $\begin{array}{l}\text { Tropical } \\
\text { Indian Ocean }\end{array}$ & $\begin{array}{l}1995 \text { to } \\
1999\end{array}$ & $\begin{array}{c}\text { http://www-indoex. } \\
\text { ucsd.edu/ } \\
\text { ProjDescription. } \\
\text { html }\end{array}$ \\
\hline
\end{tabular}

Key: ACE - Aerosol Characterization Experiments, SCAR - Smoke/ Sulfates Clouds And Radiation, SUCCESS - Subsonic Aircraft: Contrails and Clouds Effects Special Study, TARFOX - Tropospheric Aerosol Radiative Forcing Observational Experiment, SAFARI - Southern African Regional Science Initiative, FIRE - First ISCCP Regional Experiment, ISCCP - International Satellite Cloud Climatology Project, ABLE - Atmospheric Boundary Layer Experiment, UW - University of Wyoming, INDOEX - INDian Ocean Experiment. 
Table 4. Remote Sensing Aerosol Measurement Platforms.

\begin{tabular}{|c|c|c|c|c|}
\hline Name & Description/Parameters & Location & Time Period & Web Address \\
\hline AVHRR & $\begin{array}{l}\text { Onboard of NOAA's } \\
\text { satellites, } 1.1 \mathrm{~km} \text { spatial: } \\
\text { AOD, } \AA\end{array}$ & Polar Orbit & 1978 to present & $\begin{array}{l}\text { http://edcwww.cr. } \\
\text { usgs.gov/glis/ } \\
\text { hyper/guide/avhrr }\end{array}$ \\
\hline MISR & $\begin{array}{l}\text { Onboard of NASA satellite, } \\
\text { earth view at simultaneously } \\
\text { nine widely spaced angles, } \\
275 \text { m spatial : AOD, A, } \\
\text { aerosol properties vertical } \\
\text { profile }\end{array}$ & Polar Orbit & 1999 to present & $\begin{array}{l}\text { http://www- } \\
\text { misr.jpl.nasa.gov/ }\end{array}$ \\
\hline MODIS & $\begin{array}{l}\text { Onboard of NASA satellite, } \\
250 \mathrm{~m} \text { resolution : AOD, } \\
\text { aerosol size distribution }\end{array}$ & Polar Orbit & 1999 to present & $\begin{array}{l}\text { http:// modis.gsfc. } \\
\text { nasa.gov/ } \\
\text { about/index.html }\end{array}$ \\
\hline SeaWiFS & $\begin{array}{l}\text { Onboard of NASA satellite: } \\
\text { AOD, aerosol properties } \\
\text { vertical profile }\end{array}$ & Polar Orbit & 1997 to present & $\begin{array}{l}\text { http://seawifs.gsfc. } \\
\text { nasa.gov/SEAWIFS. } \\
\text { html }\end{array}$ \\
\hline TOMS & $\begin{array}{l}\text { Onboard of NASA satellite: } \\
\text { aerosol properties vertical } \\
\text { profile }\end{array}$ & Polar Orbit & 1996 to present & $\begin{array}{l}\text { http://toms.gsfc. } \\
\text { nasa.gov/aerosols / } \\
\text { aerosols.html }\end{array}$ \\
\hline LASE & $\begin{array}{l}\text { Onboard of NASA aircraft: } \\
\text { aerosol properties }\end{array}$ & $\begin{array}{l}\text { Global, } \\
\text { USA }\end{array}$ & 1995 to present & $\begin{array}{c}\text { http://asd- } \\
\text { www.larc.nasa.gov/ } \\
\text { lase/ASDlase.html }\end{array}$ \\
\hline $\begin{array}{c}\text { Lidar/David } \\
\text { Tratt }\end{array}$ & $\begin{array}{l}\text { Long term characterization } \\
\text { of tropospheric aerosol }\end{array}$ & ASIA & 1984 to present & $\begin{array}{l}\text { http://www.jpl. } \\
\text { nasa.gov/ } \\
\text { lidar/longterm.htm }\end{array}$ \\
\hline MPLNet & $\begin{array}{l}\text { In situ micro-pulse lidar, } \\
\text { long term aerosol vertical } \\
\text { distribution: AOD, } \beta\end{array}$ & World wide & 1994 to present & $\begin{array}{l}\text { http:/ / virl.gsfc. } \\
\text { nasa. } \\
\text { gov/mpl-net/ }\end{array}$ \\
\hline NOAA Lidar & $\begin{array}{l}\text { In situ lidar, aerosol } \\
\text { characterization in the low } \\
\text { troposphere }\end{array}$ & Illinois & 1996 to present & $\begin{array}{l}\text { http://www.atd.uca } \\
\text { r.edu/rsf/LIFT/ }\end{array}$ \\
\hline
\end{tabular}

Key:

AVHRR - Advanced Very High Resolution Radiometer, MISR - Multi-angle Imaging Spectro Radiometer, MODIS - MODerate resolution Imaging Spectroradiometer, SeaWiFS - Sea-viewing Wide Field-of-view Sensor, TOMS - Total Ozone Mapping Spectrometer, LASE - Lidar Atmospheric Sensing Experiment, MPLNet - Micro-Pulse Lidar Network 
Table 5. Derived quantities from the AOS system, where all symbols are defined in Appendix B.

\begin{tabular}{|l|c|c|}
\hline \multicolumn{1}{|c|}{ Quantity } & Formulae & $\mathrm{m}^{-1}$ \\
Extinction coefficient & $\beta_{e x t, \lambda}=\beta_{a p, \lambda}+\beta_{s p, \lambda}$ & No units \\
\hline Single scatter albedo & $\omega=\beta_{s p, \lambda} / \beta_{e x t, \lambda}$ & No units \\
\hline Angstrom coefficient & $\AA=-\frac{\ln \left(\beta_{s p, \lambda_{1}} / \beta_{s p, \lambda_{2}}\right)}{\ln \left(\lambda_{1} / \lambda_{2}\right)}$ & \\
\hline $\begin{array}{l}\text { Hemispheric backscatter } \\
\text { fraction }\end{array}$ & $b=\beta_{b s p, \lambda} / \beta_{s p, \lambda}$ & No units or \% \\
\hline
\end{tabular}


Table 6. MH-Determination Techniques Based on Surface Data Only.

\begin{tabular}{|c|c|c|c|}
\hline Technique & Method & Stability Regime & DATA \\
\hline $\begin{array}{l}\text { Blackdar and } \\
\text { Tennekes (1968) }\end{array}$ & $M H=\frac{0.2 u_{*}}{|f|}, \quad \frac{u_{*}}{\left|f L_{*}\right|}<4$ & Near - neutral & ECOR \\
\hline Zilitinkevich (1972) & $M H=0.4 \frac{u_{*} L_{*}}{|f|} y^{1 / 2}, \quad \frac{u_{*}}{\left|f L_{*}\right|}>4$ & Stable & ECOR \\
\hline Nieuwstadt (1981) & $M H=\frac{0.3 u_{*}}{|f| \overline{1}+1.9 \frac{M H}{L_{*}} \sqrt{ }}$ & $\begin{array}{l}\text { Near-neutral, } \\
\text { Stable }\end{array}$ & ECOR \\
\hline $\begin{array}{l}\text { Slab Model: } \\
\text { Tennekes (1973), } \\
\text { Carson (1973) }\end{array}$ & $\begin{array}{l}\frac{d(M H)}{d t}=1.4 \frac{\overline{w^{\prime} \theta_{0}^{\prime}}}{\gamma M H}, \quad \overline{w^{\prime} \theta_{0}^{\prime}}>0 \\
\frac{d(M H)}{d t}=5 \frac{\theta}{g} \frac{u_{*}^{3}}{\gamma M H^{2}}, \overline{w^{\prime} \theta_{0}^{\prime}}=0\end{array}$ & $\begin{array}{l}\text { Unstable- } \\
\text { Convective }\end{array}$ & $\begin{array}{l}\text { ECOR, } \\
\text { EBBR }\end{array}$ \\
\hline
\end{tabular}

Key:

ECOR - Eddy CORrelation flux measurement system

EBBR - Energy Balance Bowen Ratio 
Table 7. MH-Determination Techniques Based on Methods Requiring Vertical Profiles.

\begin{tabular}{|c|c|c|c|}
\hline Technique & Method & Stability Regime & DATA \\
\hline $\begin{array}{l}\text { Parcel Method: } \\
\text { Holzworth (1964, } \\
\text { 1967, 1972) }\end{array}$ & $\begin{array}{l}\text { MH is equilibrium level } \\
\text { of hypothetical rising } \\
\text { parcel of dry air } \\
\text { (representing a thermal) }\end{array}$ & Neutral, Unstable & $\begin{array}{l}\text { Radiosonde, } \\
\text { AERI }\end{array}$ \\
\hline $\begin{array}{l}\text { Surface-Based } \\
\text { Temperature } \\
\text { Inversion: } \\
\text { Seibert et al. ( 2000) }\end{array}$ & $\begin{array}{l}\mathrm{MH} \text { is depth of surface } \\
\text { temperature inversion }\end{array}$ & Stable & $\begin{array}{l}\text { Radiosonde, } \\
\text { AERI }\end{array}$ \\
\hline $\begin{array}{l}\text { Height of Low-level } \\
\text { Relative Wind } \\
\text { Maximum: } \\
\text { Angevine et al. (1994) }\end{array}$ & $\begin{array}{l}\mathrm{MH} \text { is height of lowest } \\
\text { relative wind maximum }\end{array}$ & Stable & Radiosonde \\
\hline Heffter (1980) & 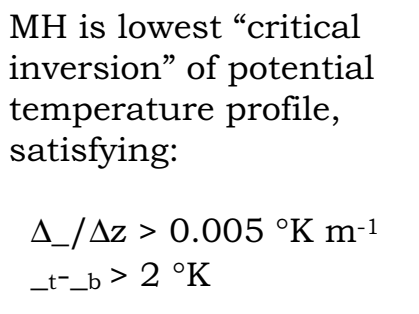 & $\begin{array}{c}\text { Stable, Neutral, } \\
\text { Unstable }\end{array}$ & $\begin{array}{c}\text { Radiosonde, } \\
\text { AERI }\end{array}$ \\
\hline
\end{tabular}

Key:

AERI - Atmospheric Emitted Radiance Interferometer 
Table 8. Least-squares linear regression statistics of the surface and column integrated ${ }^{*}$ aerosol extensive and intensive properties.

\begin{tabular}{|c|c|c|c|c|}
\hline & $\begin{array}{l}\text { Observed } \\
\text { Quantity }\end{array}$ & $\begin{array}{c}\begin{array}{c}\text { Correlation Coefficient } \\
(R)\end{array} \\
\end{array}$ & Slope & Intercept ${ }^{* *}$ \\
\hline \multirow{4}{*}{ 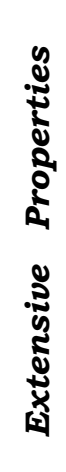 } & $\beta_{a p, g}$ & 0.66 & 0.36 & $4.17 \times 10^{-7}$ \\
\hline & $\beta_{s p, b}$ & 0.73 & 0.30 & $9.33 \times 10^{-6}$ \\
\hline & $\beta_{s p, g}$ & 0.74 & 0.30 & $6.43 \times 10^{-6}$ \\
\hline & $\beta_{s p, r}$ & 0.75 & 0.30 & $3.54 \times 10^{-6}$ \\
\hline \multirow{5}{*}{ 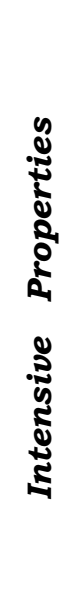 } & $b_{b}$ & 0.55 & 0.49 & 0.06 \\
\hline & $b_{g}$ & 0.65 & 0.49 & 0.07 \\
\hline & $b_{r}$ & 0.12 & 0.09 & 0.15 \\
\hline & $\omega$ & 0.72 & 0.57 & 0.39 \\
\hline & $\AA$ & 0.53 & 0.56 & 0.95 \\
\hline
\end{tabular}

* Column integrated in this context refers to an average of values across all available flight legs. The average for the intensive properties was calculated from the average of the extensive properties.

${ }^{* *}$ Intercept has the unit of the observed quantity. 
Table 9. Least-squares linear regression statistics of the surface and integrated $^{*}$ aerosol intensive properties within and above the ABL.

\begin{tabular}{|c|c|c|c|c|}
\hline & $\begin{array}{l}\text { Observed } \\
\text { Quantity }\end{array}$ & $\begin{array}{c}\text { Correlation } \\
\text { Coefficient (R) } \\
\text { Within/Above ABL } \\
\end{array}$ & $\begin{array}{c}\text { Slope } \\
\text { Within/Above } \\
\text { ABL } \\
\end{array}$ & $\begin{array}{c}\text { Intercept }^{* *} \\
\text { Within/Above } \\
\text { ABL }\end{array}$ \\
\hline \multirow{4}{*}{ 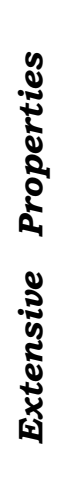 } & $\beta_{a p, g}$ & $0.86 / 0.47$ & $0.77 / 0.20$ & $\begin{array}{c}4.48 \times 10^{-7} / \\
3.89 \times 10^{-7}\end{array}$ \\
\hline & $\beta_{s p, b}$ & $0.94 / 0.37$ & $1.01 / 0.12$ & $\begin{array}{c}2.41 \times 10^{-6} / \\
8.21 \times 10^{-6}\end{array}$ \\
\hline & $\beta_{s p, g}$ & $0.94 / 0.38$ & $0.99 / 0.12$ & $\begin{array}{c}1.79 \times 10^{-6} / \\
5.73 \times 10^{-6}\end{array}$ \\
\hline & $\beta_{s p, r}$ & $0.92 / 0.11$ & $1.01 / 0.11$ & $\begin{array}{c}3.96 \times 10^{-6} / \\
3.34 \times 10^{-6}\end{array}$ \\
\hline \multirow{5}{*}{ 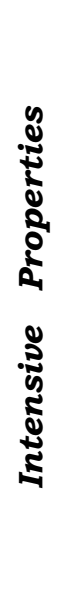 } & $b_{b}$ & $0.85 /-0.15$ & $0.74 /-0.28$ & $0.02 / 0.14$ \\
\hline & $b_{g}$ & $0.86 /-0.09$ & $0.88 /-0.16$ & $0.01 / 0.16$ \\
\hline & $b_{r}$ & $0.32 /-0.05$ & $0.19 /-0.07$ & $0.13 / 0.18$ \\
\hline & $\omega$ & $0.78 / 0.01$ & $0.75 / 0.02$ & $0.23 / 0.86$ \\
\hline & $\AA$ & $0.74 / 0.15$ & $0.62 / 0.32$ & $0.81 / 1.32$ \\
\hline
\end{tabular}

* Integrated in this context refers to an average of values within and above the ABL, across all available flight legs. The average for the intensive properties was calculated from the average of the extensive properties.

${ }^{* *}$ Intercept has the unit of the observed quantity. 
Table 10. Altitude ranges and flight days within and above the ABL.

\begin{tabular}{|c|c|c|}
\hline \multicolumn{1}{|c|}{ Altitude Range (m) } & $\begin{array}{c}\text { \# of Flight Days } \\
\text { (Within the ABL) }\end{array}$ & $\begin{array}{c}\text { of Flight Days } \\
\text { (Above the ABL) }\end{array}$ \\
\hline $\mathbf{3 9 0}-\mathbf{4 5 0}$ & $\sim 50$ & $\sim 5$ \\
\hline $\mathbf{5 4 0}-\mathbf{6 5 0}$ & $\sim 48$ & $\sim 9$ \\
\hline $\mathbf{9 9 0}-\mathbf{1 2 9 0}$ & $\sim 35$ & $\sim 20$ \\
\hline $\mathbf{1 3 8 0}-\mathbf{1 5 8 0}$ & $\sim 22$ & $\sim 42$ \\
\hline $\mathbf{1 6 8 0}-\mathbf{1 8 8 0}$ & $\sim 10$ & $\sim 47$ \\
\hline $\mathbf{2 4 0 0}-\mathbf{2 5 0 0}$ & 0 & $\sim 50$ \\
\hline $\mathbf{2 9 0 0 - 3 1 0 0}$ & $\sim 5$ & $\sim 55$ \\
\hline $\mathbf{3 4 0 0}-\mathbf{3 8 0 0}$ & 0 & \\
\hline
\end{tabular}




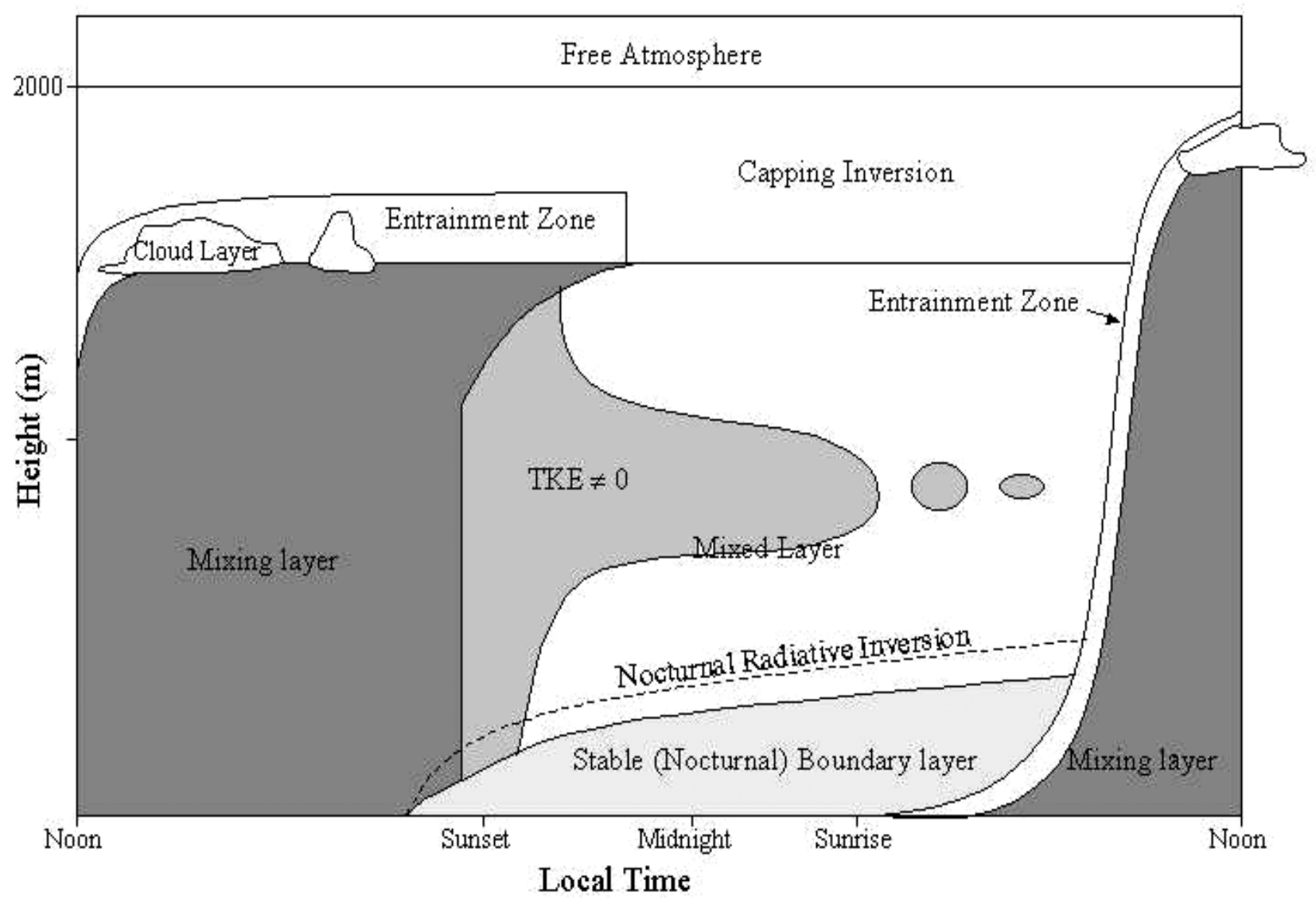

[Source: R.D. Bornstein 2001, personal communication]

Fig. 1 


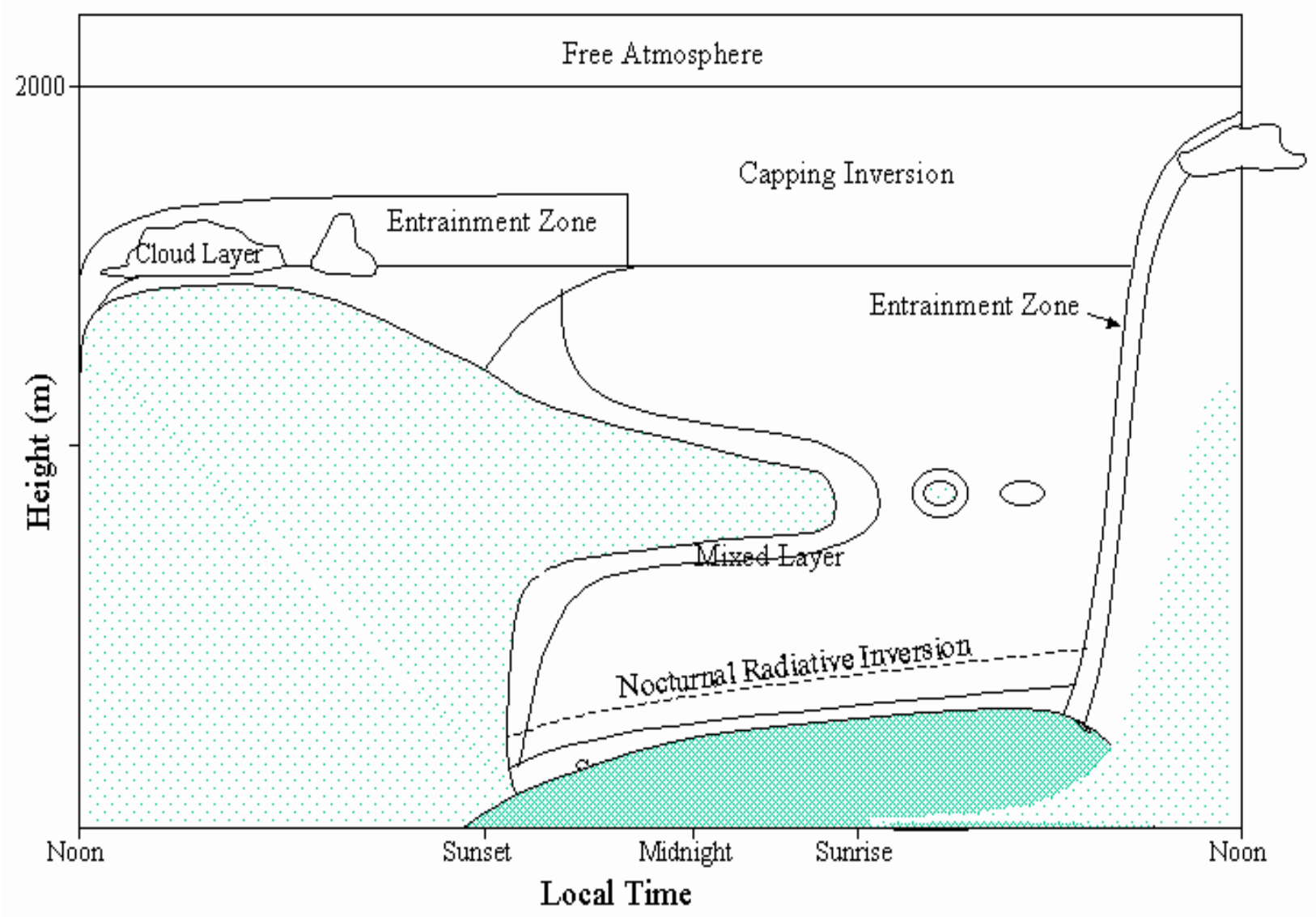

Fig. 2 


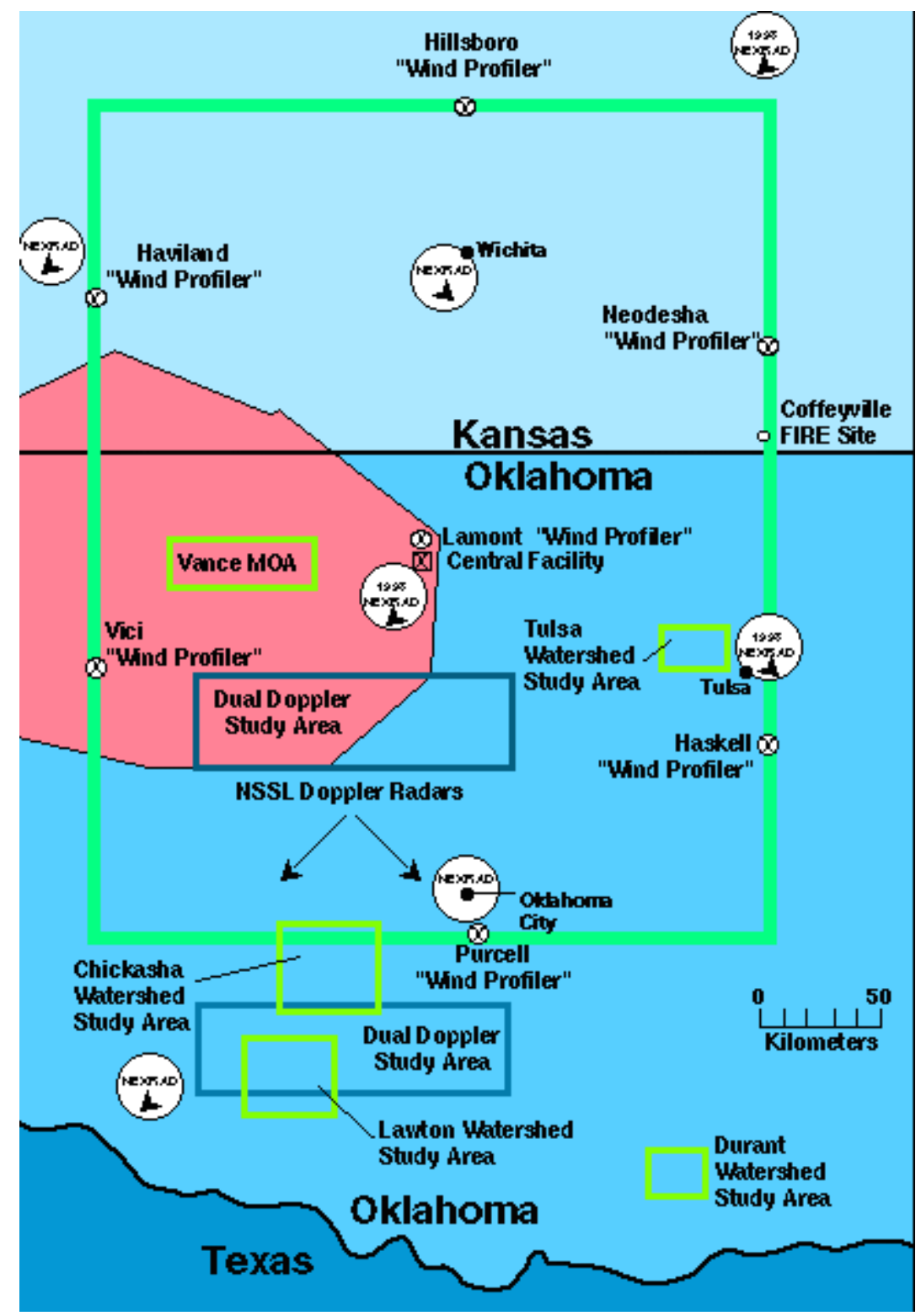

[Source: http://www.arm.gov/docs/sites/sgp/sgp.html]

Fig. 3 


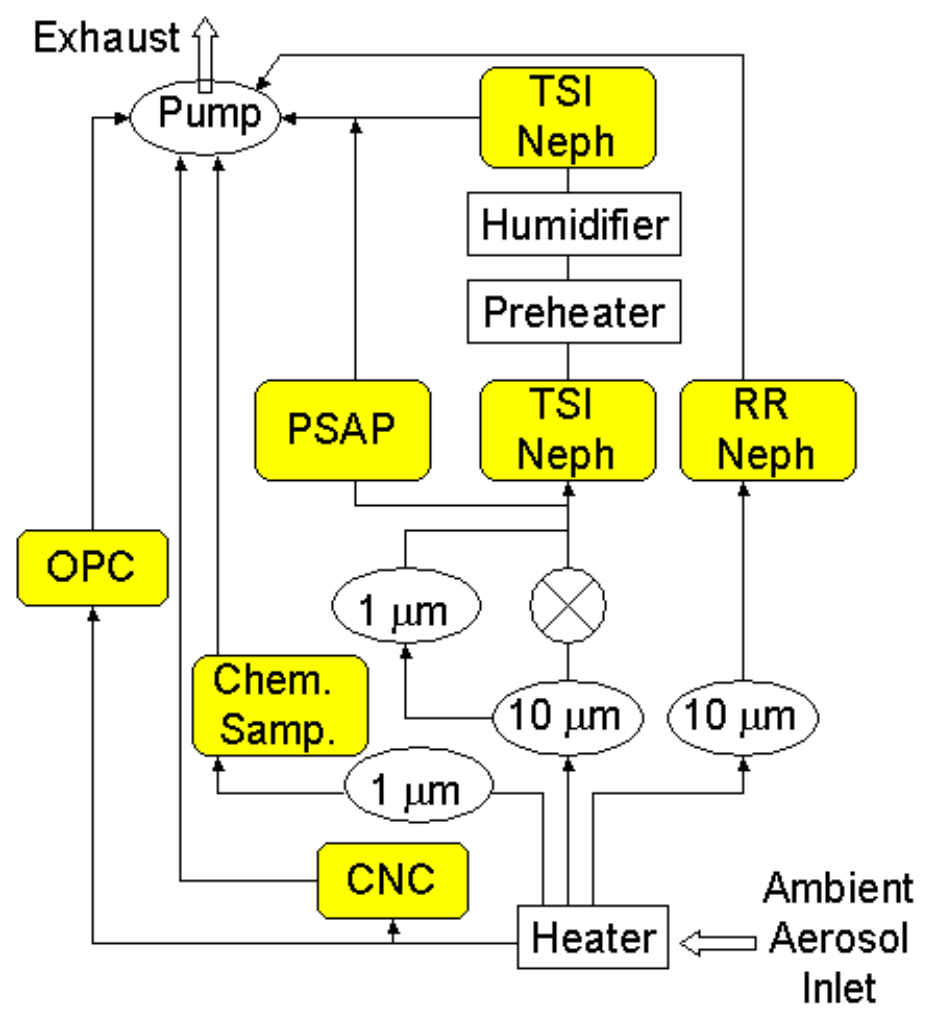

[Source: http://www.arm.gov/docs/instruments/static/aos.html]

Fig. 4 


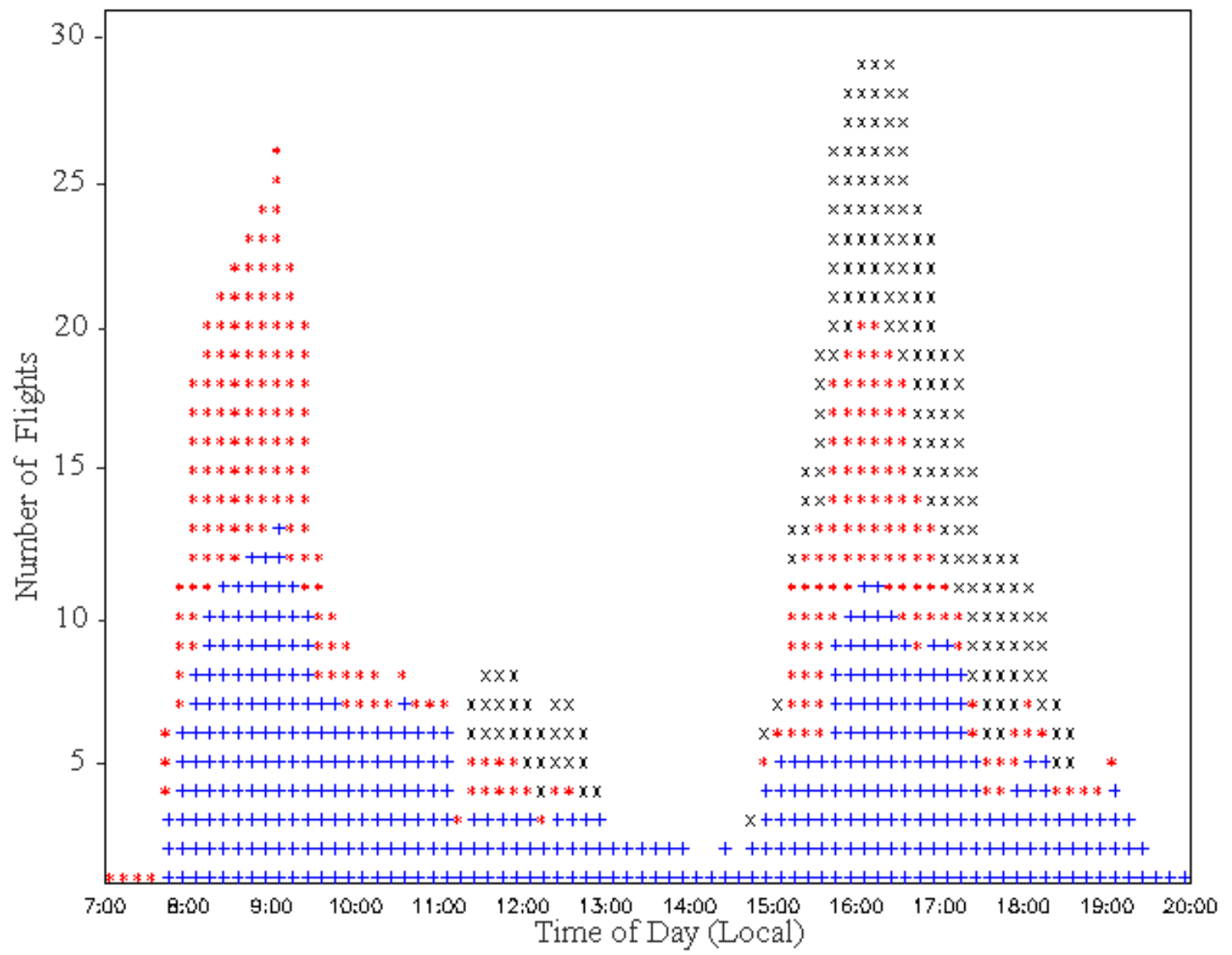

Fig. 5 


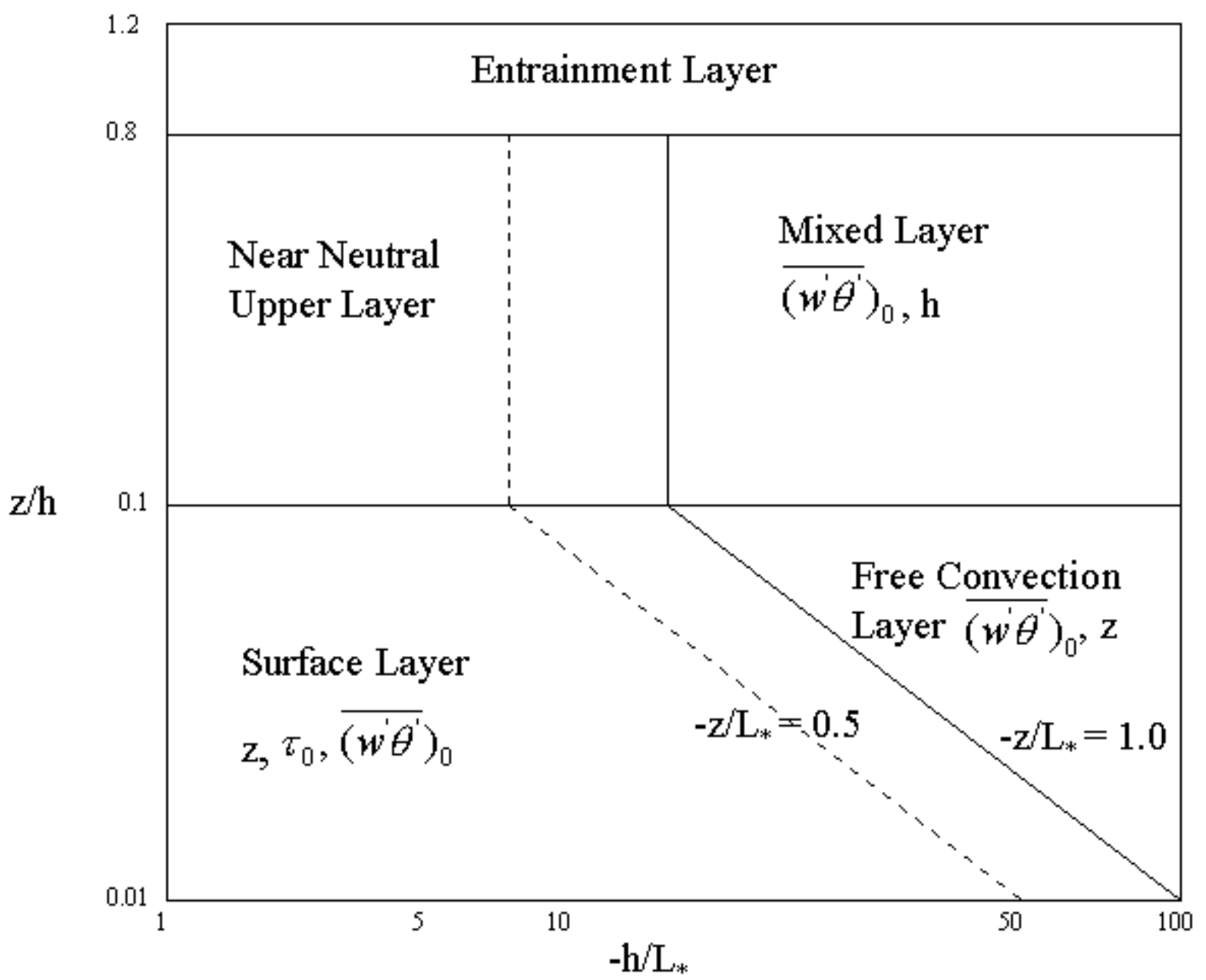

[Source: Stull 1988]

Fig. 6 


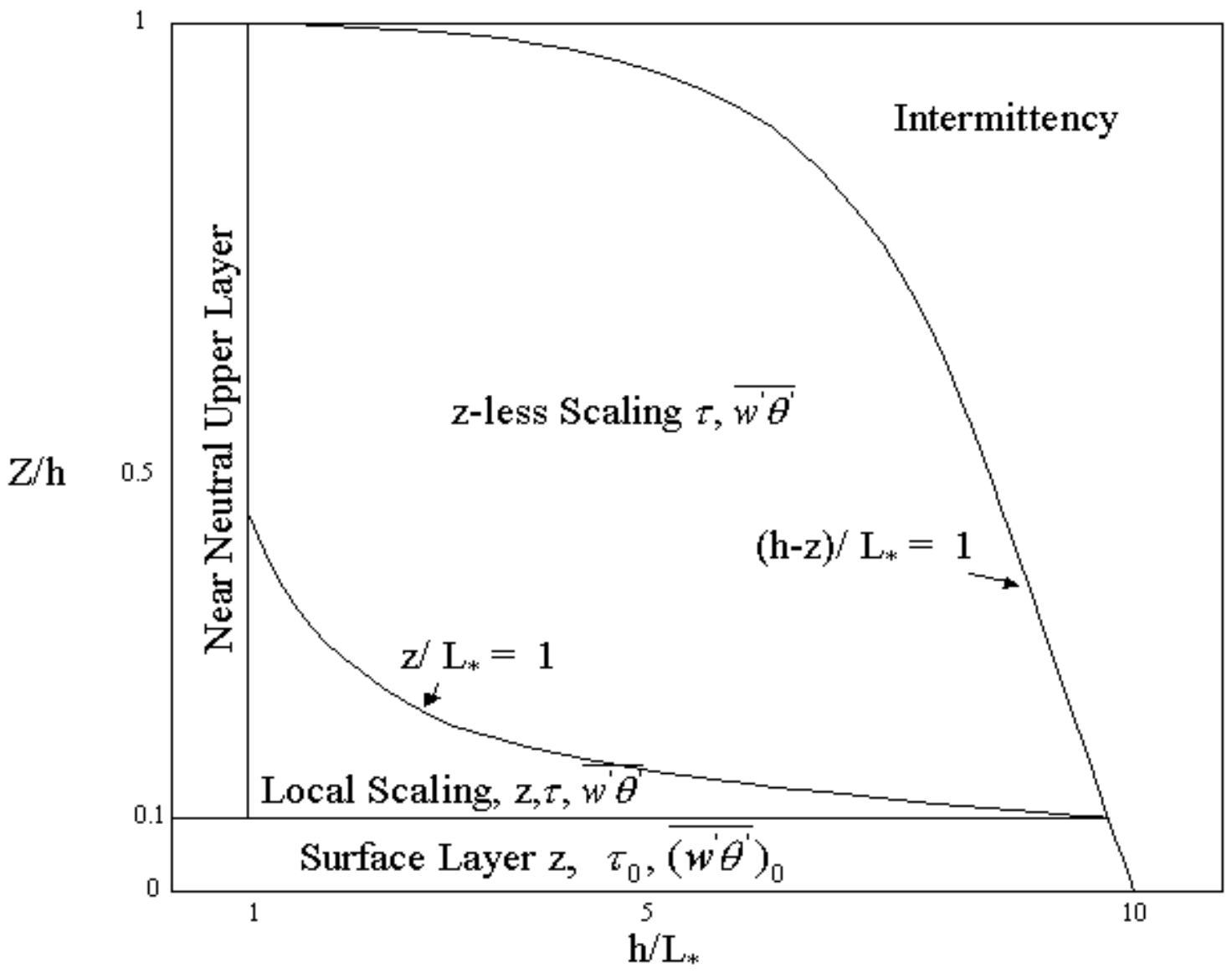

[Source: Stull 1988]

Fig. 7 


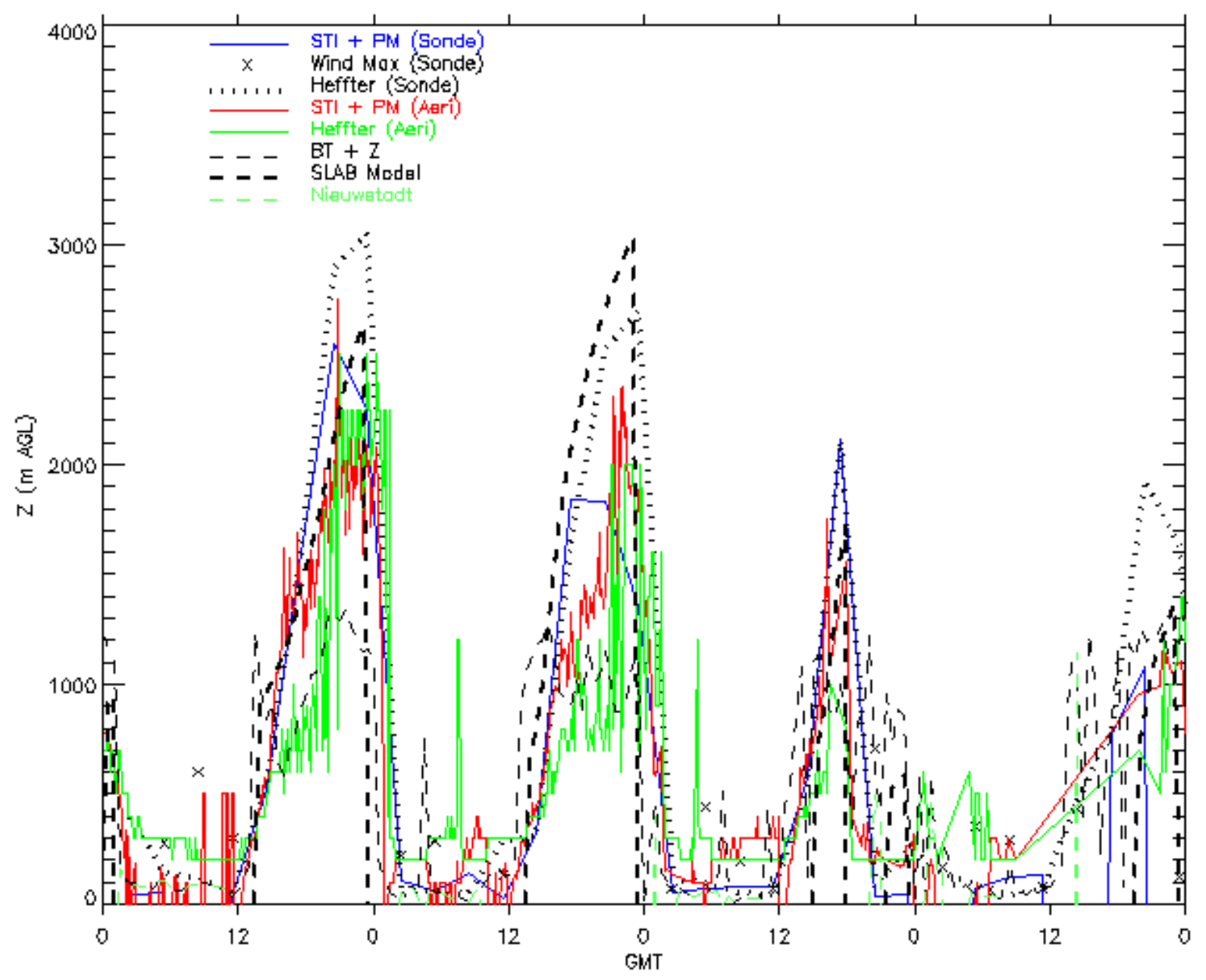

Fig. 8 


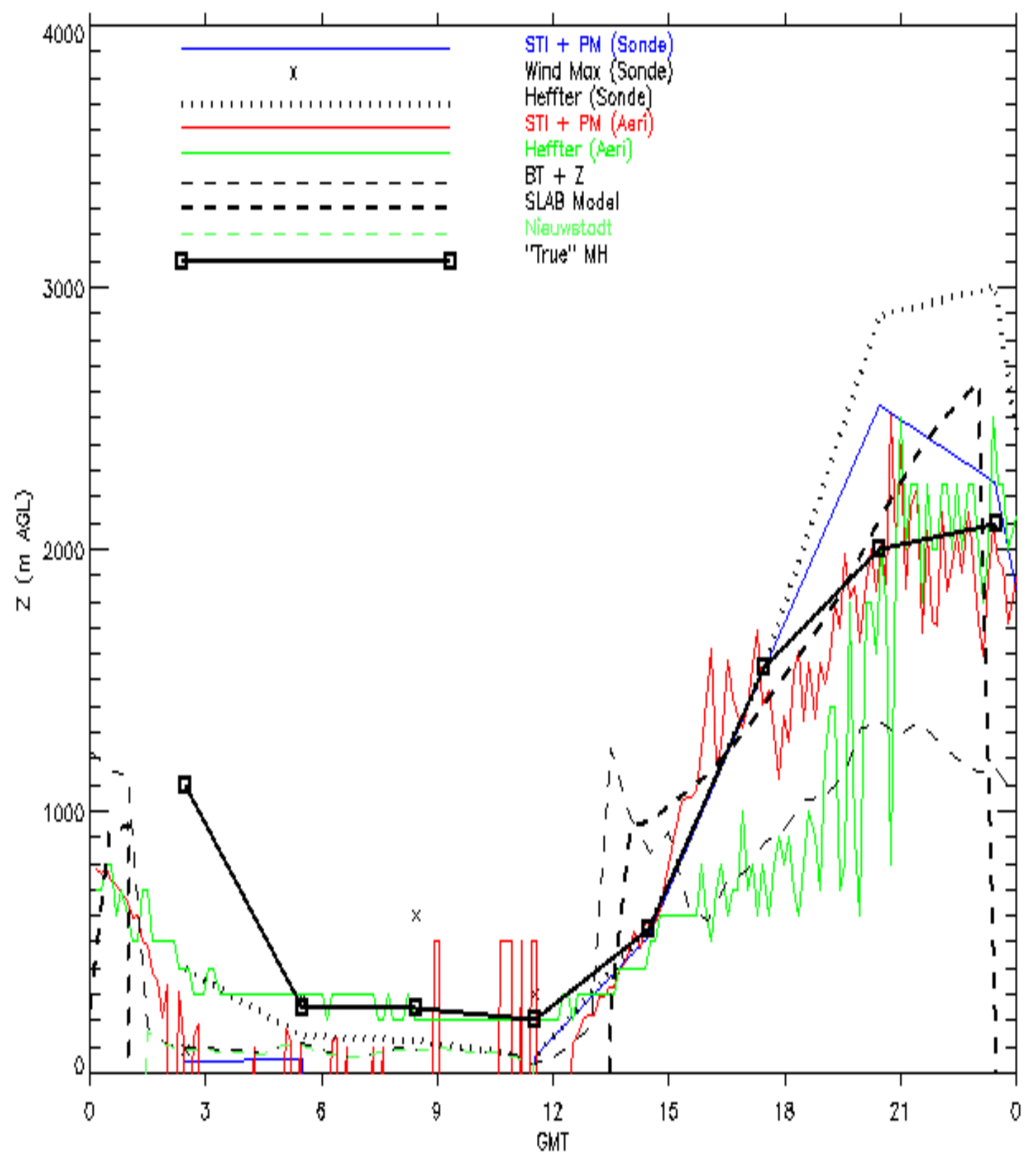

Fig 9 

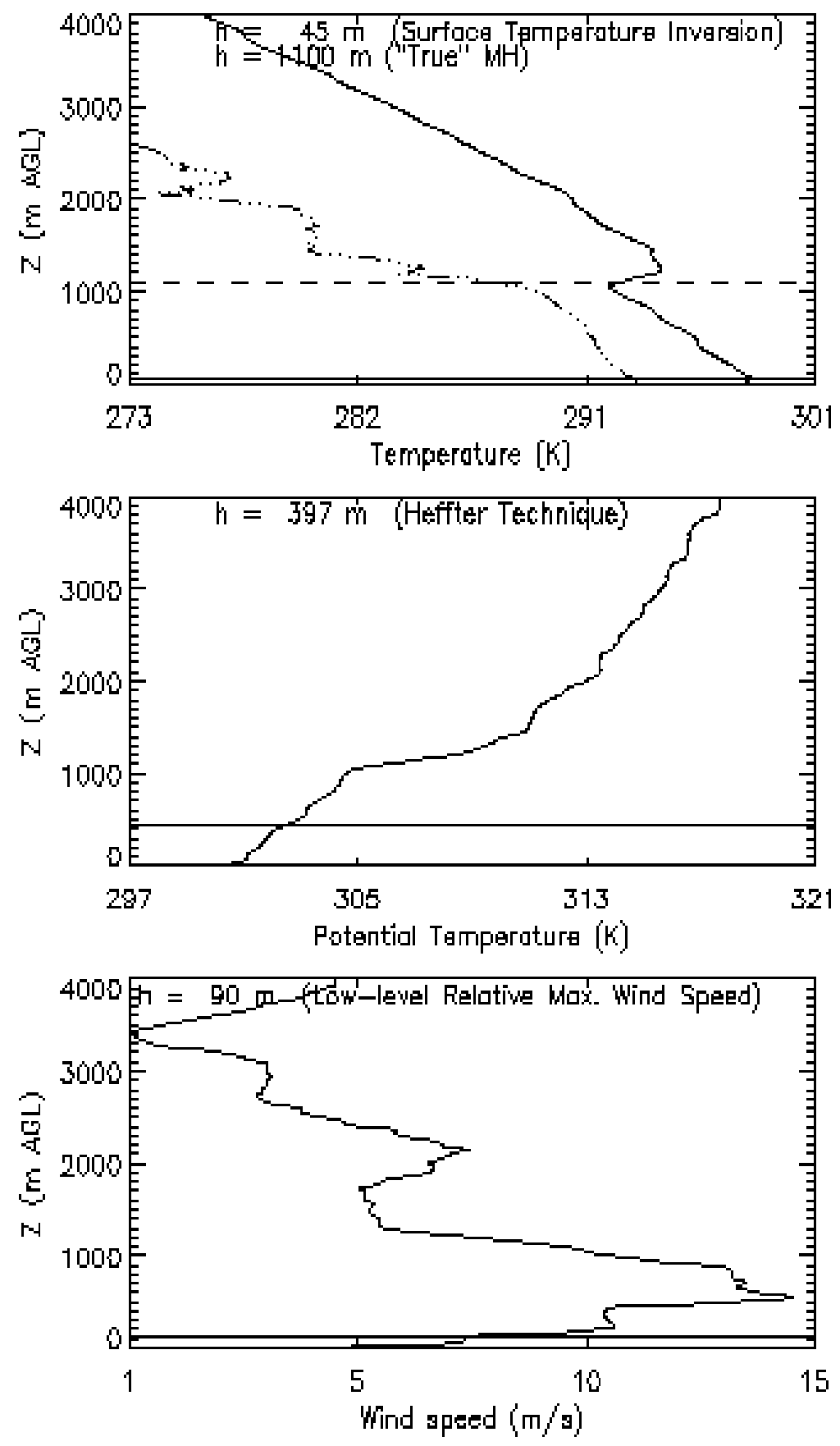

Fig. 10 

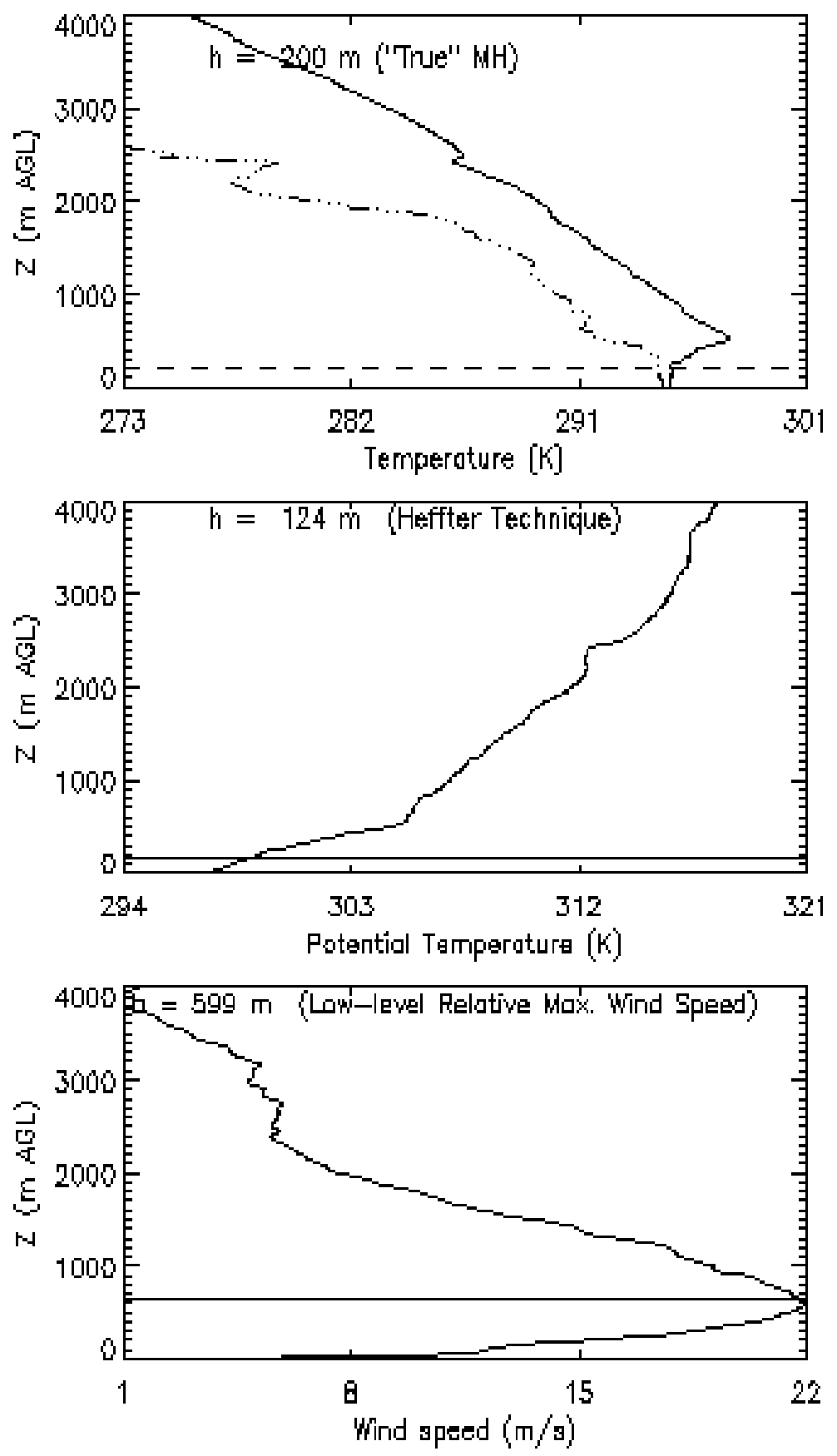

Fig. 11 

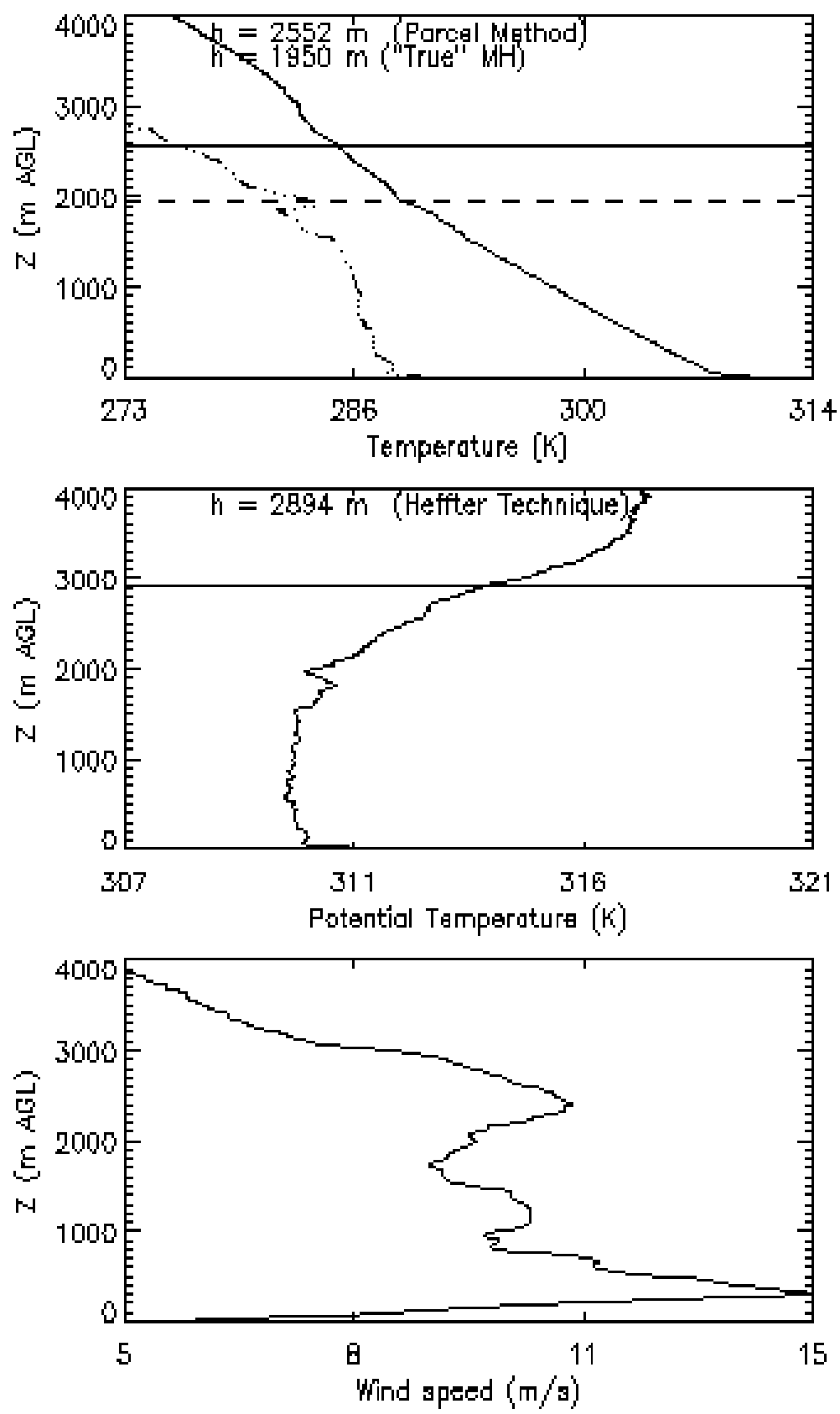

Fig. 12 

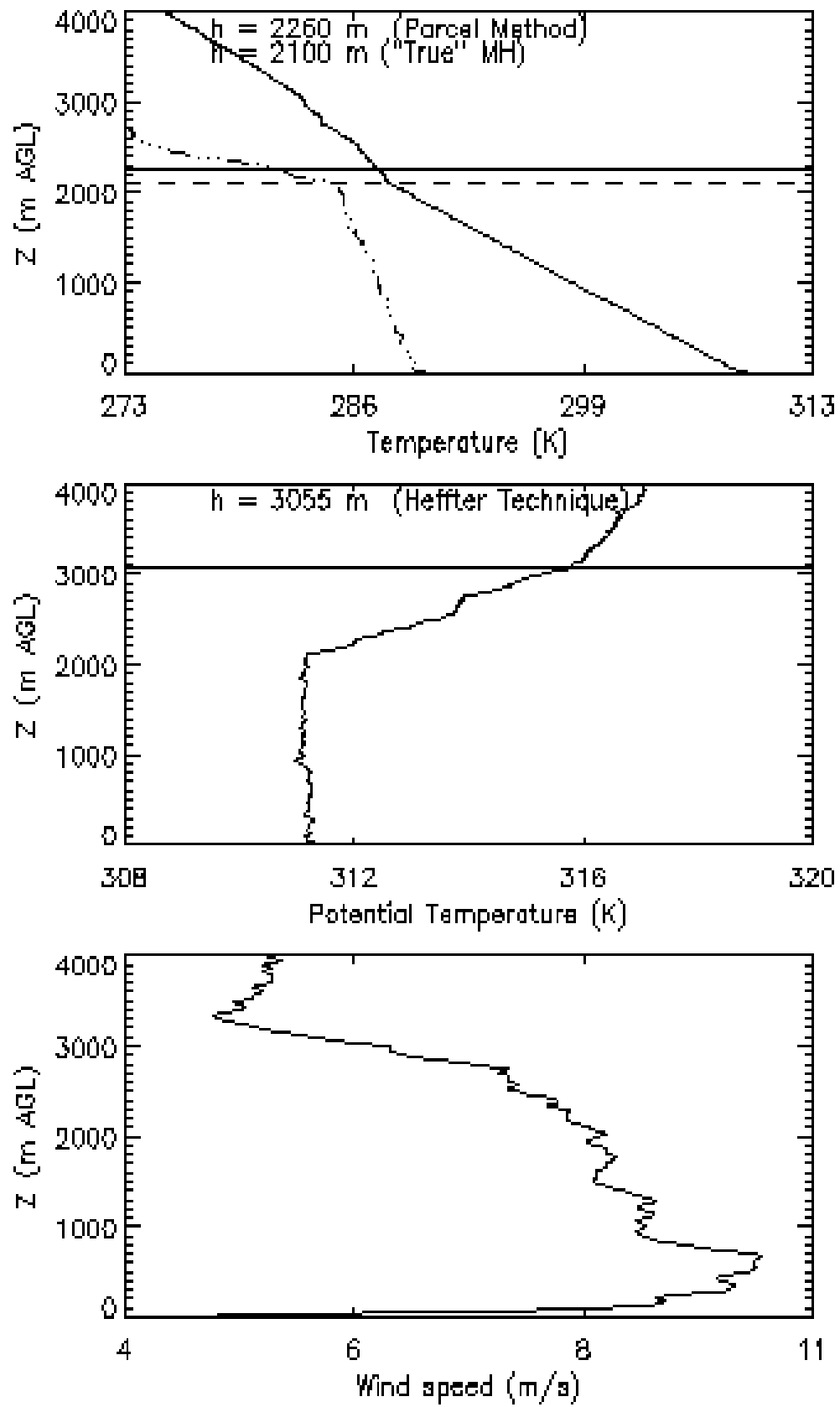

Fig. 13 

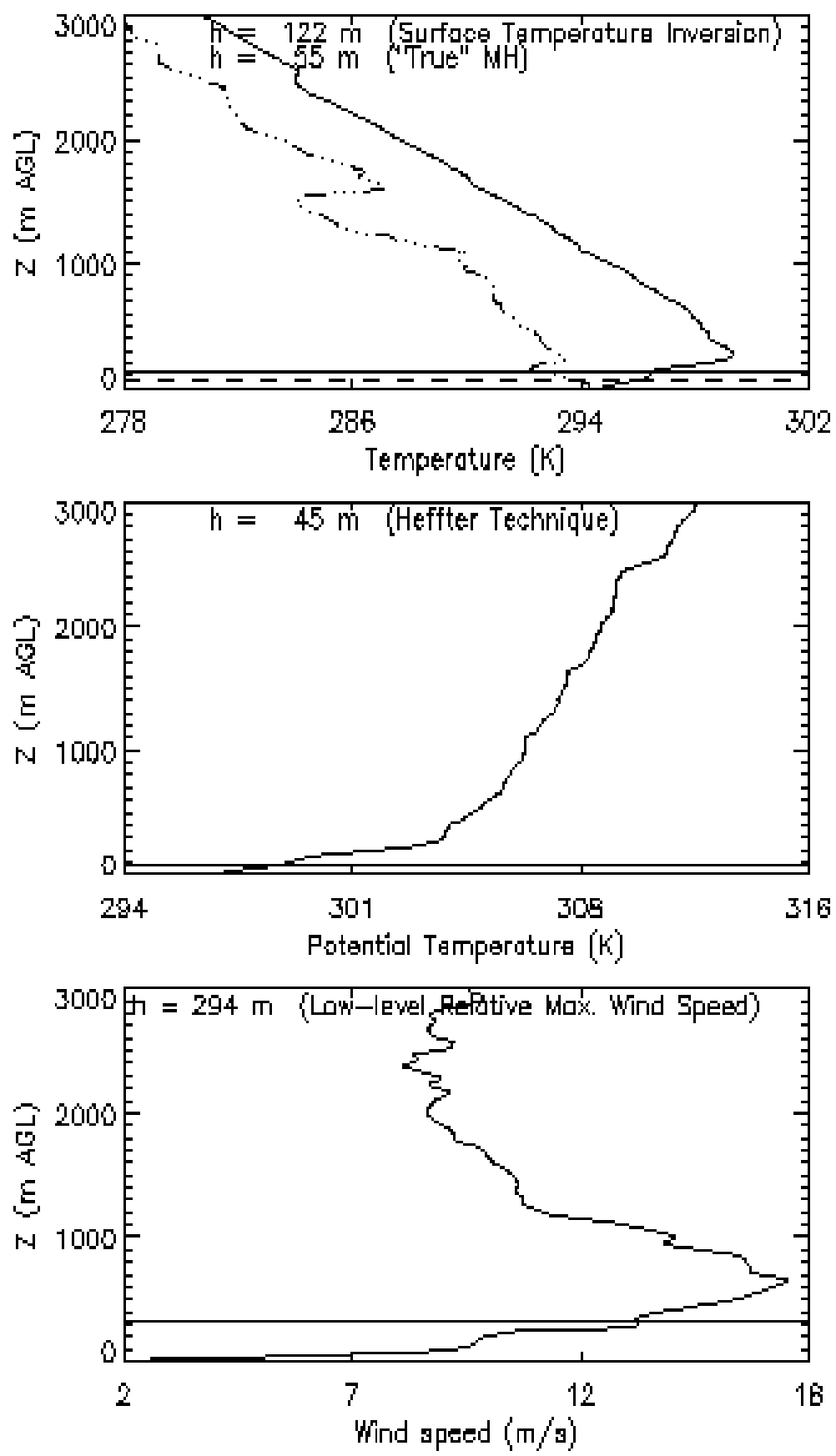

Fig. 14 

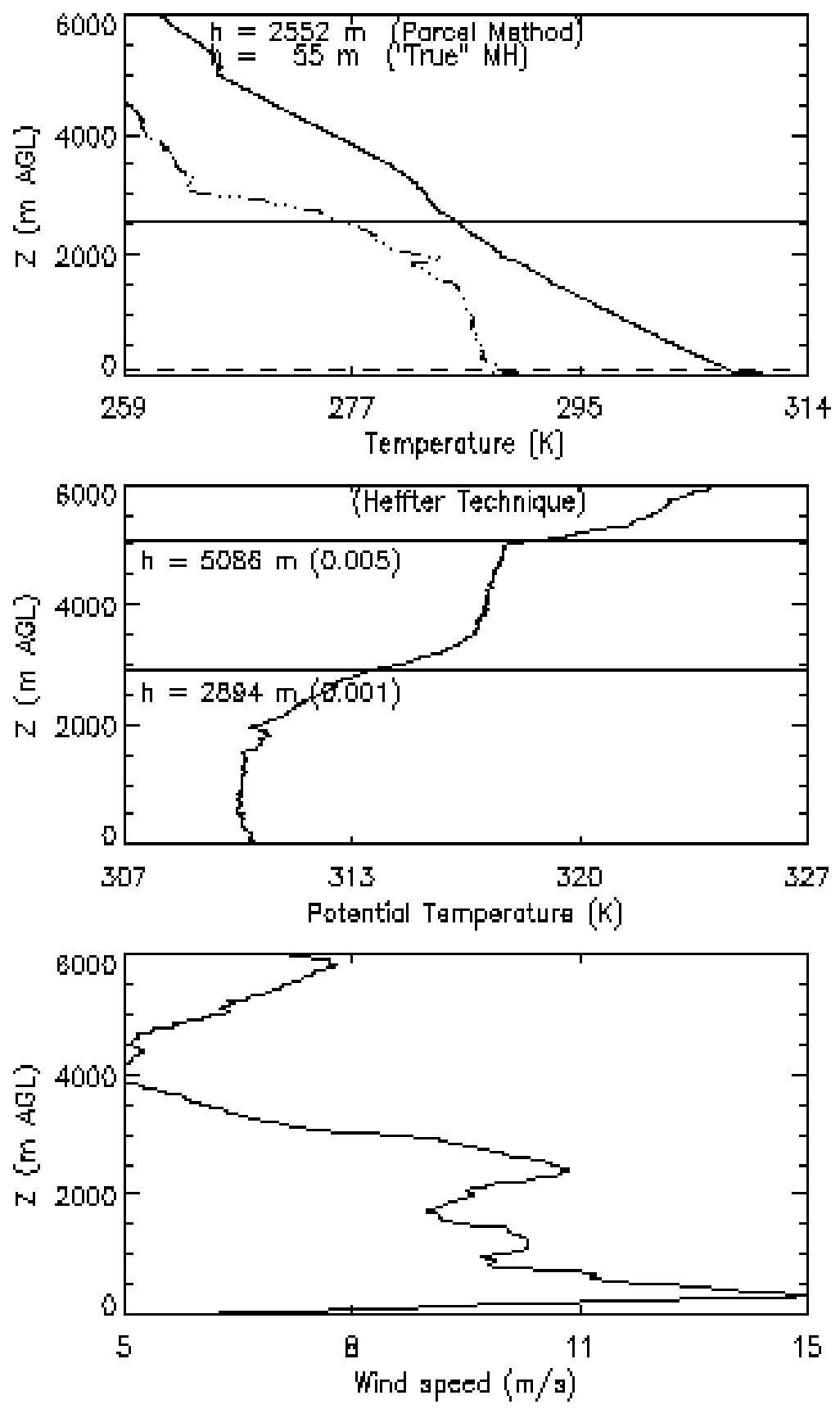

Fig. 15 


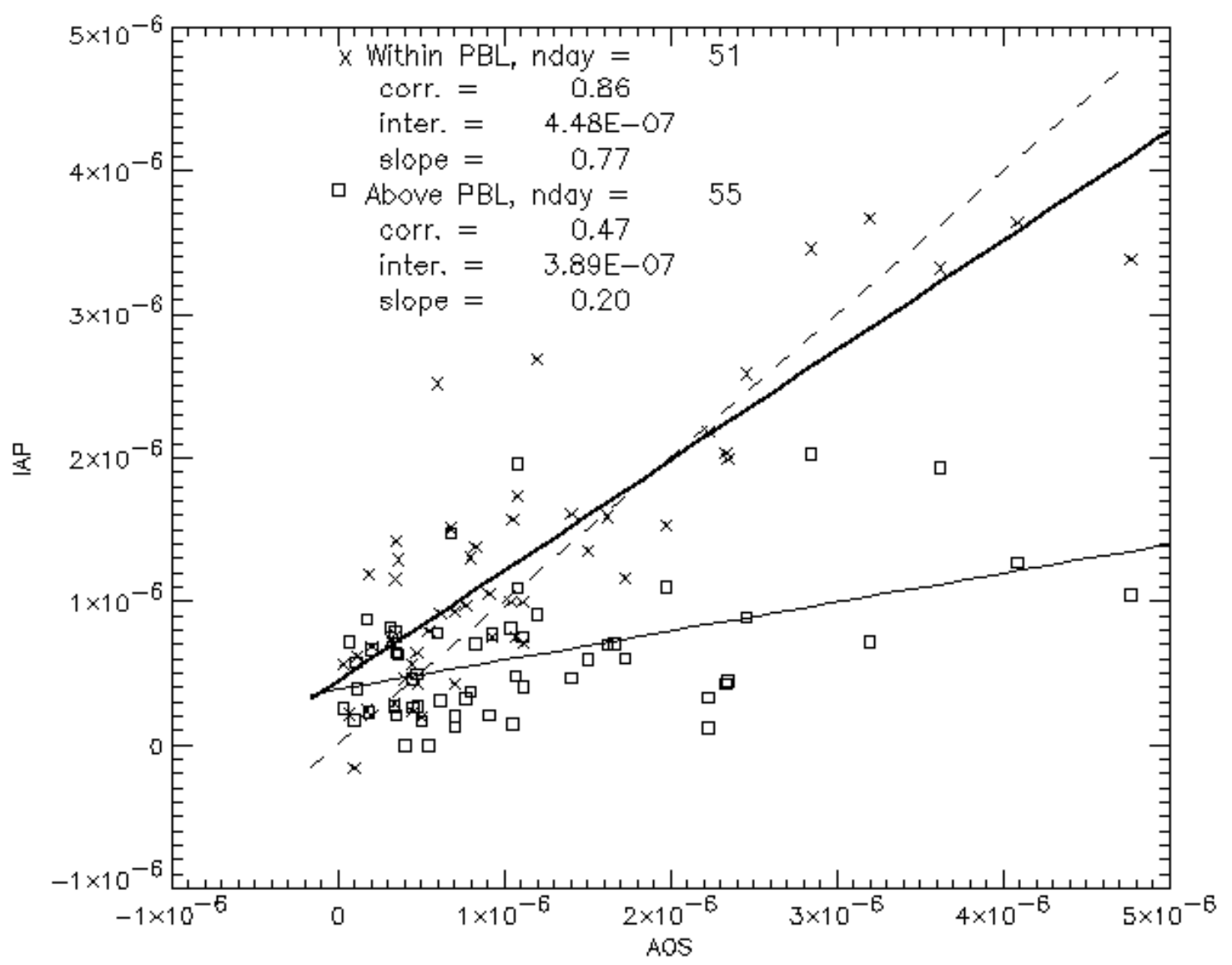

Fig. 16 


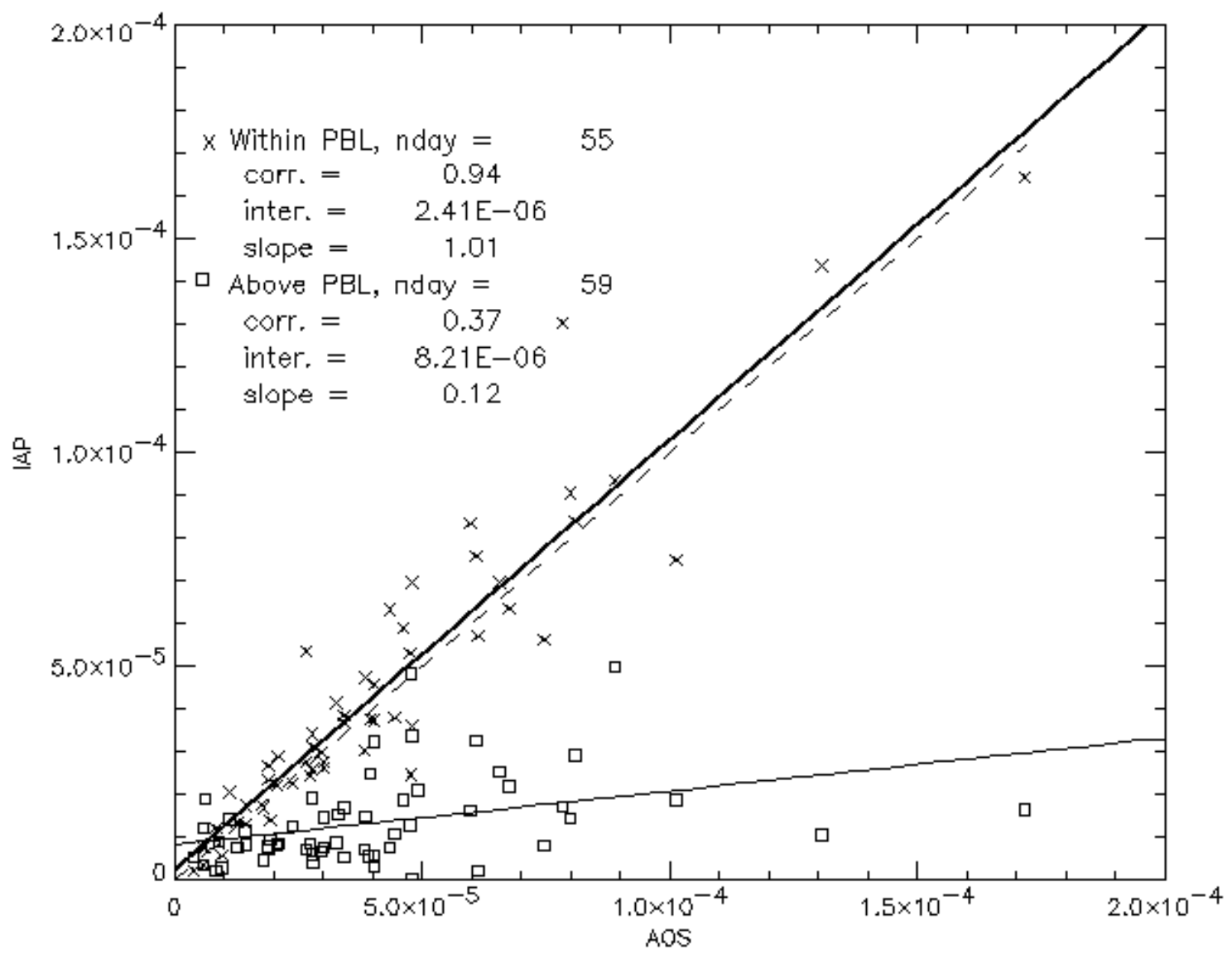

Fig 17 


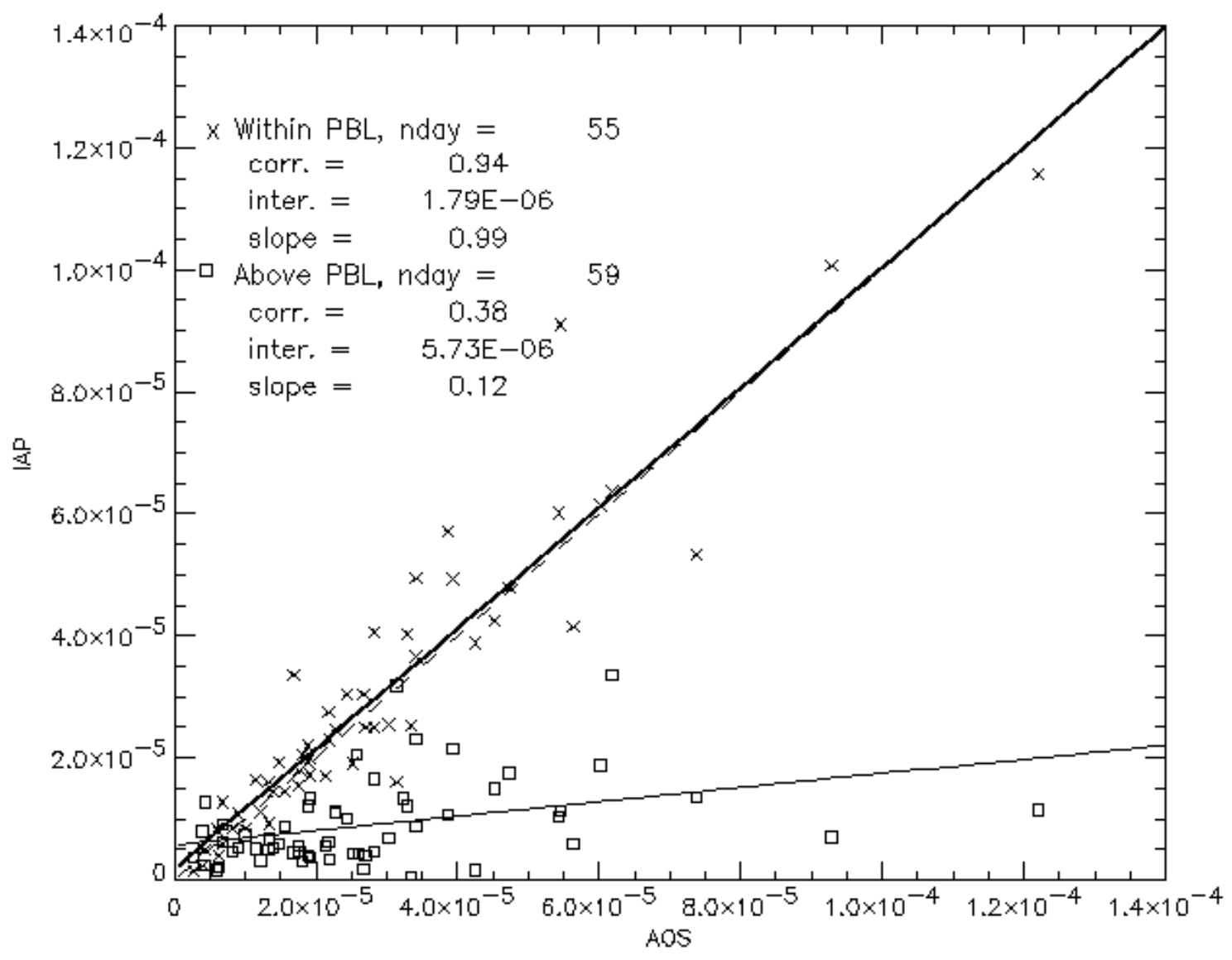

Fig 18 


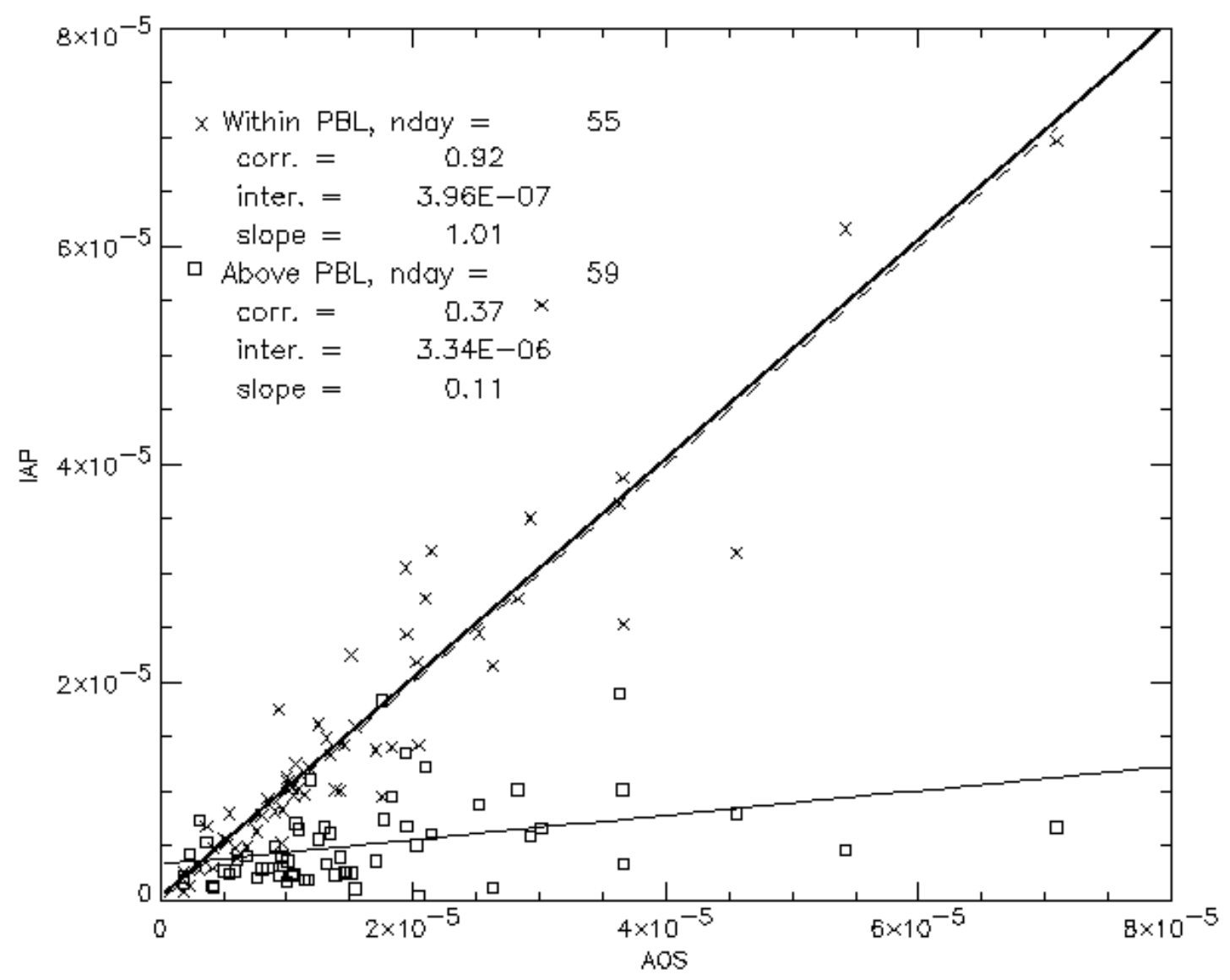

Fig. 19 


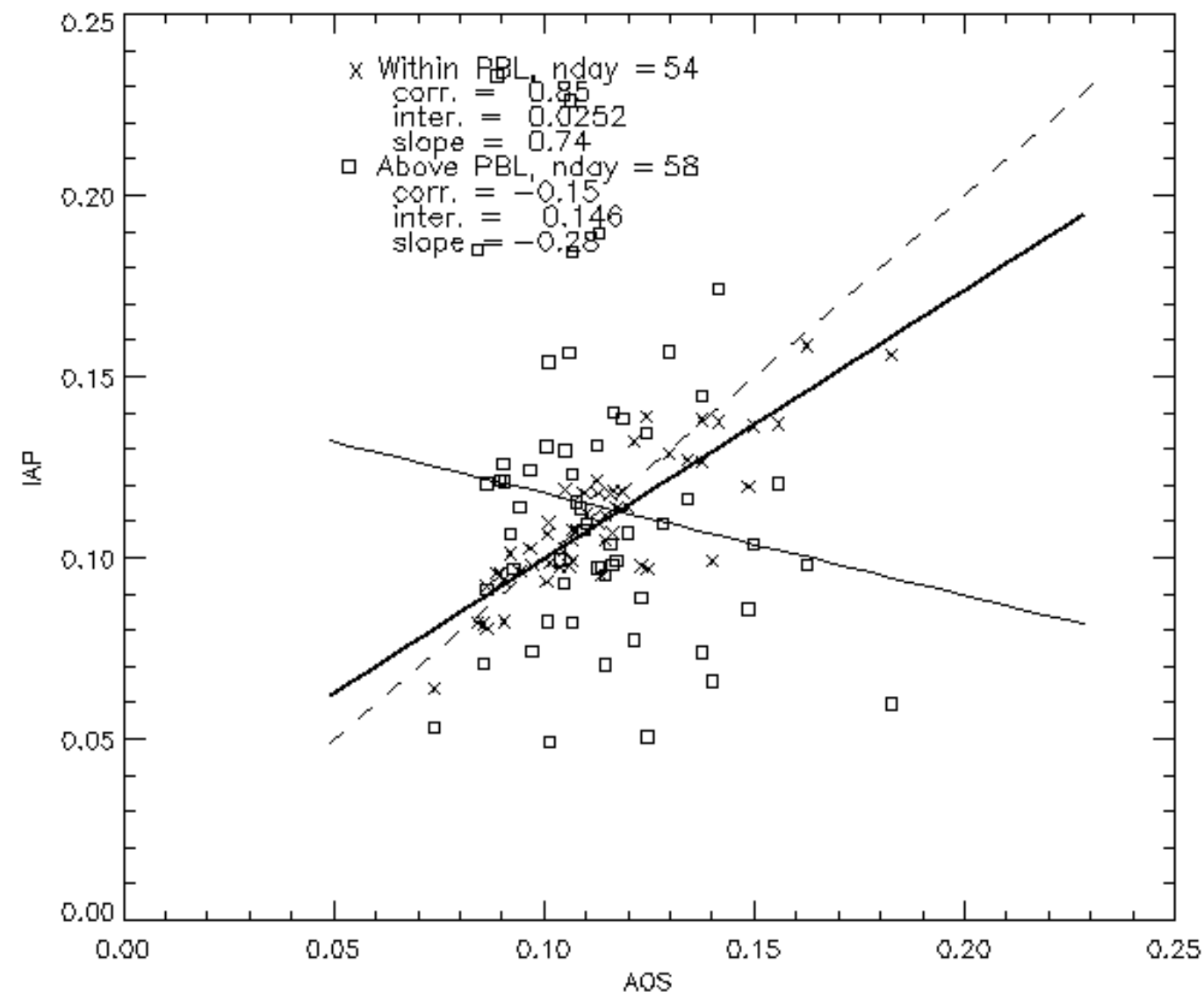

Fig. 20 


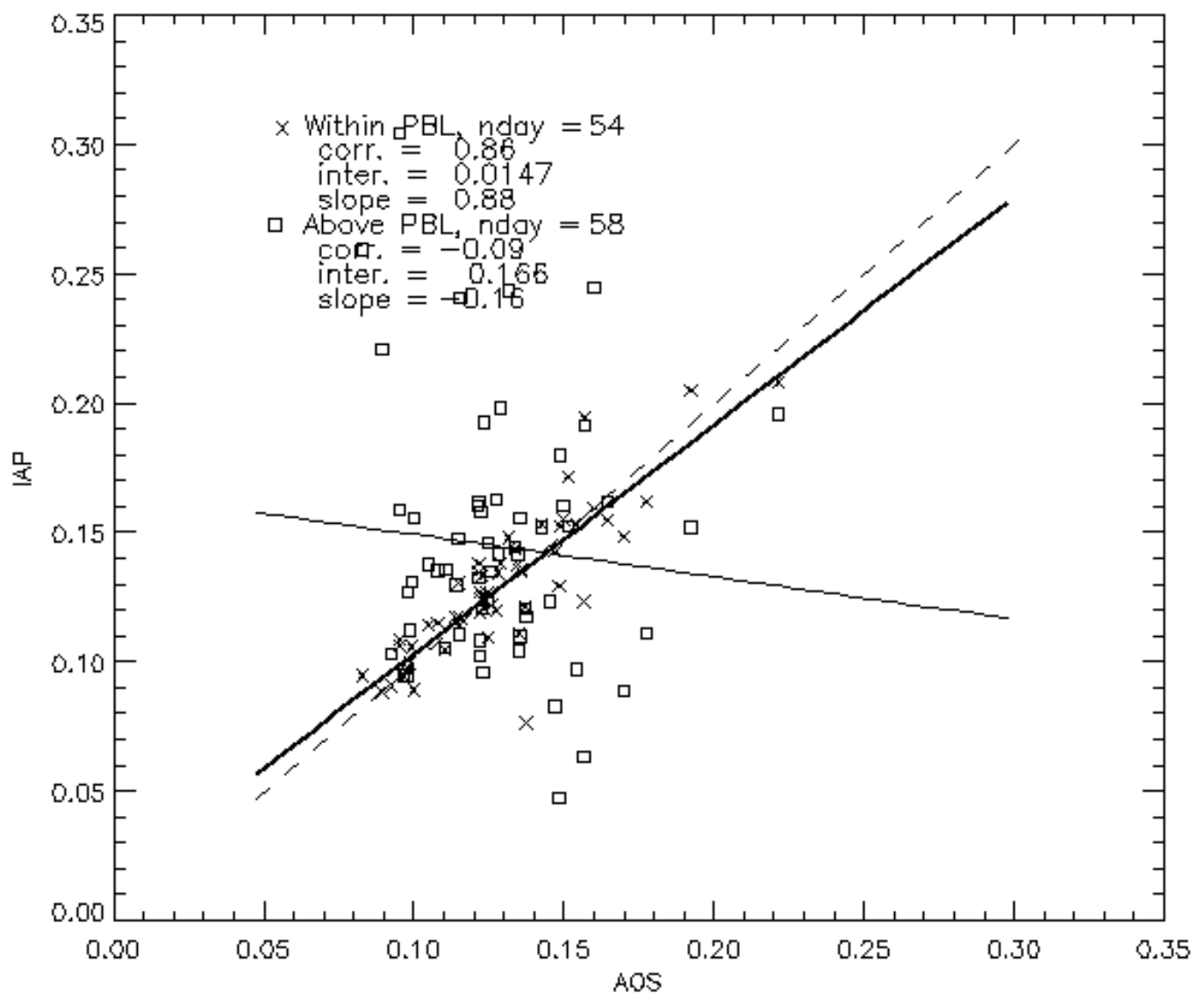

Fig. 21 


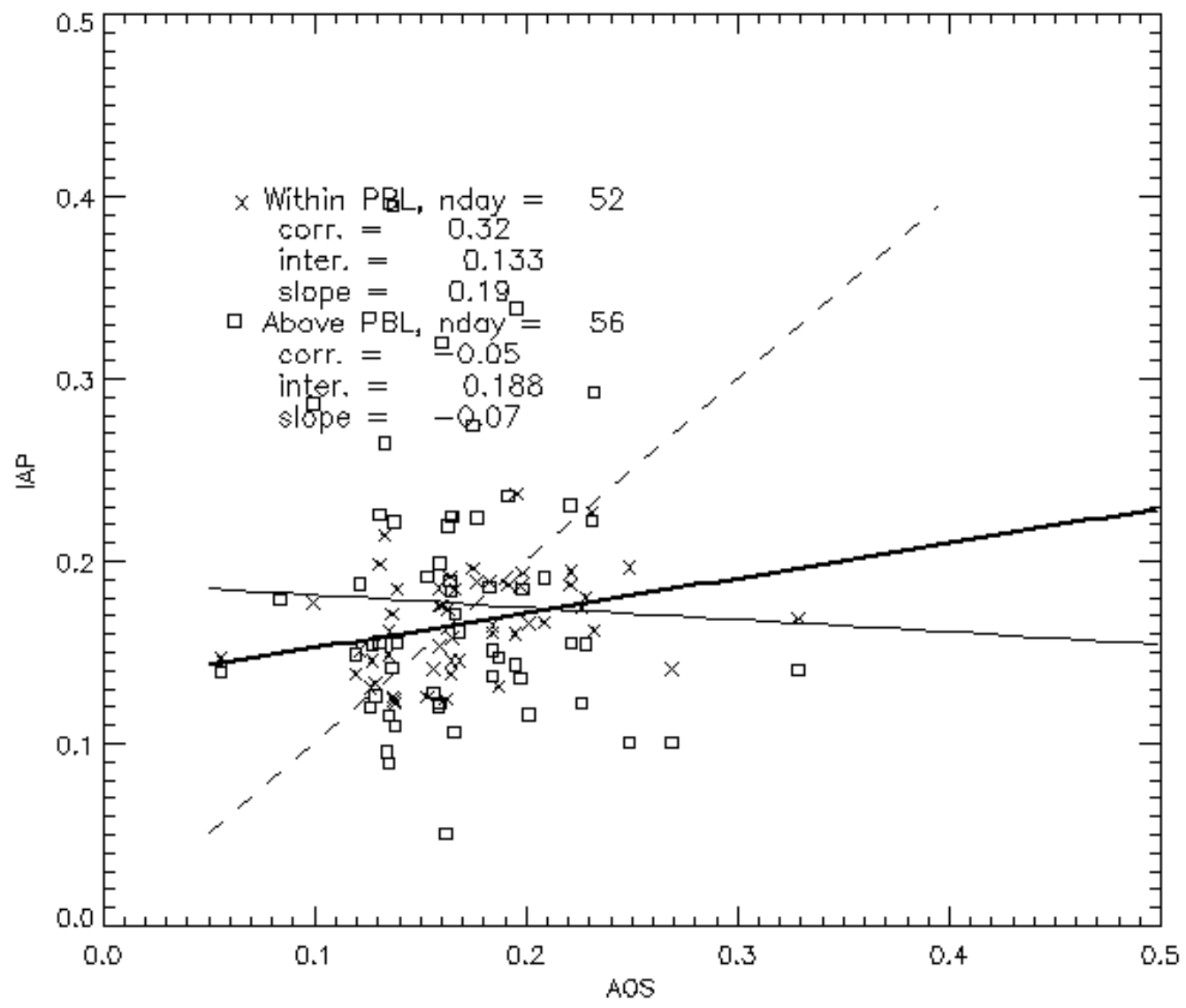

Fig. 22 


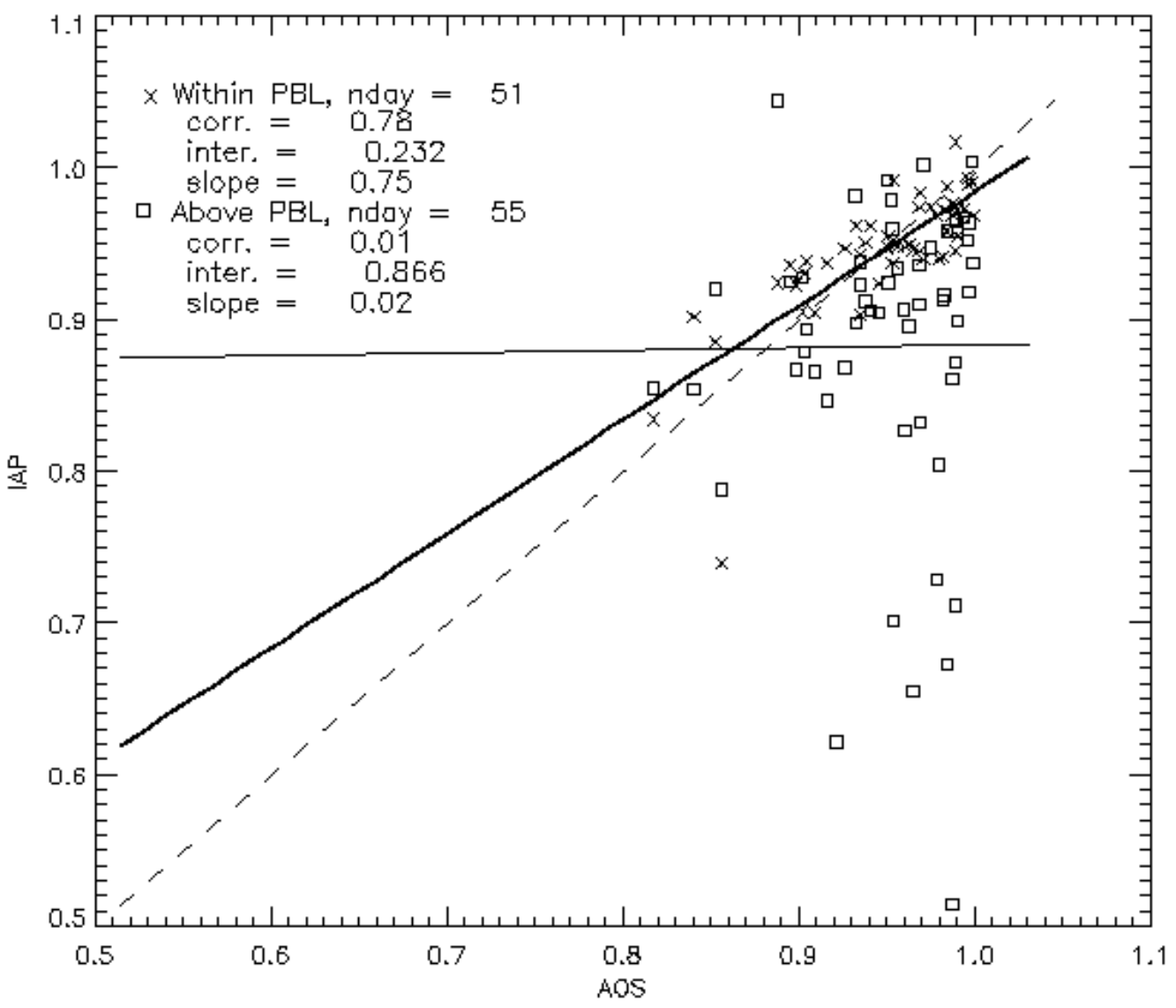

Fig. 23 


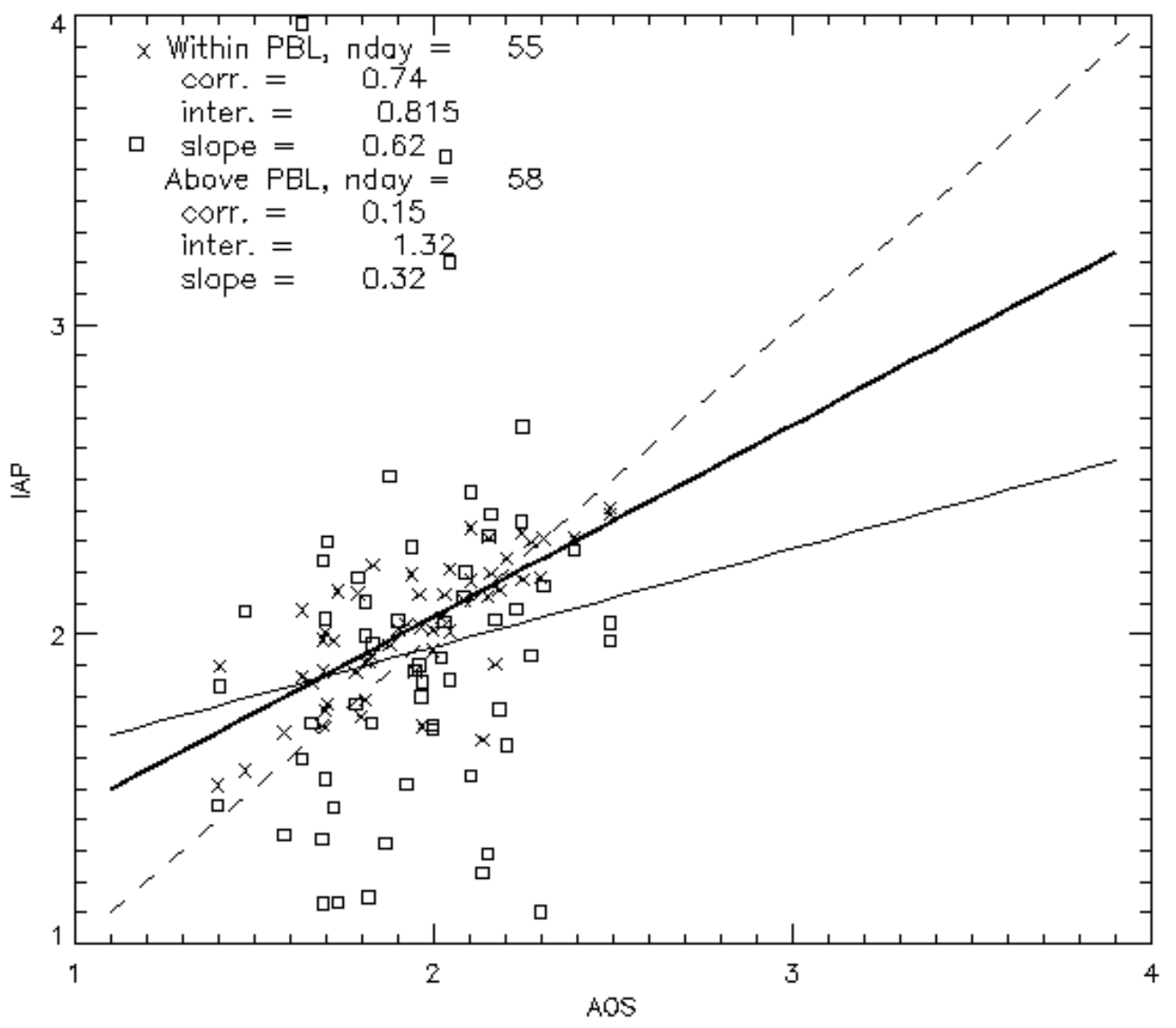

Fig. 24 


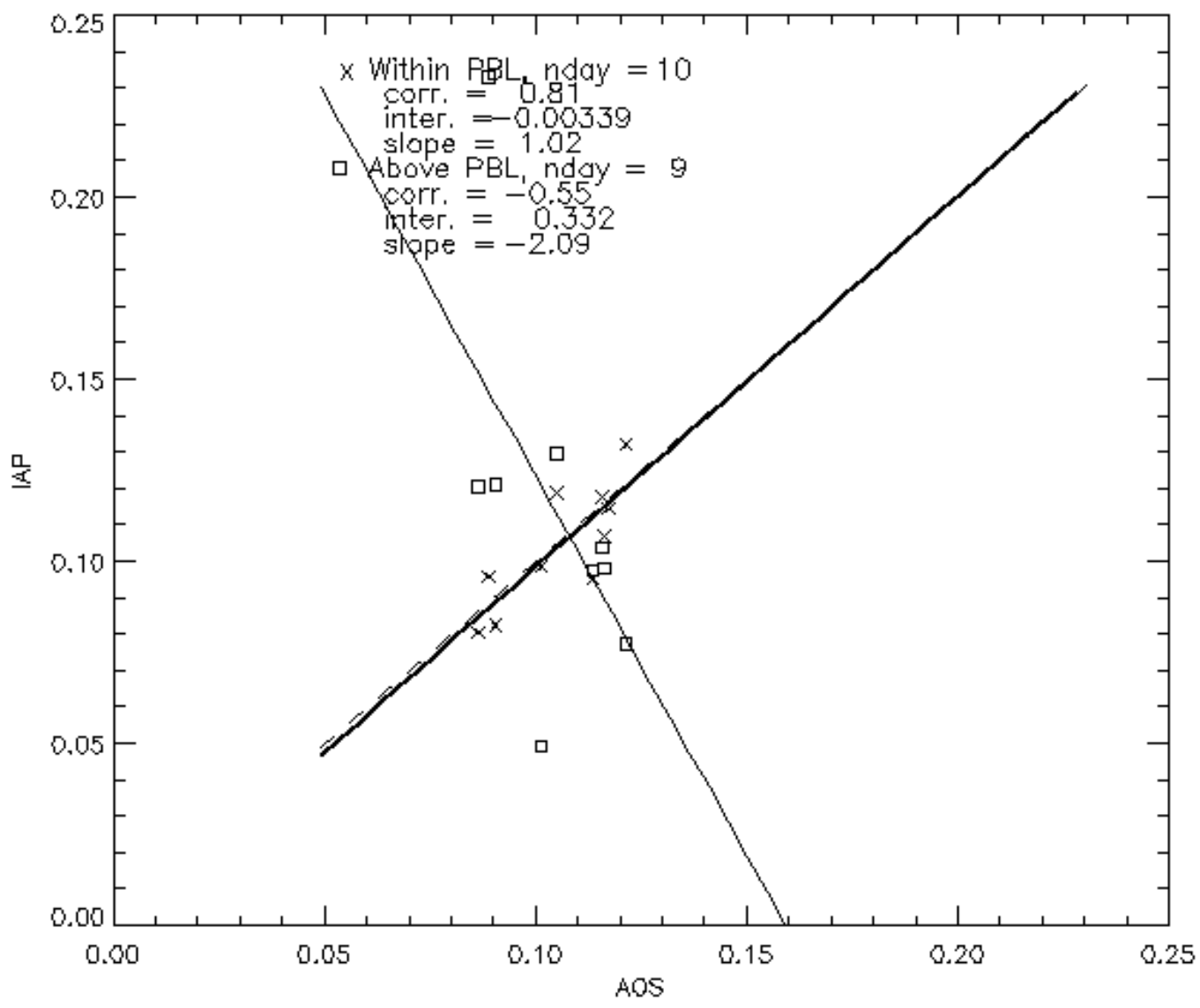

Fig. 25 


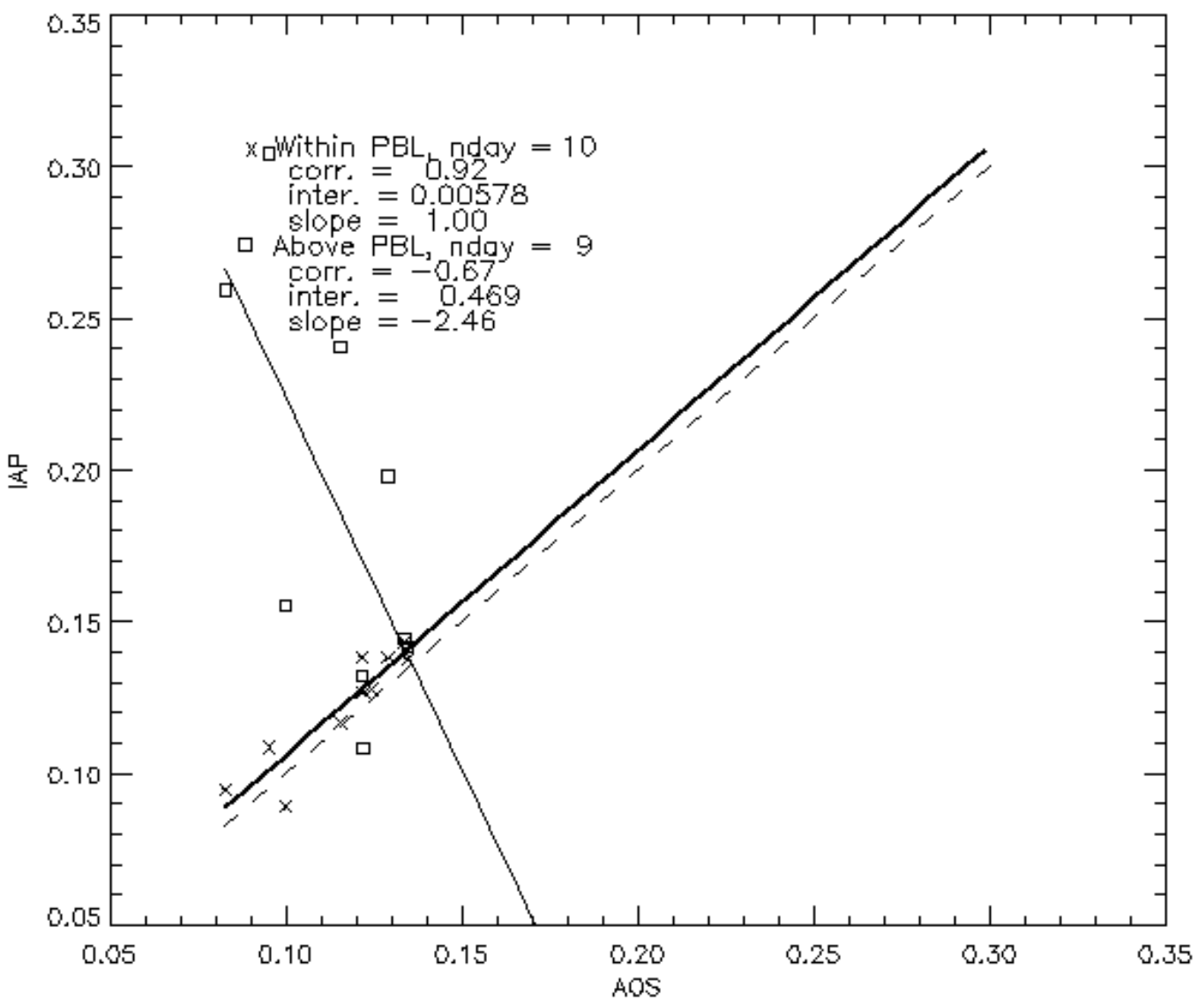

Fig. 26 


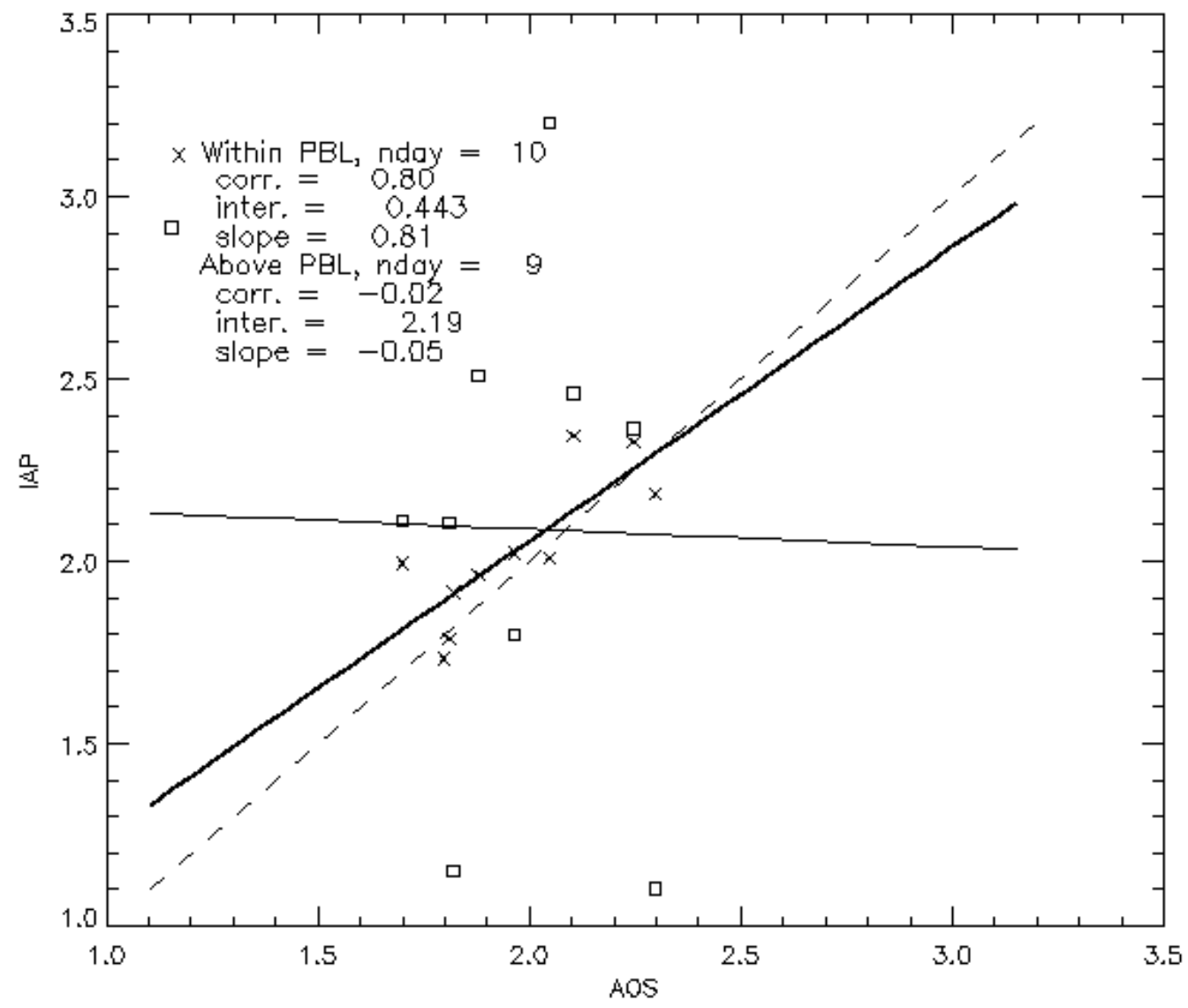

Fig. 27 


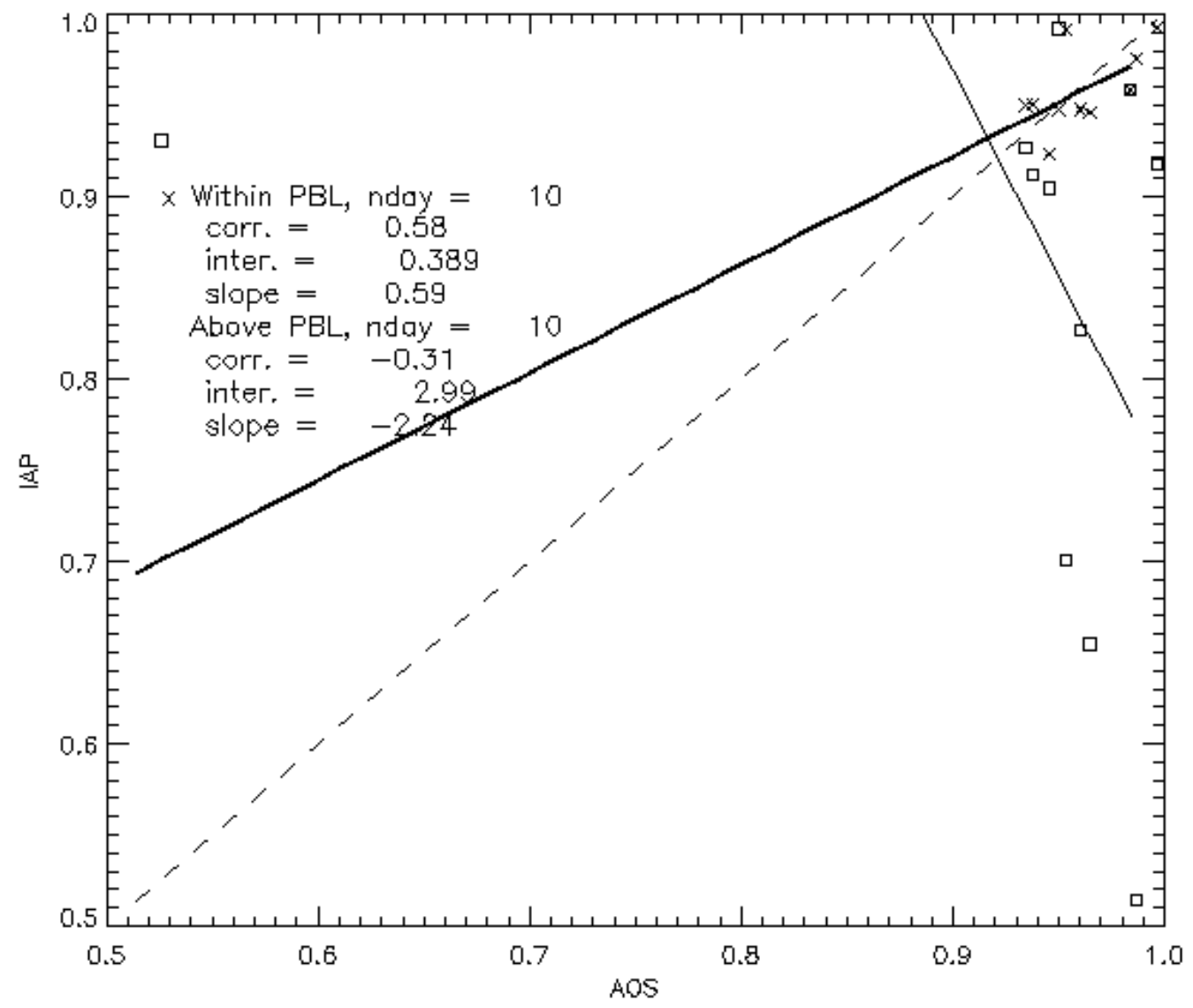

Fig. 28 


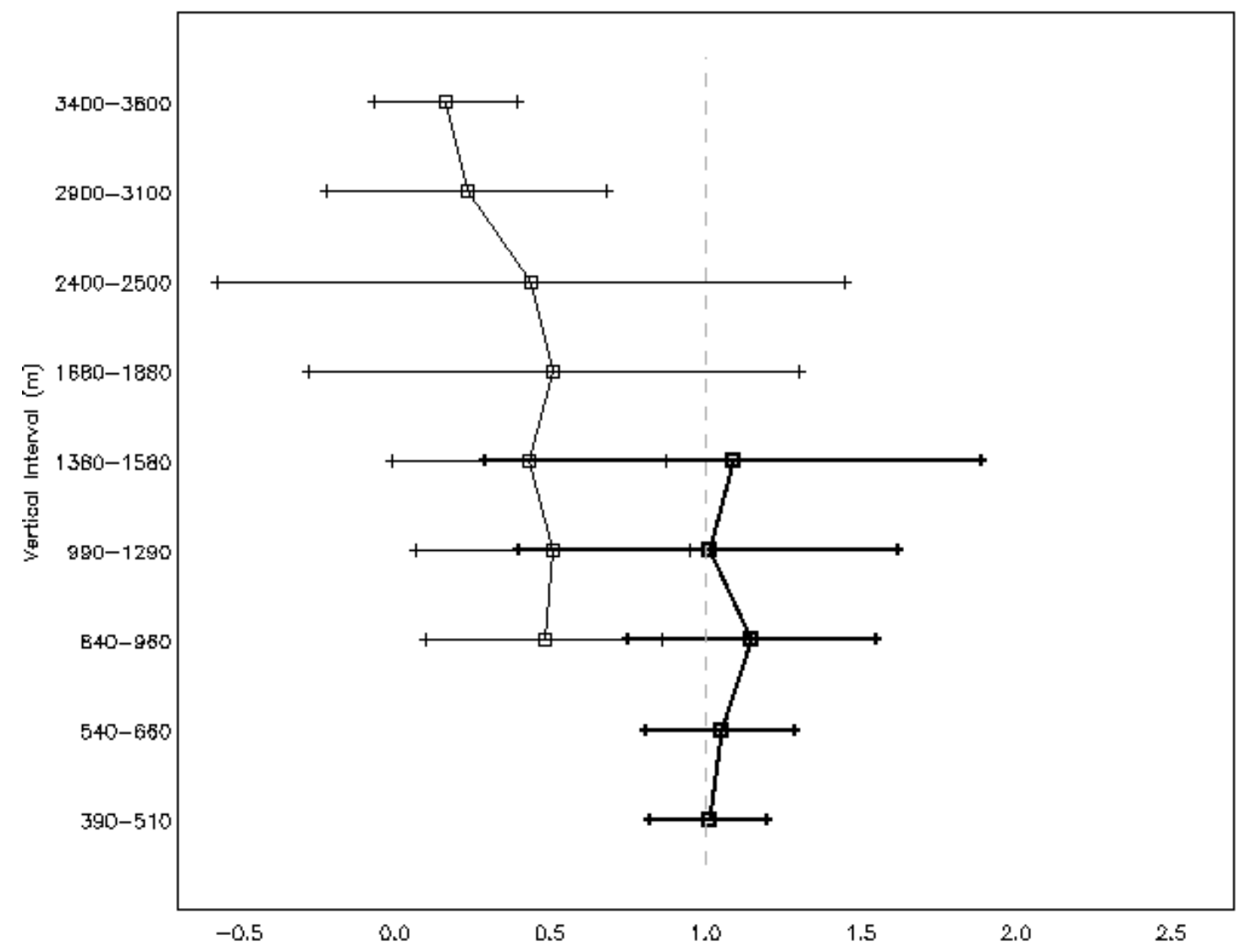

Fig. 29 


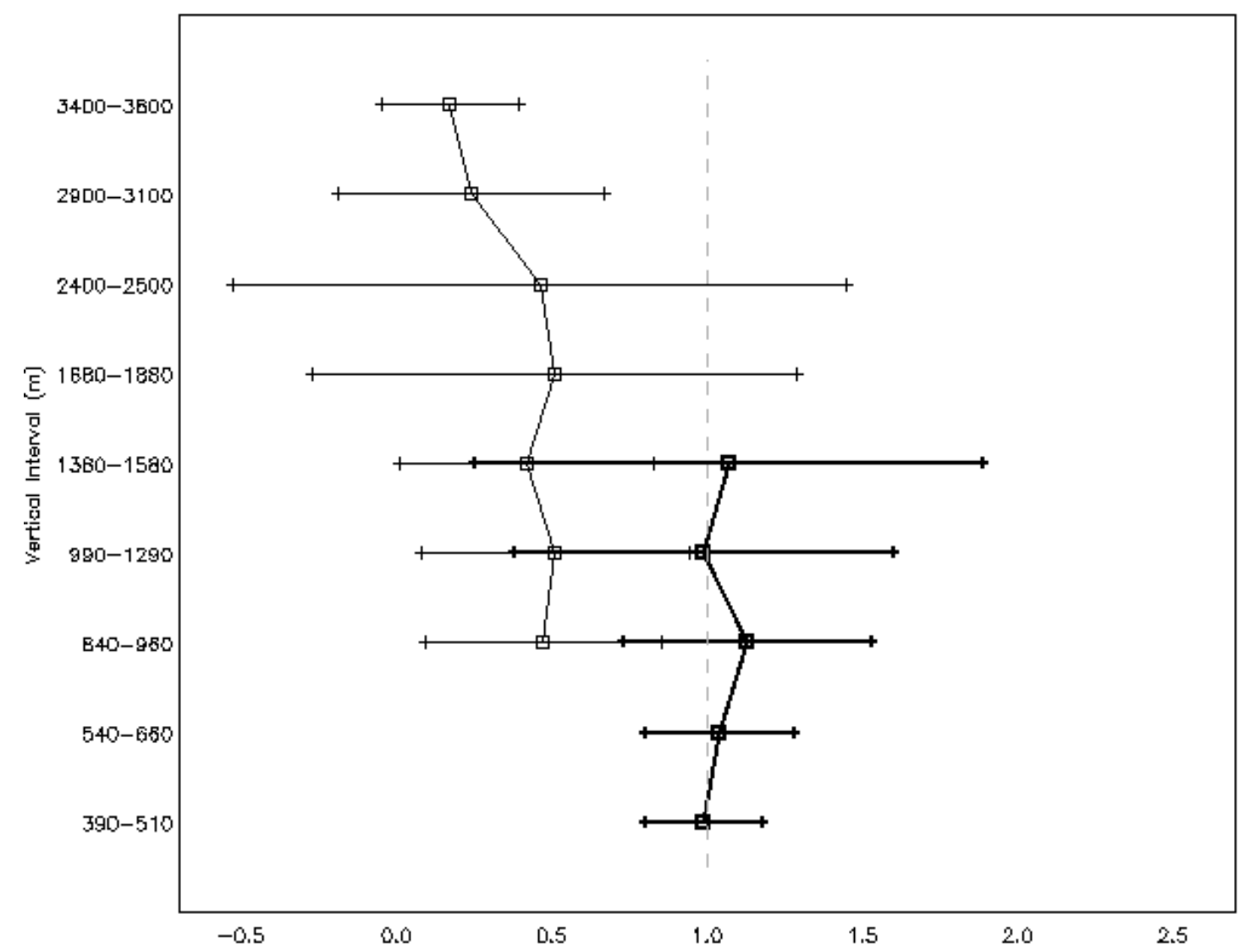

Fig. 30 


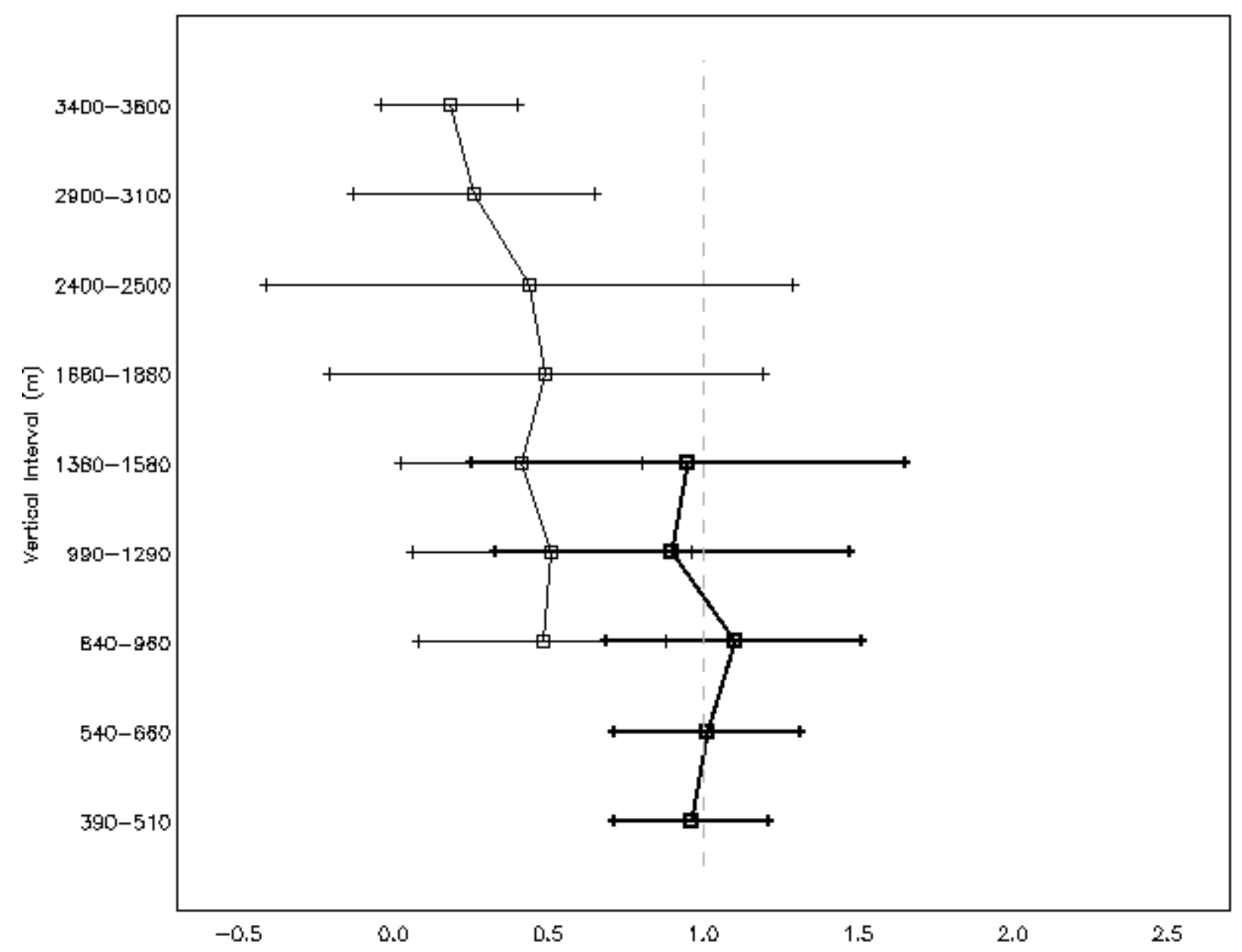

Fig. 31 


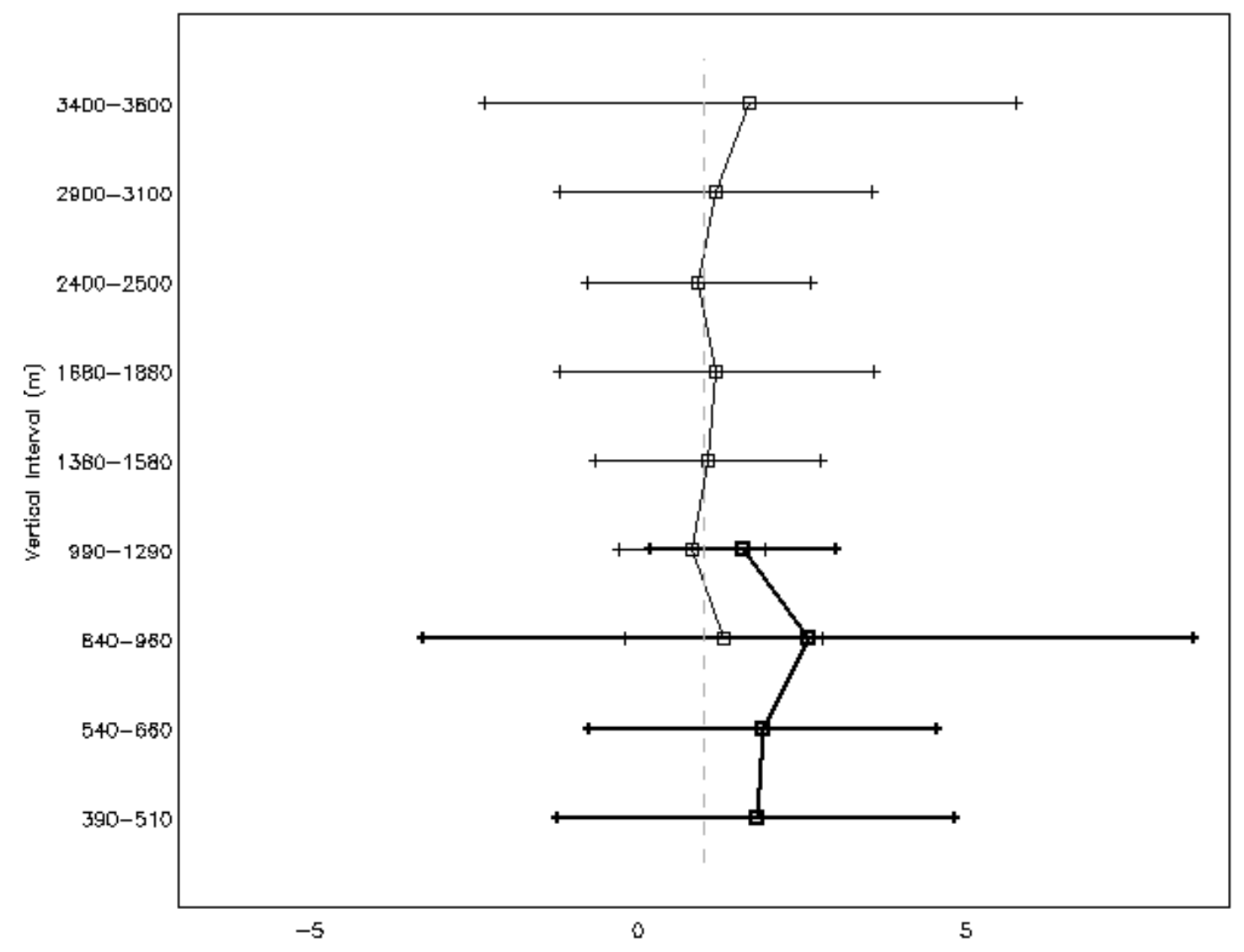

Fig. 32 


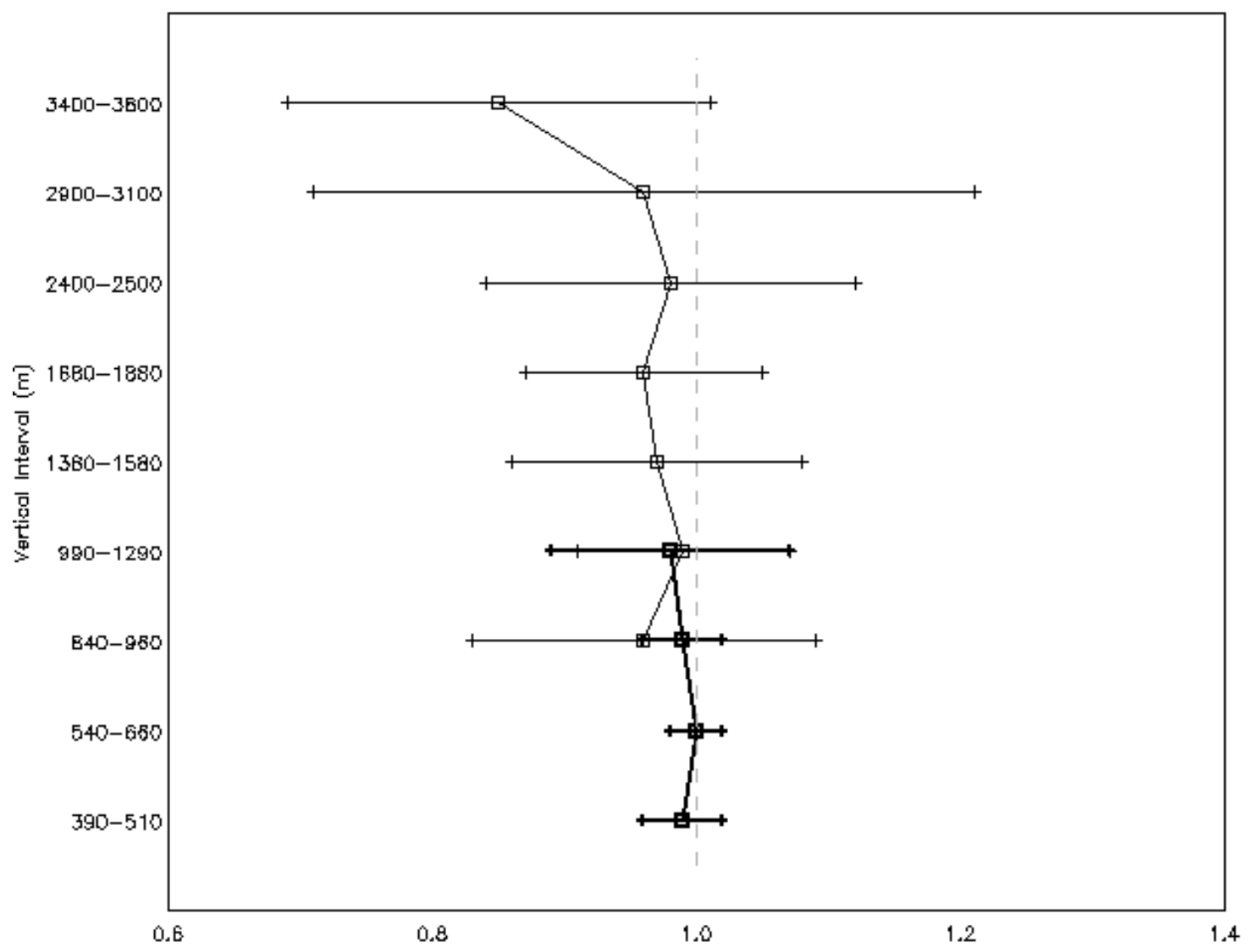

Fig. 33 


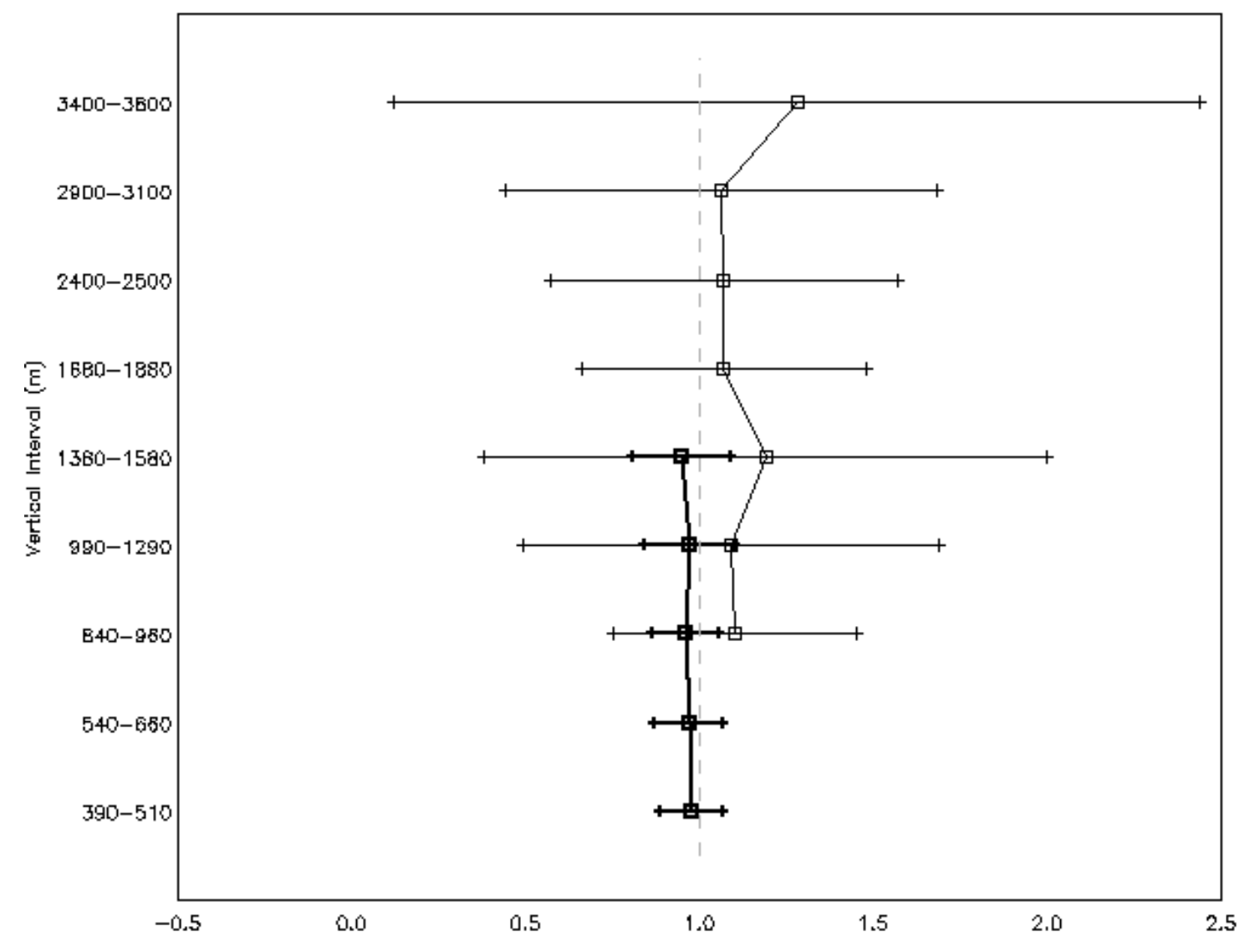

Fig. 34 


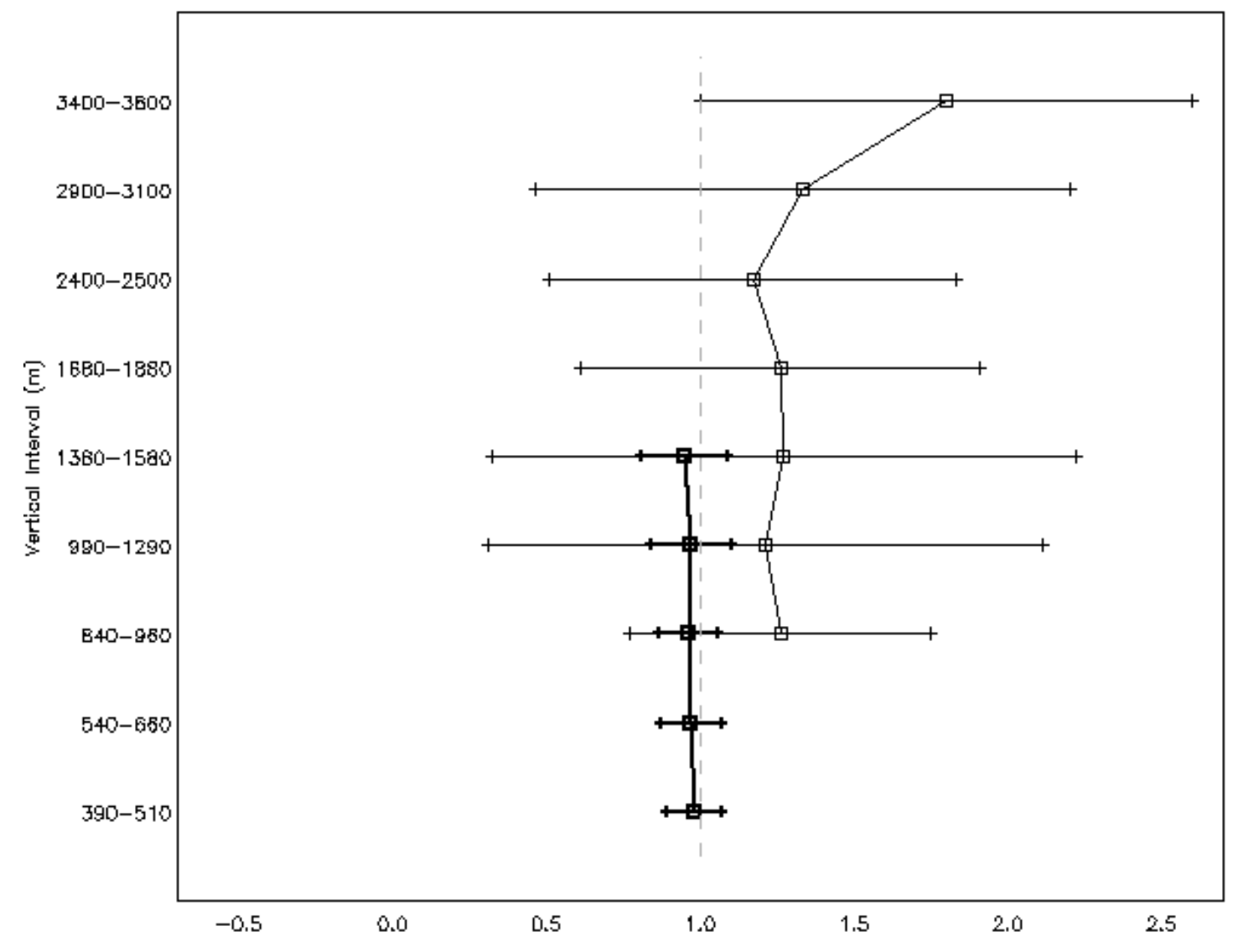

Fig. 35 


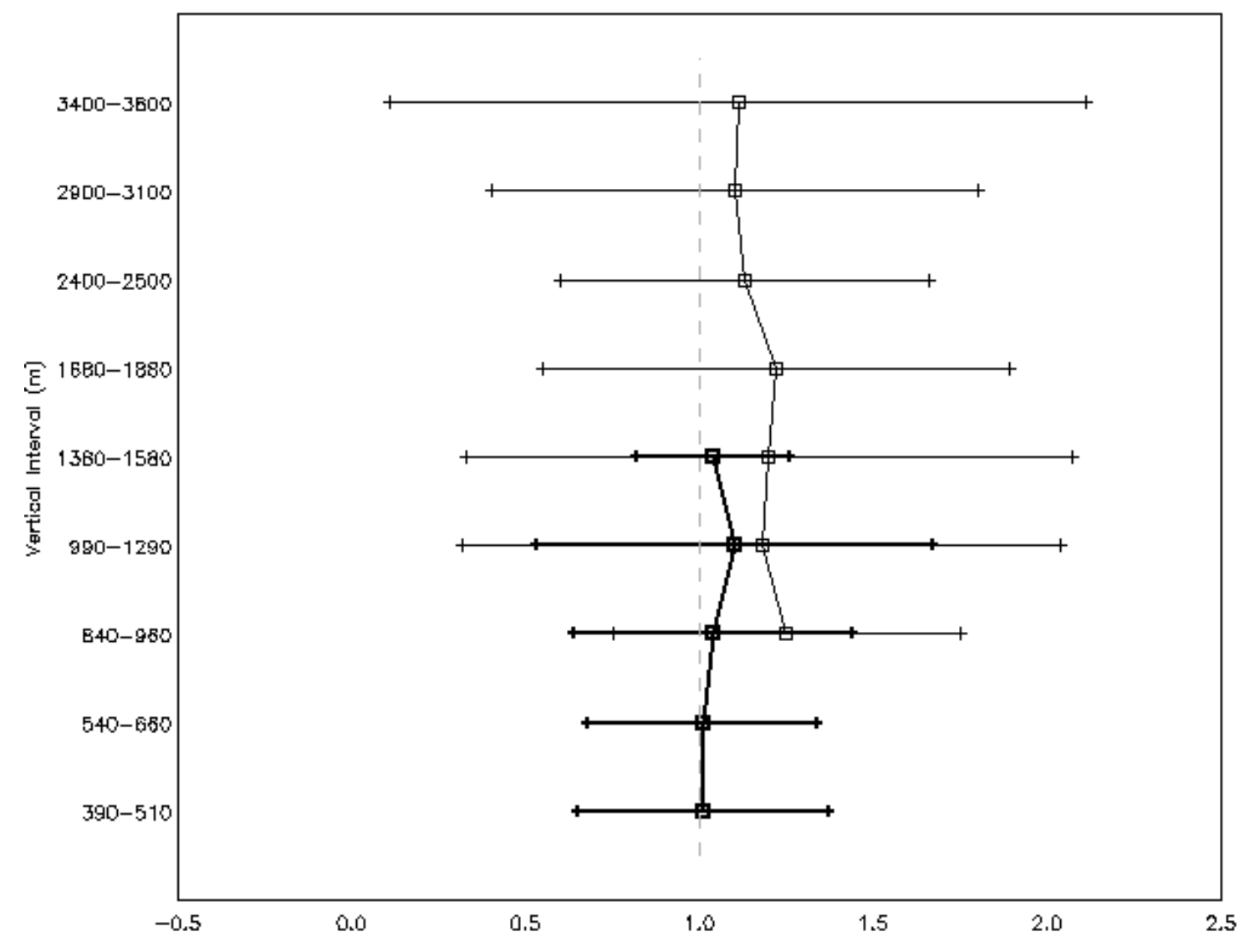

Fig. 36 


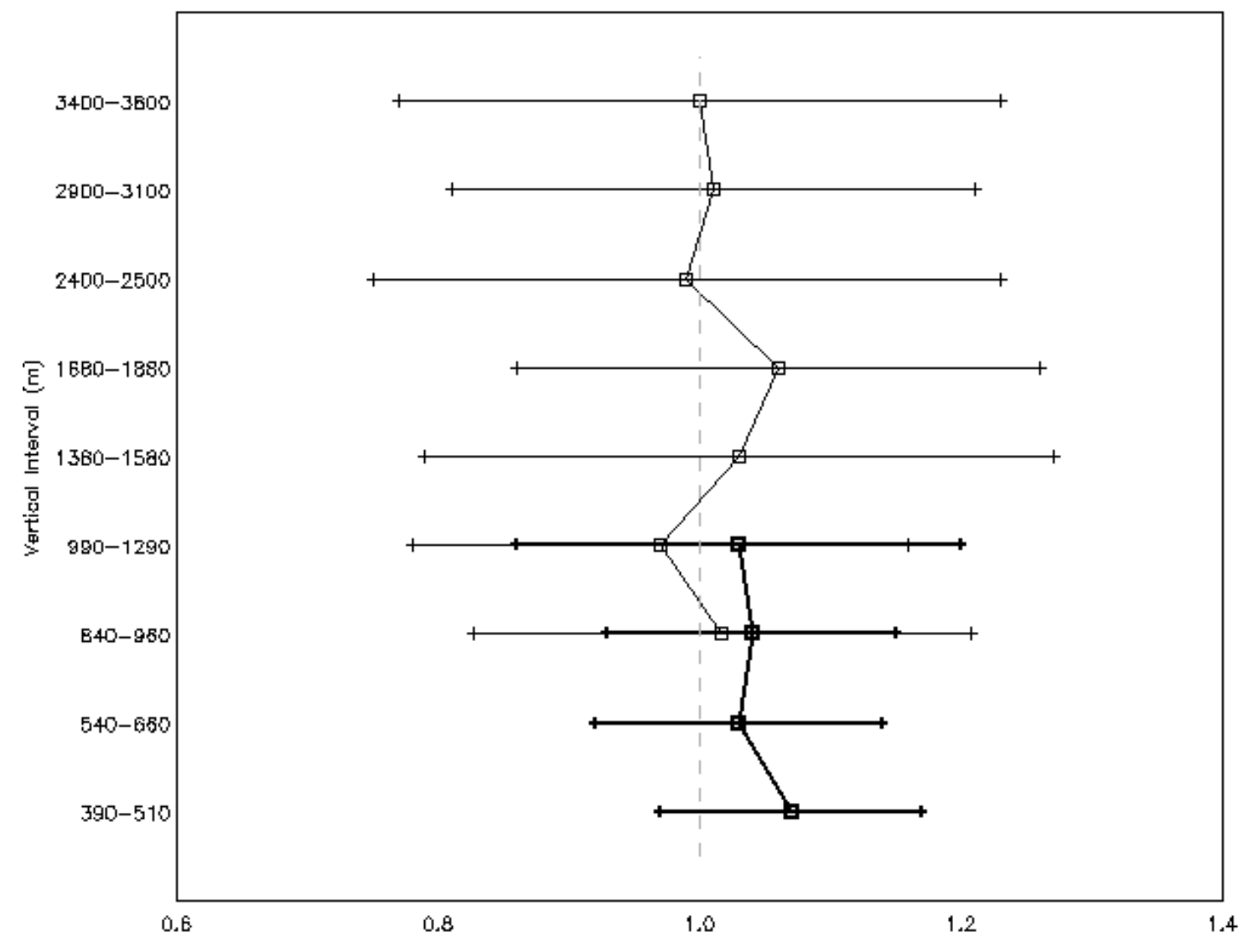

Fig. 37 